Article

\title{
Synthesis and Evaluation of Anticancer Activities of Novel C-28 Guanidine-Functionalized Triterpene Acid Derivatives
}

\author{
Anna Spivak *(1), Rezeda Khalitova, Darya Nedopekina, Lilya Dzhemileva *, \\ Milyausha Yunusbaeva, Victor Odinokov, Vladimir D'yakonov and Usein Dzhemilev \\ Institute of Petrochemistry and Catalysis, Russian Academy of Sciences, 141 Prospekt Oktyabrya, Ufa 450075, \\ Russia; rezedamuf@yandex.ru (R.K.); dashana25@gmail.com (D.N.); milyausha_ufa@mail.ru (M.Y.); \\ odinokov@anrb.ru (V.O.); DyakonovVA@gmail.com (V.D.); dzhemilev@anrb.ru (U.D.) \\ * Correspondence: spivak.ink@gmail.com (A.S.); dzhemilev@mail.ru (L.D.); \\ Tel.: +7-917-421-71-06 (A.S.); +7-917-458-47-29 (L.D.)
}

Academic Editors: Carla Boga and Gabriele Micheletti Received: 8 October 2018; Accepted: 13 November 2018; Published: 16 November 2018

\begin{abstract}
Triterpene acids, namely, 20,29-dihydrobetulinic acid (BA), ursolic acid (UA) and oleanolic acid (OA) were converted into C-28-amino-functionalized triterpenoids 4-7, 8a, 15, 18 and 20. These compounds served as precursors for the synthesis of novel guanidine-functionalized triterpene acid derivatives $\mathbf{9 b}-\mathbf{1 2 b}, \mathbf{1 5 c}, \mathbf{1 8 c}$ and 20c. The influence of the guanidine group on the antitumor properties of triterpenoids was investigated. The cytotoxicity was tested on five human tumor cell lines (Jurkat, K562, U937, HEK, and Hela), and compared with the tests on normal human fibroblasts. The antitumor activities of the most tested guanidine derivatives was lower, than that of corresponding amines, but triterpenoids with the guanidine group were less toxic towards human fibroblasts. The introduction of the tris(hydroxymethyl)aminomethane moiety into the molecules of triterpene acids markedly enhanced the cytotoxic activity of the resulting conjugates $15,15 c, 18 b, c$ and $20 \mathrm{~b}, \mathrm{c}$ irrespective of the triterpene skeleton type. The dihydrobetulinic acid amine 15, its guanidinium derivative 15c and guanidinium derivatives of ursolic and oleanolic acids $18 \mathrm{c}$ and $20 \mathrm{c}$ were selected for extended biological investigations in Jurkat cells, which demonstrated that the antitumor activity of these compounds is mediated by induction of cell cycle arrest at the S-phase and apoptosis.
\end{abstract}

Keywords: triterpenoids; betulinic acid; ursolic acid; oleanolic acid; amino group; guanidine group; cytotoxicity; apoptosis; cell cycle

\section{Introduction}

Among natural products of plant origin that are considered as abundant sources of lead structures for the discovery of new drugs, the pentacyclic lupane, ursane, and oleanane triterpenoids occupy a prominent place [1,2]. Triterpene acids (betulinic, ursolic, and oleanolic acids, Figure 1) are of interest for pharmacological research, as they exhibit a variety of biological activities including antimicrobial, antiparasitic, antitumor, and antiviral, in particular, anti-HIV, types of activity [3-6]. Among these properties of triterpenoids, of special interest is their anticancer activity and the ability to trigger the mitochondrial apoptosis pathway in various types of human cancer cells [5-9]. Thus, betulinic acid is capable of inducing apoptosis in tumor cells, such as melanoma, adenocarcinoma, neuroblastoma, medulloblastoma, glioblastoma and neuroectodermal tumors [7-9]. The in vivo anticancer activity of betulinic acid was identified using xenograft models [10,11]. The ursolic acid can also induce apoptosis, autophagy, and cell cycle arrest through various pathways, such as inhibition of DNA replication, stimulation of reactive oxygen species (ROS) production, and affecting the balance between proapoptotic and antiapoptotic proteins $[6,12,13]$. 
The useful pharmacological properties of triterpene acids are successfully combined with their acceptable systemic toxicity towards animals. However, the relatively low anticancer potential and high hydrophobicity of these secondary metabolites markedly hamper their advancement as anticancer drug candidates. For this reason, active search is in progress for analogues of natural triterpenoids with a higher biological potential and enhanced pharmacological characteristics (hydrophilicity, bioavailability) $[8,14,15]$. It has been shown [16-25] that conversion of triterpene compounds to cationic derivatives such as quaternary ammonium [16,17], pyridinium $[18,19]$ or triphenylphosphonium salts [20-25] may serve as an efficient approach to improving bioavailability and selectivity of their biological action. Our recent study has shown that triphenylphosphonium derivatives of betulinic and ursolic acids are substantially superior over their prototypes in the antitumor activity and in the triggering mitochondria-dependent apoptosis of cancer cells [24,25].

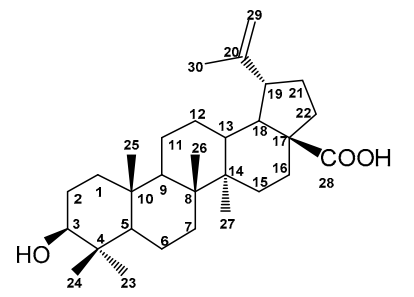

Betulinic acid (BA)

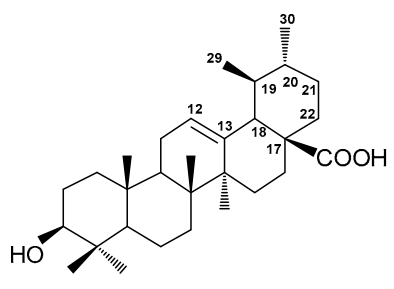

Ursolic acid (UA)

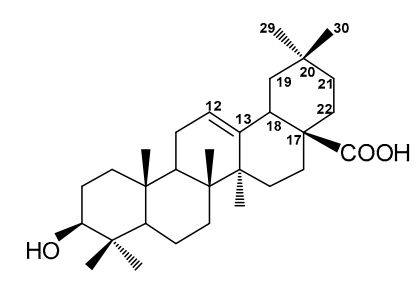

Oleanolic acid (OA)

Figure 1. Betulinic, ursolic and oleanolic acids.

However, the cytotoxic activity of the phosphonium salts was comparable with their cytotoxic activity against normal peripheral blood cells. In continuation of the search for efficient and selective antitumor agents, we have investigated novel cationic derivatives of pentacyclic triterpenoids containing guanidine groups, which are readily protonated at a physiological $\mathrm{pH}$ level. The introduction of hydrophilic guanidine groups into hydrophobic triterpene acid molecules may enhance their transmembrane transport and physicochemical characteristics. Meanwhile, the new hybrid molecules may preserve the selectivity of cytotoxic action against normal cells inherent in the natural triterpene acids. The guanidine group is a common key unit in various natural and synthetic compounds demonstrating antimicrobial, antiviral, and antitumor activities [26]. High symmetry of the Y-shaped guanidinium group promotes the formation of two parallel hydrogen bonds with the biologically relevant counterparts. Unlike ammonium groups, in which the charge is localized on one nitrogen atom (hard cations), guanidinium groups with a delocalized charge actively interact through hydrogen bonds with soft ions such as phosphates and sulfates. This feature of the guanidinium cation induce the efficient transport of biologically active substances through liposomal and cell membranes [27-29]. Furthermore, because of high basicity (pKa 13.5), the guanidinium group is important for selective delivery of cytotoxic molecules to tumor cells. Guanidine derivatives can be accumulated in the mitochondria of tumor cells, thus destroying the mitochondrial potential and inhibiting the mitochondrial respiratory chain $[29,30]$.

Polyamines, which are precursors of aminoalkylguanidines, are also used to develop chemotherapeutic agents, including antibacterial and antitumor compounds [31,32]. Structurally, polyamine molecules contain positively charged nitrogen atoms at physiological $\mathrm{pH}$ value and can serve as electrostatic bridges between negatively charged phosphates. They are able to bind to negatively charged DNA macromolecules. However, some of physiological diamines, polyamines, and their synthetic analogues have exhibited high toxicity toward normal cells. A large body of data has now been accumulated on the biological activity of polyaminosterols, among which squalamine, trodusquemine, and their synthetic analogues are best known [33-36]. The synthesis and biological properties of polyamino triterpene acids are described in several publications [6,37-40]; the effect of introduction of the guanidine group into triterpenoid molecules has not been studied so far. Here we describe the synthesis and comparative evaluation of the cytotoxic and apoptosis-inducing activities of new guanidine derivatives of pentacyclic lupane, ursane, and oleanane triterpenoids 
and their precursors-C-28 conjugates of triterpene acids with some linear and branched mono-, di-, and triaminoalkanes.

\section{Results and Discussion}

\subsection{Chemistry}

While synthesizing the target compounds, we found that the Boc-deprotection of guanidine derivatives of betulinic and betulonic acids in acid medium (50\% TFA in $\mathrm{CH}_{2} \mathrm{Cl}_{2}$ ) is complicated by skeletal rearrangements of the lupane skeleton. It is known from the literature [41,42] that hydrogenation of the C-20 double bond of lupane triterpenoids does not considerably affect their cytotoxic activity and selectivity between normal and tumor cell lines; therefore, in the subsequent experiments, we used 20,29-dihydrobetulinic and 20,29-dihydrobetulonic acids $\mathbf{1}$ and $\mathbf{2}$ to prepare target compounds $\mathbf{9 b} \mathbf{- 1 2} \mathbf{b}$ and $\mathbf{1 4}$ (Scheme 1 ).

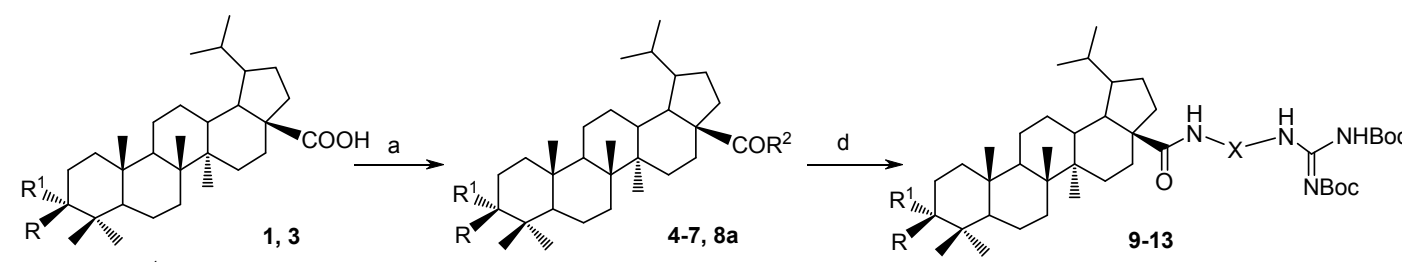

1: $\mathrm{R}+\mathrm{R}^{1}=\mathrm{O}$

b 2: $\mathrm{R}=\mathrm{OH}, \mathrm{R}^{1}=\mathrm{H}$

$\rightarrow 3: \mathrm{R}=\mathrm{AcO}, \mathrm{R}^{1}=\mathrm{H}$

4: $\mathrm{R}+\mathrm{R}^{1}=\mathrm{O} ; \mathrm{R}^{2}=-\mathrm{NH}-\left(\mathrm{CH}_{2}\right)_{4}-\mathrm{NH}_{2}$

5: $\mathrm{R}=\mathrm{AcO}, \mathrm{R}^{1}=\mathrm{H} ; \mathrm{R}^{2}=-\mathrm{NH}-\left(\mathrm{CH}_{2}\right)_{2}-\mathrm{NH}_{2}$

6: $\mathrm{R}=\mathrm{AcO}, \mathrm{R}^{1}=\mathrm{H} ; \mathrm{R}^{2}=-\mathrm{NH}-\left(\mathrm{CH}_{2}\right)_{4}-\mathrm{NH}_{2}$

7: $\mathrm{R}=\mathrm{AcO}, \mathrm{R}^{1}=\mathrm{H} ; \mathrm{R}^{2}=-\mathrm{NH}-\left(\mathrm{CH}_{2}\right)_{2}-\mathrm{N}-\left(\mathrm{CH}_{2}\right)_{2}-\mathrm{NH}_{2}$

$\left(\mathrm{CH}_{2}\right)_{2}-\mathrm{NH}_{2}$
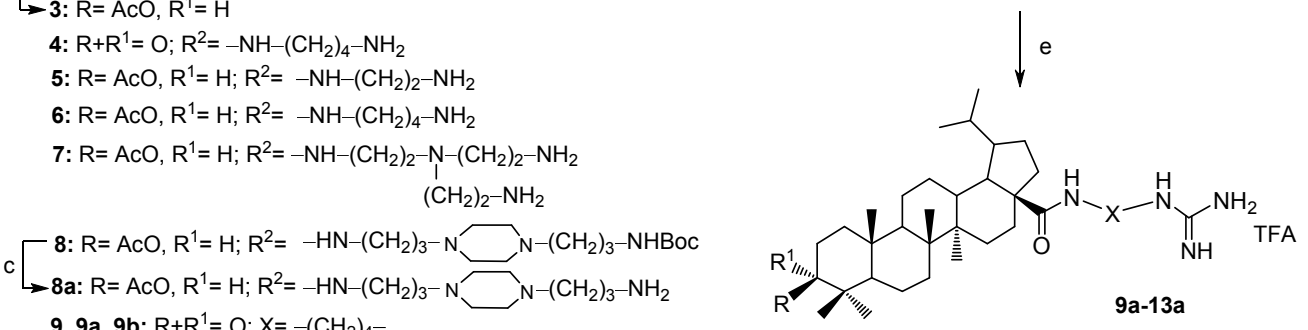

9, 9a, 9b: $\mathrm{R}+\mathrm{R}^{1}=\mathrm{O} ; \mathrm{X}=-\left(\mathrm{CH}_{2}\right)_{4-}$

10, 10a, 10b: $\mathrm{R}=\mathrm{AcO}, \mathrm{R}^{1}=\mathrm{H} ; \mathrm{X}=-\left(\mathrm{CH}_{2}\right)_{2}-$

11, 11a, 11b: $\mathrm{R}=\mathrm{AcO}, \mathrm{R}^{1}=\mathrm{H} ; \mathrm{X}=-\left(\mathrm{CH}_{2}\right)_{4}-$

12: $\mathrm{R}=\mathrm{AcO}, \mathrm{R}^{1}=\mathrm{H} ; \mathrm{X}=-\left(\mathrm{CH}_{2}\right)_{2}-\mathrm{N}-\left(\mathrm{CH}_{2}\right)_{2}-$

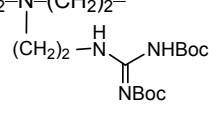

12a: $\mathrm{R}=\mathrm{AcO}, \mathrm{R}^{1}=\mathrm{H} ; \mathrm{X}=-\left(\mathrm{CH}_{2}\right)_{2}-\mathrm{N}-\left(\mathrm{CH}_{2}\right)_{2}-$<smiles>CCCNC(=N)NC(C)C(C)C</smiles>

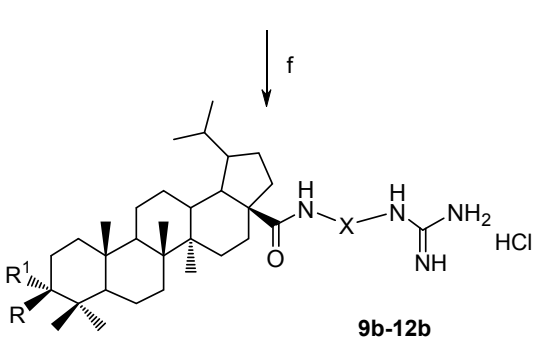

12b: $\mathrm{R}=\mathrm{AcO}, \mathrm{R}^{1}=\mathrm{H} ; \mathrm{X}=-\left(\mathrm{CH}_{2}\right)_{2}-\mathrm{N}-\left(\mathrm{CH}_{2}\right)_{2}-$

$$
\prod_{\mathrm{NH}} \mathrm{HCl}
$$

13, 13a: $\mathrm{R}=\mathrm{AcO}, \mathrm{R}^{1}=\mathrm{H} ; \mathrm{X}=-\left(\mathrm{CH}_{2}\right)_{3}-\mathrm{N} \mathrm{N}-\left(\mathrm{CH}_{2}\right)_{3}-$

14: $\mathrm{R}=\mathrm{OH}, \mathrm{R}^{1}=\mathrm{H} ; \mathrm{X}=-\left(\mathrm{CH}_{2}\right)_{4}-$

Scheme 1. Synthesis of target compounds $\mathbf{9 b - 1 2 b}$ and 14. Reagents and conditions: (a) 1 . $(\mathrm{COCl})_{2}, \mathrm{CH}_{2} \mathrm{Cl}_{2}$; 2. 1,2-diaminoethane or 1,4-diaminobutane or tris(2-aminoethyl)amine or N-tert-butoxy-carbonyl-1,4-bis(3aminopropyl)piperazine, $\mathrm{Et}_{3} \mathrm{~N}, \mathrm{CH}_{2} \mathrm{Cl}_{2}$, r.t.; (b) $\mathrm{AcCl}$, THF, Py, DMAP, r.t.; (c) $10 \% \mathrm{TFA}, \mathrm{CH}_{2} \mathrm{Cl}_{2}, 3$ h, r.t.; (d) 1,3-di-Boc-2-(trifluoromethylsulfonyl)guanidine, $\mathrm{Et}_{3} \mathrm{~N}, \mathrm{CH}_{2} \mathrm{Cl}_{2}$; (e) $50 \%$ TFA, $\mathrm{CH}_{2} \mathrm{Cl}_{2}$, 2-4 h, r.t.; (f) $5 \mathrm{M}$ $\mathrm{HCl}, \mathrm{MeOH} ;$ (g) $4 \mathrm{~N} \mathrm{NaOH}, \mathrm{MeOH}$, THF.

Acetate 3 obtained upon hydroxyl group protection in dihydrobetulinic acid 2, and dihydrobetulonic acid 1 were converted to C-28 amide derivatives $4-7$ and 8 a via relatively unstable acid chlorides (Scheme 1 ).

The reactions were carried out with 1,2-diaminoethane, 1,4-diaminobutane (putrescine), tris(2-aminoethyl)amine, and $\mathrm{N}$-tert-butyloxycarbonyl-1,4-bis(3-aminopropyl)piperazine. The use of branched triamine resulted in two guanidine functions being introduced into the triterpenoid molecule. 
Amides 4-7 were synthesized using a 3-fold molar excess of amines over triterpenes in order to avoid the formation of dimeric products. Compound 8a was formed in a good yield only with the use of $N$-Boc bis-aminopropylpiperazine, which was synthesized as described in reference [43]. The N-Boc protection was then removed by treatment with $10 \%$ trifluoroacetic acid in $\mathrm{CH}_{2} \mathrm{Cl}_{2}$. Guanylation of amines 4-7 and 8a was carried out according to the typical procedure [44] by using commercially available $N, N^{\prime}$-di-Boc- $N^{\prime \prime}$-triflylguanidine. The expected compounds 9-13 were obtained in 60-88\% yields after column chromatography on $\mathrm{SiO}_{2}$. The subsequent treatment of Boc derivatives 9-13 with $\mathrm{CF}_{3} \mathrm{COOH}$ and then with $\mathrm{HCl} / \mathrm{MeOH}$ gave hydrochlorides $\mathbf{9 b}-\mathbf{1 3 b}$. Dihydrobetulinic acid guanidinium hydrochloride $\mathbf{1 4}$ was prepared by saponification of the 3-OAc function in conjugate $\mathbf{1 1 b}$. A well studied and promising betulinic acid derivative is 2-amino-3-hydroxy-2-(hydroxymethyl)propyl 3-O-acetyl betulinate, known as the anticancer agent NVX-207 [45-48]. We have synthesized its C-20,29 hydrogenated derivative 15. Ursolic and oleanolic acetates 16 and 17 were converted into NVX-207 analogues 18 and 20 with ursane and oleanane skeletons (Scheme 2).
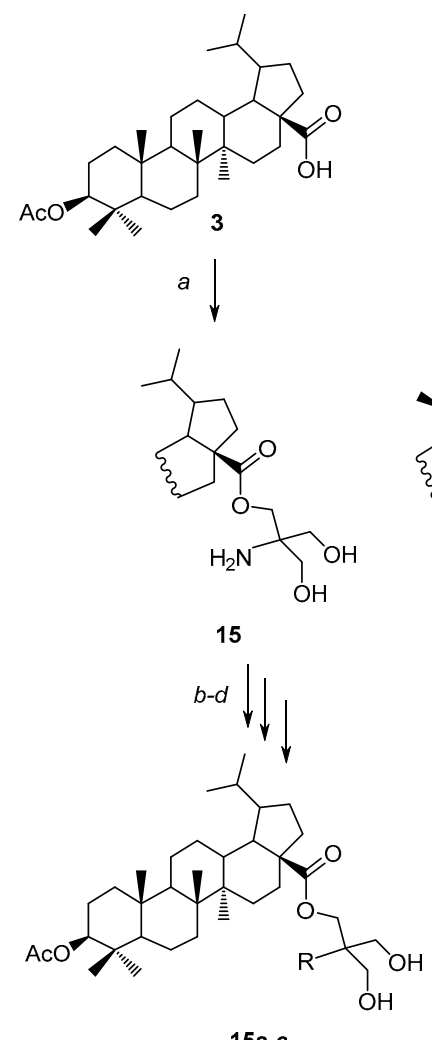

15a-c

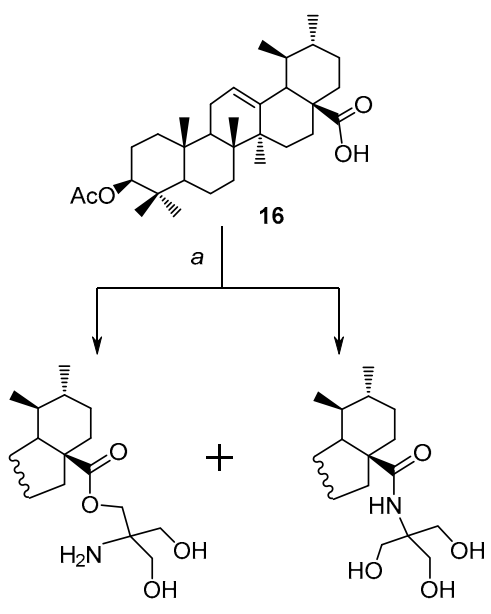

19

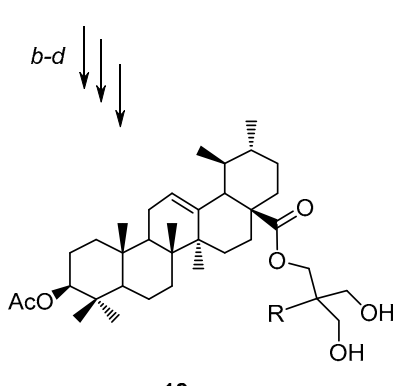

$18 a-c$

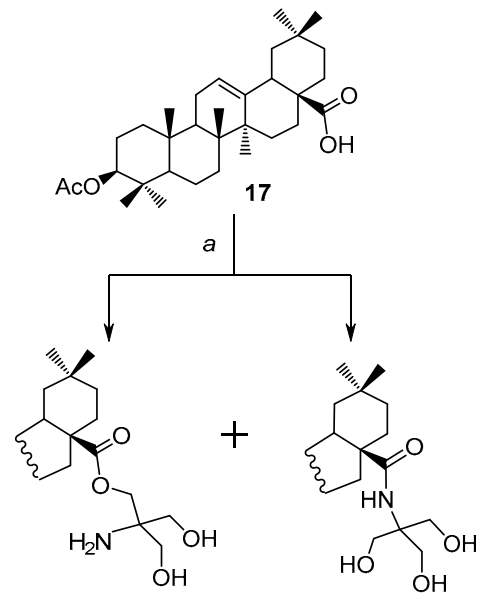

20 21

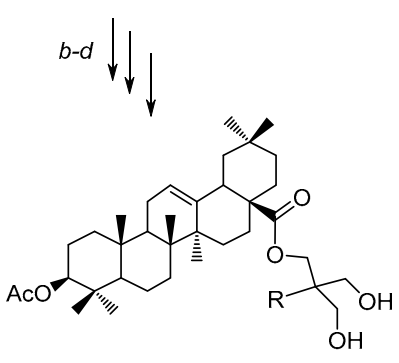

20a-c<smiles></smiles>

Scheme 2. Synthesis of compounds $15 a-c, 18 a-c, 20 a-c$. Reagents and conditions: (a) 1 . $(\mathrm{COCl})_{2}, \mathrm{CH}_{2} \mathrm{Cl}_{2}$; 2. tris(hydroxymethyl)aminomethane, DMAP, $\mathrm{Py}, \mathrm{CH}_{2} \mathrm{Cl}_{2}$; (b) 1,3-di-Boc-2-(trifluoromethyl-sulfonyl) guanidine, $\mathrm{Et}_{3} \mathrm{~N}, \mathrm{CHCl}_{3}$, reflux; (c) $50 \%$ TFA, $\mathrm{CH}_{2} \mathrm{Cl}_{2}, 2-4$ h, r.t.; (d) $5 \mathrm{M} \mathrm{HCl}, \mathrm{MeOH}$.

The reactions under reported conditions [45] afforded the desired esters 15, 18, and 20 containing the terminal $\mathrm{NH}_{2}$ group in the branched C-28 chain and amides 19 and 21 in 15-23\% and 24-32\% yields, respectively. Guanylation of the free amino groups in the resulting amines 15, 18, and 20 on treatment with $N, N^{\prime}$-di-Boc- $N^{\prime \prime}$-triflylguanidine gave rise to guanidine derivatives 15a, 18a, and 20a in $63-79 \%$ yields. The Boc-deprotection with $50 \%$ TFA $/ \mathrm{CH}_{2} \mathrm{Cl}_{2}$ and the subsequent treatment of salts $\mathbf{1 5 b}, \mathbf{1 8 b}$, and $\mathbf{2 0 b}$ with $5 \mathrm{M} \mathrm{HCl}$ in $\mathrm{MeOH}$ yielded hydrochlorides $\mathbf{1 5 c}$, 18c, and 20c. 
The structures of all products were confirmed by $1 \mathrm{D}\left({ }^{1} \mathrm{H},{ }^{13} \mathrm{C},{ }^{19} \mathrm{~F}\right)$ and $2 \mathrm{D}(\mathrm{HSQC}, \mathrm{HMBC}, \mathrm{COSY})$ NMR experiments and MALDI TOF MS. The ${ }^{13} \mathrm{C}-\mathrm{NMR}$ spectra of compounds 4-7, 8a, 15, 18, and 20 show signals for amide carbon atoms at $176.3-179.3 \mathrm{ppm}$, while the amide group protons resonate at 5.86-6.79 ppm in the ${ }^{1} \mathrm{H}-\mathrm{NMR}$ spectra. In the spectra of guanidine derivatives 9-13, 15a, 18a, and 20a, the $\mathrm{NH}-\mathrm{C}=\mathrm{N}$ and NH-Boc proton signals occurred at 8.30-9.06 ppm and 11.47-11.53 ppm, respectively. The signals for the guanidine group carbon atoms were observed at 161.8-163.6 ppm.

\subsection{Biological Evaluation}

The in vitro cytotoxic activity of triterpene acids (dihydrobetulinic, ursolic and oleanolic acids), twelve guanidinium salts, and some of their precursors, primary amines 4-6, 8a, and 15, was evaluated on five human tumor cell lines: Jurkat (T-lymphoblastic leukemia), K562 (chronic myeloid leukemia), U937 (histiocytic lymphoma), HEK 293 (embryonic kidney), and HeLa (cervical cancer). The possible cell toxicity was assessed against normal human fibroblasts. Most of the tested compounds showed moderate or significant activity against Jurkat, K562, and U937 cells as compared to triterpenoic acids (Table 1).

Table 1. Cytotoxicity of dihydrobetulinic-, ursolic- and oleanolic acids and compounds 4-6, 8a, 9b-12b,

12a, 13a, 14, 15, 15c, 18b,c, and 20b,c against Jurkat, K562, Hek293, HeLa, U937, and normal fibroblast cells.

\begin{tabular}{ccccccc}
\hline \multirow{2}{*}{ Compound } & \multicolumn{5}{c}{ IC $_{\mathbf{5 0}}(\boldsymbol{\mu m o l} / \mathbf{L})^{\mathbf{a}}$} \\
\cline { 2 - 7 } & Jurkat & K562 & U937 & HEK293 & HeLa & Fibroblasts \\
\hline Dihydro BA & $59 \pm 0.31$ & $44 \pm 0.24$ & $39 \pm 0.38$ & $128 \pm 0.32$ & $132 \pm 0.47$ & $517 \pm 0.26$ \\
UA & $23 \pm 0.34$ & $68 \pm 0.11$ & $17 \pm 0.12$ & $96 \pm 0.22$ & $88 \pm 0.35$ & $324 \pm 0.16$ \\
OA & $271 \pm 0.19$ & $235 \pm 0.24$ & $186 \pm 0.18$ & $247 \pm 0.27$ & $258 \pm 0.31$ & $694 \pm 0.17$ \\
$\mathbf{4}$ & $1.4 \pm 0.41$ & $1.3 \pm 0.49$ & $1.7 \pm 0.36$ & $2.4 \pm 0.35$ & $2.8 \pm 0.28$ & $3.4 \pm 0.19$ \\
$\mathbf{5}$ & $2.3 \pm 0.11$ & $2.8 \pm 0.23$ & $1.9 \pm 0.34$ & $4.8 \pm 0.25$ & $3.9 \pm 0.41$ & $5.3 \pm 0.27$ \\
$\mathbf{6}$ & $7.7 \pm 0.31$ & $1.8 \pm 0.12$ & $4.5 \pm 0.43$ & $6.7 \pm 0.21$ & $7.1 \pm 0.18$ & $8.3 \pm 0.29$ \\
$\mathbf{8 a}$ & $4.5 \pm 0.29$ & $3.0 \pm 0.19$ & $8.2 \pm 0.13$ & $5.9 \pm 0.14$ & $6.1 \pm 0.38$ & $7.3 \pm 0.43$ \\
$\mathbf{9 b}$ & $21 \pm 0.24$ & $57 \pm 0.36$ & $14 \pm 0.16$ & $92 \pm 0.34$ & $81 \pm 0.19$ & $179 \pm 0.43$ \\
$\mathbf{1 0 b}$ & $67 \pm 0.21$ & $98 \pm 0.35$ & $82 \pm 0.14$ & $128 \pm 0.35$ & $152 \pm 0.49$ & $354 \pm 0.46$ \\
$\mathbf{1 1 b}$ & $16 \pm 0.18$ & $55 \pm 0.38$ & $63 \pm 0.29$ & $98 \pm 0.27$ & $106 \pm 0.51$ & $117 \pm 0.38$ \\
$\mathbf{1 2 a}$ & $22 \pm 0.21$ & $89 \pm 0.18$ & $28 \pm 0.25$ & $112 \pm 0.19$ & $101 \pm 0.22$ & $149 \pm 0.43$ \\
$\mathbf{1 2 b}$ & $14 \pm 0.37$ & $52 \pm 0.26$ & $13 \pm 0.06$ & $68 \pm 0.29$ & $72 \pm 0.34$ & $106 \pm 0.23$ \\
$\mathbf{1 3 a}$ & $24 \pm 0.27$ & $11 \pm 0.33$ & $18 \pm 0.21$ & $74 \pm 0.15$ & $79 \pm 0.29$ & $104 \pm 0.26$ \\
$\mathbf{1 4}$ & $17 \pm 0.34$ & $36 \pm 0.42$ & $20 \pm 0.12$ & $59 \pm 0.21$ & $62 \pm 0.24$ & $96 \pm 0.17$ \\
$\mathbf{1 5}$ & $3.3 \pm 0.11$ & $2.1 \pm 0.13$ & $6.6 \pm 0.23$ & $17 \pm 0.25$ & $19 \pm 0.49$ & $31 \pm 0.29$ \\
$\mathbf{1 5 c}$ & $3.1 \pm 0.41$ & $2.3 \pm 0.34$ & $15 \pm 0.23$ & $16 \pm 0.27$ & $14 \pm 0.31$ & $27 \pm 0.14$ \\
$\mathbf{1 8 b}$ & $6.8 \pm 0.32$ & $40 \pm 0.29$ & $2.1 \pm 0.41$ & $13 \pm 0.19$ & $11 \pm 0.27$ & $47 \pm 0.15$ \\
$\mathbf{1 8 c}$ & $3.8 \pm 0.23$ & $11 \pm 0.18$ & $5.3 \pm 0.29$ & $14 \pm 0.34$ & $12 \pm 0.29$ & $51 \pm 0.26$ \\
$\mathbf{2 0 b}$ & $6.7 \pm 0.15$ & $20 \pm 0.14$ & $6.1 \pm 0.43$ & $12 \pm 0.23$ & $13 \pm 0.41$ & $49 \pm 0.25$ \\
$\mathbf{2 0 c}$ & $7.6 \pm 0.33$ & $13 \pm 0.45$ & $6.8 \pm 0.11$ & $19 \pm 0.17$ & $17 \pm 0.32$ & $54 \pm 0.12$ \\
\hline
\end{tabular}

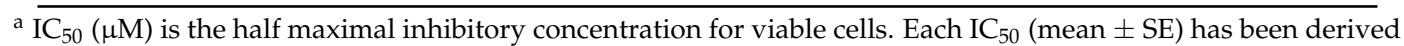
from at least three experiments in duplicate.

Amino derivatives 4-6 and 8a showed cytotoxic activity against all tumor cell cultures with $\mathrm{IC}_{50}$ values of 1.3-8 $\mu \mathrm{M}$. However, these compounds were also cytotoxic against fibroblasts. Contrary to our expectations, guanylation of the terminal amino groups of lupane triterpenoids with C-28 linear aminoalkane chains (compounds $\mathbf{9 b - 1 1 b}, \mathbf{1 3} a$, and 14) or the branched tris-aminoethyl moiety (compounds 12a,b) did not considerably enhance the cytotoxic action. Of the listed guanidinium salts, only compounds $\mathbf{9 b}, \mathbf{1 1 b}$, and $\mathbf{1 4}$ showed an approximately 3 -fold increase in the cytotoxic activity against Jurkat cells in comparison with dihydrobetulinic acid $\mathbf{2}$ and also showed selectivity towards Jurkat cells with an SI of 8.5, 7.3, and 5.6 respectively ( $\mathrm{SI}=\mathrm{IC}_{50}$ fibroblasts $/ \mathrm{IC}_{50}$ Jurkat cells). The introduction of the tris(hydroxymethyl)aminomethane moiety into the molecules of triterpene acids 3, 16 and 17 markedly enhanced the cytotoxic activities for the resulting conjugates $15,15 c, 18 b, c$, and $20 \mathrm{~b}, \mathrm{c}$, irrespective of the triterpene skeleton type. The C-28 esters of dihydrobetulinic, ursolic, and oleanolic acids with amino and guanidine groups in the ester side chain had from moderate to 
good activity against Jurkat and $\mathrm{K} 562$ cell lines. For example, the $\mathrm{IC}_{50}$ values of compounds $15 \mathrm{c}$ and 18c were 3.1 and $3.8 \mu \mathrm{M}$ for T-lymphoblastic leukemia cells and 2.3 and $11.0 \mu \mathrm{M}$ for chronic myeloid leukemia cells. The most pronounced differences in the antitumor activity were found for oleanolic acid and its conjugates $\mathbf{2 0 b}$,c. Indeed, the $\mathrm{IC}_{50}$ values of oleanolic acid, $\mathbf{2 0 b}$, and $\mathbf{2 0 c}$ for Jurkat cells were $271,6.7$, and $7.6 \mu \mathrm{M}$, respectively. It is worth noting that amine 15 , its guanidine derivative $15 \mathrm{c}$, and guanidinium salts of ursolic and oleanolic acids $\mathbf{1 8 b , c}$ and 20b,c showed acceptable selectivity towards Jurkat tumor cell with an SI from 6.9 to 13.4 .

The identified lead compounds with the highest cytotoxicity characteristics, 15, 15c, 18c, and 20c, were further evaluated for the possible apoptosis induction in tumor cell cultures. The measurements were done by flow cytometry (Figure 2).
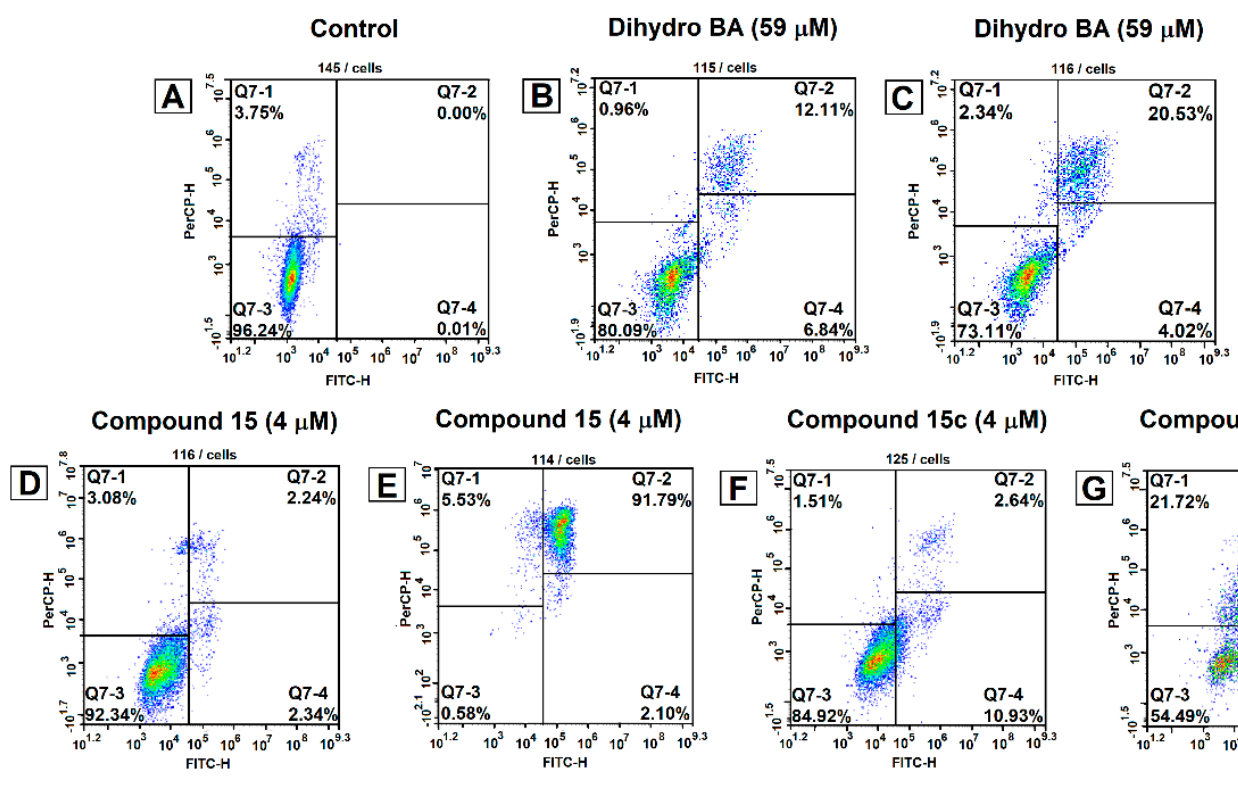

Compound $15(4 \mu \mathrm{M})$
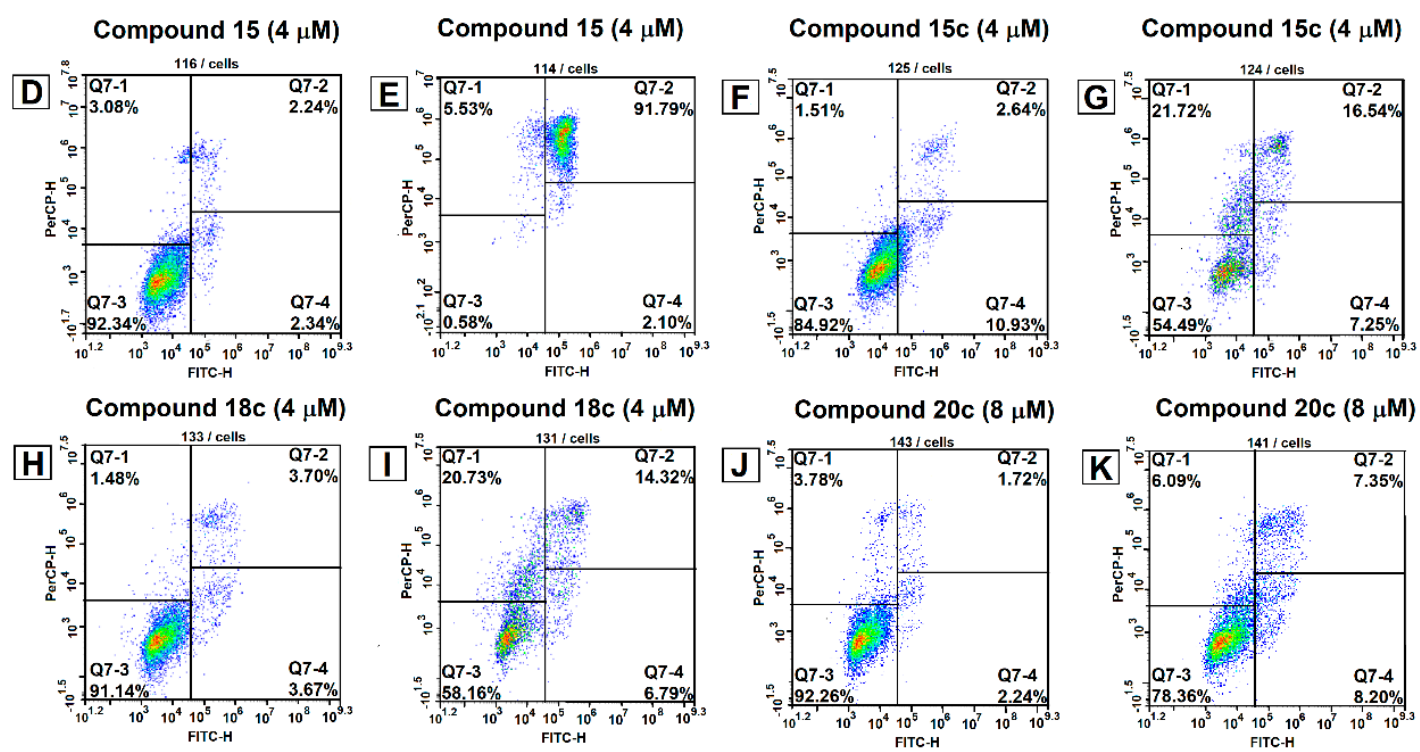

Figure 2. AnnexinV/7-AAD staining upon induction of apoptosis in Jurkat cells. Cells were treated with compounds at their $\mathrm{IC}_{50}$ concentration for 24 and $48 \mathrm{~h}$. Then, the cells were harvested, stained with Annexin V/7-AAD and analyzed by flow cytometry. The experiments were performed three times, and the results of the representative experiments are shown. The first cytogram represents an untreated cell sample (A); after incubation with dihydrobetulinic acid for $24 \mathrm{~h} \mathrm{(B)}$ and for $48 \mathrm{~h}$ (C); after incubation with compound 15 for $24 \mathrm{~h}$ (D) and for $48 \mathrm{~h}$ (E); after incubation with compound 15c for $24 \mathrm{~h}(\mathrm{~F})$ and for $48 \mathrm{~h} \mathrm{(G);} \mathrm{after} \mathrm{incubation} \mathrm{with} \mathrm{compound} 18 \mathrm{c}$ for $24 \mathrm{~h}(\mathbf{H})$ and for $48 \mathrm{~h}(\mathrm{I})$; after incubation with compound 20c for $24 \mathrm{~h}(\mathrm{~J})$ and for $48 \mathrm{~h}(\mathrm{~K})$. Q7-1, necrotic cells; Q7-2, late apoptotic cells; Q7-3, living cells; Q7-4, early apoptotic cells.

The highest percentage of late apoptosis (91.7\%) was detected upon the treatment of Jurkat cells with the test compound $\mathbf{1 5}$ at $\mathrm{IC}_{50}$ concentration exposure for $48 \mathrm{~h}$ as depicted in Figure $2 \mathrm{E}$. Compounds 15c, 18c and 20c also showed apoptotic mode of cell death on Jurkat cells line, but, in this case, the apoptotic effect of these guanidine derivatives was notably weaker. Thus, after treatment of Jurkat cells with compound $\mathbf{1 5 c}$ at $\mathrm{IC}_{50}$ concentration $(4 \mu \mathrm{M})$ the number of vital cells is decreased from 
$96.2 \%$ (control) to $54.5 \%$. Total number of apoptotic cells population constituted $23.7 \%(7.2 \%$ and $16.5 \%$ of early and late apoptotic cells, respectively) and number of necrotic cells was $21.7 \%$. Comparable results were obtained with the guanidine derivative of ursolic acid 18c $(6.8,14.3$, and $20.7 \%$ of early, late apoptotic cells and necrotic cells, respectively). Treatment of the Jurkat cells with 20c resulted in about $15.5 \%$ apoptotic cells and $6.1 \%$ necrotic cells, with $78.4 \%$ of the cells still being considered vital (Figure 2K). Next, we analyzed the ability of dihydrobetulinic acid to stimulate apoptosis. Our results showed that dihydrobetulinic acid triggers apoptosis in Jurkat cells at higher doses as compared to derivatives 15, 15c, and 18c. The number of apoptotic cells on treatment with dihydrobetulinic acid $(59 \mu \mathrm{M})$ for $48 \mathrm{~h}$ constituted around $24 \%$ (4.0\% of early-stage and $20.5 \%$ of secondary necrotic/late-stage apoptotic), while the number of vital cells was $73.1 \%$ (Figure $2 \mathrm{C}$ ).

In summary, our results indicate that the apoptosis is induced in Jurkat cells by all test compounds. However, we observed a higher rate of necrosis after 15c, 18c and 20c incubation compared to derivative 15.

DNA flow cytometry was also used to analyze the cell cycle kinetics in Jurkat cells pre-incubated with dihydrobetulinic acid and derivatives $15,15 c, 18 c$, or $20 \mathrm{c}$ at their $\mathrm{IC}_{50}$ concentration for 24 and 48 h (Figure 3).

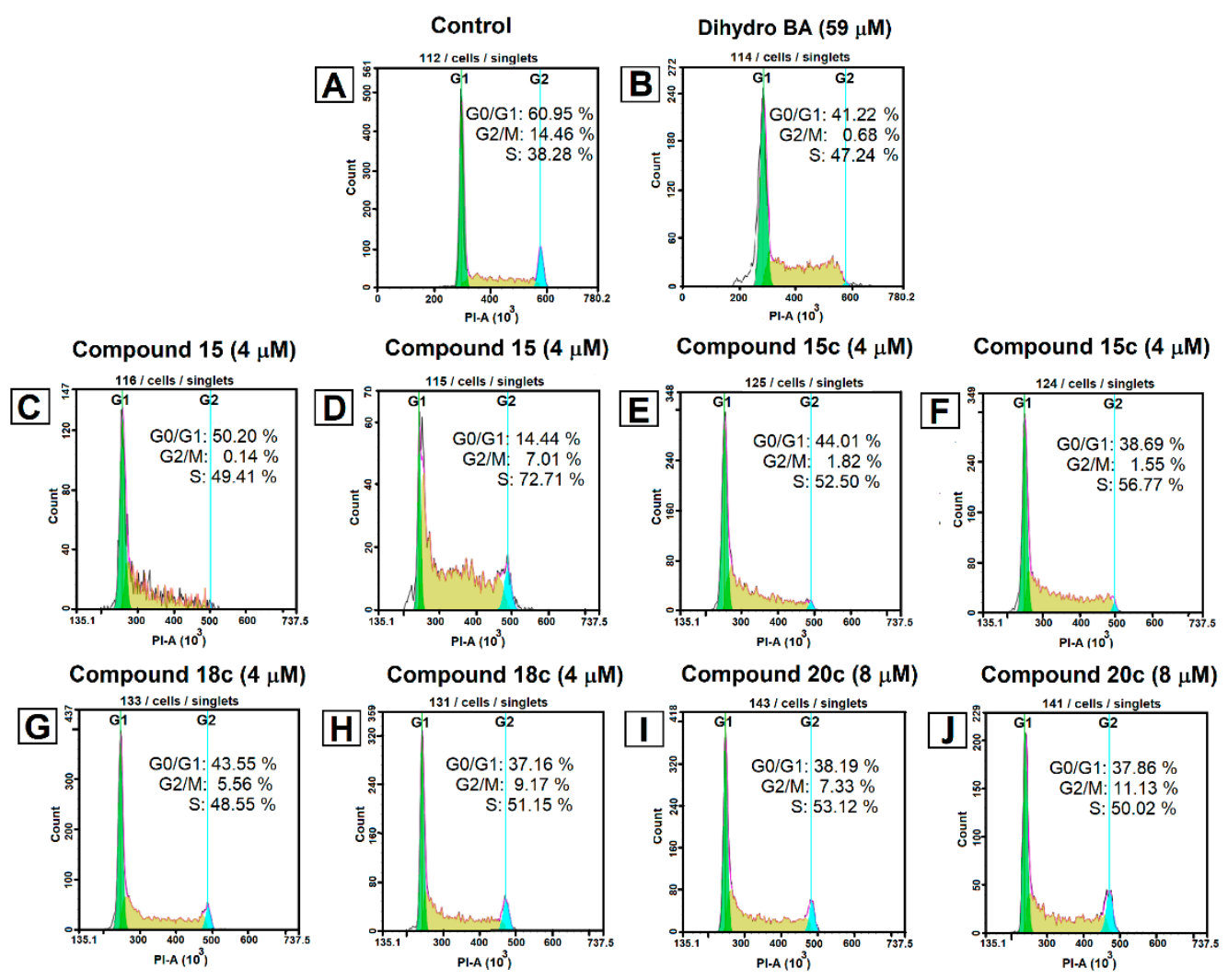

Figure 3. Cell cycle analysis in Jurkat cells. Jurkat cells treated with tested compounds at the $\mathrm{IC}_{50}$ concentration for 24 and $48 \mathrm{~h}$. The cells were trypsinized, harvested and washed three times with ice-PBS for PI-stained DNA content detected by flow cytometry. The experiments were performed three times, and the results of the representative experiments are shown. The first cytogram represents an untreated cell sample (A); after incubation with dihydrobetulinic acid for $48 \mathrm{~h}$ (B); after incubation with compound 15 for $24 \mathrm{~h}(\mathrm{C})$ and for $48 \mathrm{~h}(\mathbf{D})$; after incubation with compound $15 \mathrm{c}$ for $24 \mathrm{~h}(\mathrm{E})$ and for $48 \mathrm{~h}(\mathbf{F})$; after incubation with compound 18c for $24 \mathrm{~h}(\mathbf{G})$ and for $48 \mathrm{~h}(\mathbf{H})$; after incubation with compound 20c for $24 \mathrm{~h} \mathrm{(I)}$ and for $48 \mathrm{~h} \mathrm{(J)}$.

The distribution of DNA content in Jurkat cells reveals whether cell proliferation is arrested at one checkpoint. The results of all experiments showed in significant S-phase arrest in cells after treating with these compounds. Thus, the ratio of cells in the $S$ phase increased from $38.3 \%$ (control) to $72.7 \%$ in 
cells treated with 15 ( $4 \mu \mathrm{M}$ for $48 \mathrm{~h}$ ) and increased to $47.2-56.8 \%$ in cells treated with dihidrobetulinic acid, 15c, 18c, or 20c. The appropriate decrease of the number of cells in the G2/M phase was observed. For example, the treatment of Jurkat cells with 15 and $15 \mathrm{c}$ resulted in a decrease of cells in the G2/M phase from $14.5 \%$ (control) to 7.0 and $1.5 \%$ (Figure 3D,F). Considering these results, we assume that dihydrobetulinic acid and compounds $15,15 c, 18 c$, or $20 \mathrm{c}$ are able to trigger programmed cell death, including apoptotic mechanisms and cell cycle arrest in the S-phase.

\section{Materials and Methods}

\subsection{Chemistry}

IR spectra (thin films or solutions in $\mathrm{CHCl}_{3}$ ) were obtained with use of a Vertex 70v spectrometer (Bruker, Karlsruhe, Germany). ${ }^{1} \mathrm{H}$ - and ${ }^{13} \mathrm{C}-\mathrm{NMR}$ spectra were recorded in $\mathrm{CDCl}_{3}$, in $\mathrm{MeOD}$ or in $d_{6}$-DMSO with $\mathrm{Me}_{4} \mathrm{Si}$ as the internal standard on an AVANCE-500 instrument $\left(500.13\left({ }^{1} \mathrm{H}\right), 125.78 \mathrm{MHz}\right.$ $\left.\left({ }^{13} \mathrm{C}\right), 470.59 \mathrm{MHz}\left({ }^{19} \mathrm{~F}\right)\right)$ or on an AVANCE-400 $\left(400.13\left({ }^{1} \mathrm{H}\right), 100.62 \mathrm{MHz}\left({ }^{13} \mathrm{C}\right), 376.50 \mathrm{MHz}\left({ }^{19} \mathrm{~F}\right)\right)$ (Bruker). Mass spectra of new compounds were recorded on a Bruker-Autoflex III spectrometer (MALDI TOF, positive ion mode, sinapic acid as the matrices). Optical rotation was determined on a 141 polarimeter (Perkin-Elmer, Beaconsfield, UK). Specific rotation $[\alpha]_{\mathrm{D}}$ is expressed in $(\mathrm{deg} \cdot \mathrm{mL}) /(\mathrm{g} \cdot \mathrm{dm})^{-1}$; the concentration of the solution $c$ is expressed in $\mathrm{g} / 100 \mathrm{~mL}$. Elemental analysis was carried out on a 1106 analyzer (Carlo Erba, Milan, Italy). TLC was carried out on Sorbfil plates (Sorbpolimer, Krasnodar, Russia) in hexane-EtOAc and chloroform-methanol, spots were visualized with anisaldehyde. Silica gel L (KSKG grade, 50-160 $\mu \mathrm{m}$ ) was employed for column chromatography. All reagents and solvents were of the purest grade available, and generally were used without further treatment. The starting compounds ursolic, oleanolic acids and reagents: sodium borohydride $\left(\mathrm{NaBH}_{4}\right)$, acetyl chloride, $10 \% \mathrm{Pd} / \mathrm{C}$, oxalyl chloride, 1,2-diaminoethane, 1,4-diaminobutane, tris(2-aminoethyl)amine, 1,4-bis(3-aminopropyl)piperazine, tris(hydroxymethyl)aminomethane, 1,3-di-Boc-2-(trifluoromethylsulfonyl)guanidine, triethylamine ( $\left.\mathrm{Et}_{3} \mathrm{~N}\right)$, dimethylaminopyridine (DMAP), trifluoroacetic acid (TFA) were purchased from Acros Organics (Geel, Belgium). Dihydrobetulonic and dihydrobetulinic acids were obtained from betulin according to the known procedures [41]. Acetates of oleanolic, ursolic, dihydrobetulonic and dihydrobetulinic acids were synthesized according to the typical procedures. Mono-Boc-protected bis-aminopropylpiperazine and compounds 19-23 were prepared by a reported methods $[43,45]$. NMR ${ }^{1} \mathrm{H}$ and ${ }^{13} \mathrm{C}$ spectra of all new compounds are in Supplementary Materials.

\subsubsection{General Procedure for the Synthesis of Amines 4-7}

Oxalyl chloride $(0.13 \mathrm{~mL}, 1.5 \mathrm{mmol})$ was added with stirring to a solution of compounds 1 or 3 $(0.5 \mathrm{mmol})$ in dry $\mathrm{CH}_{2} \mathrm{Cl}_{2}(5 \mathrm{~mL})$ precooled to $0{ }^{\circ} \mathrm{C}$, and stirring of the reaction mixture was continued at room temperature for $2 \mathrm{~h}$. Then the solvent and excess oxalyl chloride were removed under vacuum. The amine $(1.5 \mathrm{mmol})$ was dissolved in dry $\mathrm{CH}_{2} \mathrm{Cl}_{2}(2 \mathrm{~mL})$ and under vigorous stirring were added

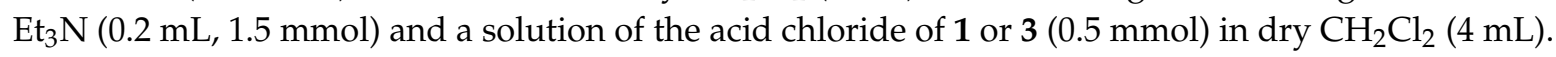
The mixture was stirred for $24 \mathrm{~h}$ (monitoring by TLC). The mixture was then poured into cold $\mathrm{H}_{2} \mathrm{O}$ and extracted with $\mathrm{CH}_{2} \mathrm{Cl}_{2}(2 \times 15 \mathrm{~mL}$ each). The organic phases washed brine and were dried over $\mathrm{Na}_{2} \mathrm{SO}_{4}$ and evaporated under reduced pressure. The residue was chromatographed on silica gel, using $\mathrm{CH}_{2} \mathrm{Cl}_{2} / \mathrm{MeOH} 30: 1 \rightarrow 1: 1(v / v)$, to obtain pure compounds 4-7.

N-(4-Aminobuthyl)-3-oxolupane-28-amide (4), White powder, 78\% yield; mp $170-172{ }^{\circ} \mathrm{C}(\mathrm{EtOH}) ;[\alpha]_{\mathrm{D}}^{19}$ : $+4^{\circ}\left(\mathrm{c} 0.23, \mathrm{CH}_{2} \mathrm{Cl}_{2}\right)$; IR $\left(\mathrm{CHCl}_{3}\right) v_{\max } 1641,1702(\mathrm{C}=\mathrm{O}), 3357(\mathrm{NH}) \mathrm{cm}^{-1} ;{ }^{1} \mathrm{H}-\mathrm{NMR}\left(500 \mathrm{MHz}, \mathrm{CDCl}_{3}\right)$ $\delta: 5.86(\mathrm{t}, J=5.5 \mathrm{~Hz}, 1 \mathrm{H}, \mathrm{CONH}), 3.32-3.20\left(\mathrm{~m}, 2 \mathrm{H}, \mathrm{H}-1^{\prime}\right), 2.76\left(\mathrm{t}, J=6.5 \mathrm{~Hz}, 2 \mathrm{H}, \mathrm{H}-4^{\prime}\right), 2.55-1.14(\mathrm{~m}$, $26 \mathrm{H}, \mathrm{CH}, \mathrm{CH}_{2}$ in pentacyclic skeleton, $\left.4 \mathrm{H}, \mathrm{H}-2^{\prime}, \mathrm{H}-3^{\prime}\right), 1.08,1.03,0.98,0.97,0.94$ (all s, 3H each, H-23-H-27), 0.87 (d, J = 6.5 Hz, 3H, H-29), 0.75 (d, J = 7.0 Hz, 3H, H-30); ${ }^{13} \mathrm{C}-\mathrm{NMR}\left(125 \mathrm{MHz}, \mathrm{CDCl}_{3}\right) \delta$ : 218.2 (C-3), 176.3 (C-28), 56.0 (C-17), 55.0 (C-5), 49.8 (C-9), 49.5 (C-19), 47.4 (C-4), 44.2 (C-18), 42.7 (C-14), $41.6\left(\mathrm{C}-4^{\prime}\right), 40.7$ (C-8), 39.6 (C-1), 39 (C-22), 38.8 (C-1'), 37.7 (C-13), 36.9 (C-10), 34.2 (C-2), 33.8 (C-16), 33.6 (C-7), $30.6\left(\mathrm{C}-3^{\prime}\right), 29.9$ (C-20), 29.4 (C-15), 27.2 (C-23), 27.0 (C-2'), 26.6 (C-12), 23.1 (C-29), 23.0 (C-21), 
21.5 (C-24), 21.1 (C-11), 19.7 (C-6), 16.0 (C-25), 15.9 (C-26), 14.6 (C-30), 14.5 (C-27); Anal. Calcd. for $\mathrm{C}_{34} \mathrm{H}_{58} \mathrm{~N}_{2} \mathrm{O}_{2}: \mathrm{C}, 77.51, \mathrm{H}, 11.10$. Found: $\mathrm{C}, 78.03, \mathrm{H}, 11.02 \%$. MS: $m / z 527.45[\mathrm{M}+\mathrm{H}]^{+}$(calcd. for $\left.\mathrm{C}_{34} \mathrm{H}_{58} \mathrm{~N}_{2} \mathrm{O}_{2}, 526.45\right)$.

33-N-(2-Aminoethyl)-3-O-acetyl-lupane-28-amide (5), White powder, $74 \%$ yield; mp $120-122{ }^{\circ} \mathrm{C}(\mathrm{EtOH})$; $[\alpha]_{\mathrm{D}}^{19}-8^{\circ}\left(c 0.24, \mathrm{CH}_{2} \mathrm{Cl}_{2}\right)$; IR $\left(\mathrm{CHCl}_{3}\right) v_{\max } 1647,1735(\mathrm{C}=\mathrm{O}), 3367(\mathrm{NH}) \mathrm{cm}^{-1} ;{ }^{1} \mathrm{H}-\mathrm{NMR}(500 \mathrm{MHz}$, $\left.\mathrm{CDCl}_{3}\right) \delta: 6.14(\mathrm{t}, J=5.5 \mathrm{~Hz}, 1 \mathrm{H}, \mathrm{CONH}), 4.48-4.44(\mathrm{~m}, 1 \mathrm{H}, \mathrm{H}-3), 3.35-3.21\left(\mathrm{~m}, 2 \mathrm{H}, \mathrm{H}-1^{\prime}\right), 2.81(\mathrm{t}$, $\left.J=6.0 \mathrm{~Hz}, 2 \mathrm{H}, \mathrm{H}-2^{\prime}\right), 2.43-0.97\left(\mathrm{~m}, 25 \mathrm{H}, \mathrm{CH}, \mathrm{CH}_{2}\right.$ in pentacyclic skeleton), 2.01 (s, 3H, $\left.\mathrm{CH}_{3} \mathrm{CO}-\right)$, 0.94, 0.92, 0.85, 0.84, 0.83, 0.82 (all s, 3H each, H-23-H-27 and H-29), 0.77 (d, J = $10.0 \mathrm{~Hz}, 1 \mathrm{H}, \mathrm{H}-5$ ), $0.73(\mathrm{~d}, J=7.0 \mathrm{~Hz}, 3 \mathrm{H}, \mathrm{H}-30) ;{ }^{13} \mathrm{C}-\mathrm{NMR}\left(125 \mathrm{MHz}, \mathrm{CDCl}_{3}\right) \delta: 176.7(\mathrm{C}-28), 171.0\left(\mathrm{COCH}_{3}\right), 80.9(\mathrm{C}-3)$, 56.2 (C-17), 55.4 (C-5), 50.3 (C-9), 49.5 (C-19), 44.3 (C-18), 42.6 (C-14), 41.8 (C-2'), 41.7 (C-1'), 40.8 (C-8), 38.7 (C-1), 38.4 (C-22), 37.8 (C-4), 37.6 (C-13), 37.1 (C-10), 34.4 (C-7), 33.6 (C-16), 29.9 (C-20), 29.5 (C-15), 27.9 (C-23), 27.0 (C-2), 23.7 (C-12), 23.1 (C-21, C-29), $21.3\left(\mathrm{COCH}_{3}\right), 21.0$ (C-11), 18.2 (C-6), 16.5 (C-25), 16.2 (C-24, C-26), 14.6 (C-30), 14.5 (C-27); Anal. Calcd. for $\mathrm{C}_{34} \mathrm{H}_{58} \mathrm{~N}_{2} \mathrm{O}_{3}: \mathrm{C}, 75.23, \mathrm{H}, 8.84$. Found: C, 75.74, H, 8.79\%. MS: $m / z 543.40[\mathrm{M}+\mathrm{H}]^{+}$(calcd. for $\mathrm{C}_{34} \mathrm{H}_{58} \mathrm{~N}_{2} \mathrm{O}_{3}, 542.44$ ).

$3 \beta$-N-(4-Aminobuthyl)-3-O-acetyl-lupane-28-amide (6), White powder, $58 \%$ yield; mp $104-106{ }^{\circ} \mathrm{C}(\mathrm{EtOH})$; $[\alpha]_{\mathrm{D}}^{19}-11^{\circ}\left(c 0.69, \mathrm{CHCl}_{3}\right)$; IR $\left(\mathrm{CHCl}_{3}\right) v_{\max } 1646,1734(\mathrm{C}=\mathrm{O}), 3367(\mathrm{NH}) \mathrm{cm}^{-1} ;{ }^{1} \mathrm{H}-\mathrm{NMR}(500$ $\left.\mathrm{MHz}, \mathrm{CDCl}_{3}\right) \delta: 5.86(\mathrm{t}, J=5.5 \mathrm{~Hz}, 1 \mathrm{H}, \mathrm{CONH}), 4.48-4.45(\mathrm{~m}, 1 \mathrm{H}, \mathrm{H}-3), 3.30-3.17\left(\mathrm{~m}, 2 \mathrm{H}, \mathrm{H}-1^{\prime}\right)$, $2.73\left(\mathrm{t}, J=6.5 \mathrm{~Hz}, 2 \mathrm{H}, \mathrm{H}-4^{\prime}\right), 2.47-0.98\left(\mathrm{~m}, 25 \mathrm{H}, \mathrm{CH}, \mathrm{CH}_{2}\right.$ in pentacyclic skeleton, $\left.4 \mathrm{H}, \mathrm{H}-2^{\prime}, \mathrm{H}-3^{\prime}\right)$, 2.03 (s, 3H, $\mathrm{CH}_{3} \mathrm{CO}-$ ), 0.95, 0.93, 0.92, 0.84, 0.83, 0.82, (all s, 3H each, H-23-H-27 and H-29), 0.78 (d, $J=10.0 \mathrm{~Hz}, 1 \mathrm{H}, \mathrm{H}-5), 0.73(\mathrm{~d}, J=7.0 \mathrm{~Hz}, 3 \mathrm{H}, \mathrm{H}-30) ;{ }^{13} \mathrm{C}-\mathrm{NMR}\left(125 \mathrm{MHz}, \mathrm{CDCl}_{3}\right) \delta: 176.3(\mathrm{C}-28)$, $171.0\left(\mathrm{COCH}_{3}\right), 80.9$ (C-3), 56.0 (C-17), 55.4 (C-5), 50.3 (C-9), 49.5 (C-19), 44.3 (C-18), 42.6 (C-14), $41.6\left(\mathrm{C}-4^{\prime}\right), 40.8$ (C-8), 39.0 (C-1'), 38.7 (C-22), 38.4 (C-1), 37.8 (C-4), 37.6 (C-13), 37.1 (C-10), 34.4 (C-7), 33.6 (C-16), 30.7 (C-3'), 29.9 (C-20), 29.4 (C-15), 27.9 (C-23), 27.2 (C-2'), 27.0 (C-2), 23.7 (C-12), 23.0 (C-21, C-29), $21.3\left(\mathrm{COCH}_{3}\right), 21.0$ (C-11), 18.2 (C-6), 16.5 (C-25), 16.2 (C-26, C-24), 14.6 (C-30), 14.5 (C-27); Anal. Calcd. for $\mathrm{C}_{36} \overline{\mathrm{H}}_{62} \mathrm{~N}_{2} \mathrm{O}_{3}: \mathrm{C}, 75.74, \mathrm{H}, 10.95$. Found: $\mathrm{C}, 76.01, \mathrm{H}, 10.89 \%$. MS: $m / z 609.43[\mathrm{M}+\mathrm{K}]^{+}$(calcd. for $\left.\mathrm{C}_{36} \mathrm{H}_{62} \mathrm{~N}_{2} \mathrm{O}_{3}, 570.48\right)$.

$3 \beta-N-\left[2-\left(N, N^{\prime}\right.\right.$-bis-Aminoethyl)-aminoethyl]-3-O-acetyl-lupane-28-amide (7), White powder, $69 \%$ yield; $\mathrm{mp} 108-110{ }^{\circ} \mathrm{C}(\mathrm{EtOH}) ;[\alpha]_{\mathrm{D}}^{19}-5^{\circ}\left(c 0.16, \mathrm{C}_{2} \mathrm{H}_{5} \mathrm{OH}\right) ; \mathrm{IR}\left(\mathrm{CHCl}_{3}\right) v_{\max } 1648,1735(\mathrm{C}=\mathrm{O}), 3441(\mathrm{NH})$ $\mathrm{cm}^{-1} ;{ }^{1} \mathrm{H}-\mathrm{NMR}(400 \mathrm{MHz}, \mathrm{MeOD}) \delta: 4.49-4.45$ (m, 1H, H-3), 3.33-3.27 (m, 2H, H-1'), 2.74-2.72 (m, $\left.4 \mathrm{H}, \mathrm{H}-4^{\prime}, \mathrm{H}-42^{\prime \prime}\right), 2.60-2.58$ (m, 6H, H-2' $\left.{ }^{\prime} \mathrm{H}-3^{\prime}, \mathrm{H}-3^{\prime \prime}\right), 2.32-0.84\left(\mathrm{~m}, 26 \mathrm{H}, \mathrm{CH}, \mathrm{CH}_{2}\right.$ in pentacyclic skeleton), 2.05 (s, 3H, $\mathrm{CH}_{3} \mathrm{CO}-$ ), 1.02, 1.00, 0.93, 0.90, 0.89, 0.88 (all s, 3H each, H-23-H-27 and H-29), $0.79(\mathrm{~d}, J=6.4 \mathrm{~Hz}, 3 \mathrm{H}, \mathrm{H}-30) ;{ }^{13} \mathrm{C}-\mathrm{NMR}(100 \mathrm{MHz}, \mathrm{MeOD}) \delta: 179.3(\mathrm{C}-28), 172.8\left(\mathrm{COCH}_{3}\right), 82.5(\mathrm{C}-3)$, 57.7 (C-17), 57.4 (C-5), 57.0 (C-3', C-3"), 55.2 (C-2'), 51.9 (C-9), 51.1 (C-19), 45.5 (C-18), 43.8 (C-14), 42.2 (C-8), 40.2 (C-22), 39.9 (C-1), 39.8 (C-4', $\left.\mathrm{C}-4^{\prime \prime}\right), 39.0$ (C-4), 38.8 (C-1'), 38.4 (C-13), 38.3 (C-10), 35.8 (C-7), 34.1 (C-16), 31.4 (C-20), 30.9 (C-15), 28.7 (C-23), 28.5 (C-2), 24.8 (C-12), 24.2 (C-29), 23.8 (C-21), $22.4\left(\mathrm{COCH}_{3}\right), 21.4$ (C-11), 19.4 (C-6), 17.2 (C-25), 17.0 (C-24, C-26), 15.3 (C-30, C-27); Anal. Calcd. for $\mathrm{C}_{38} \mathrm{H}_{68} \mathrm{~N}_{4} \mathrm{O}_{3}: \mathrm{C}, 72.56, \mathrm{H}, 10.90$. Found: $\mathrm{C}, 73.04, \mathrm{H}, 10.87 \%$. MS: $m / z 629.56[\mathrm{M}+\mathrm{H}]^{+}$(calcd. for $\left.\mathrm{C}_{38} \mathrm{H}_{68} \mathrm{~N}_{4} \mathrm{O}_{3}, 628.53\right)$.

$3 \beta-N-\{[3-(3-A m i n o p r o p y l)$ piperazinyl]propyl\}-3-O-acetyl-lupane-28-amide (8a), The acid chloride of $\mathbf{3}$ was synthesized according to the general procedure for synthesis of amines 4-7. Then the $N$-tert-butoxycarbonyl1,4-bis(3-aminopropyl)piperazine $(0.45 \mathrm{~g}, 1.5 \mathrm{mmol})$ and $\mathrm{Et}_{3} \mathrm{~N}(0.25 \mathrm{~mL}, 1.8 \mathrm{mmol})$ were added to acid chloride of $3(0.50 \mathrm{~g}, 1 \mathrm{mmol})$ in dry $\mathrm{CH}_{2} \mathrm{Cl}_{2}(10 \mathrm{~mL})$. The mixture was stirred at room temperature for $16 \mathrm{~h}$ (monitoring by TLC), then was poured into cold $\mathrm{H}_{2} \mathrm{O}$ and extracted with $\mathrm{CH}_{2} \mathrm{Cl}_{2}(2 \times 15 \mathrm{~mL})$. The organic phases washed brine, dried over $\mathrm{Na}_{2} \mathrm{SO}_{4}$ and evaporated under reduced pressure to obtain compound 8. Then the compound 8 was dissolved in $\mathrm{CH}_{2} \mathrm{Cl}_{2}(7 \mathrm{~mL})$, acidified with TFA $10 \%(\mathrm{v} / \mathrm{v})$ in $\mathrm{CH}_{2} \mathrm{Cl}_{2}(17 \mathrm{~mL})$ for deprotection reaction and stirred for around $5 \mathrm{~h}$. The reaction was quenched using saturated aqueous potassium carbonate solution $(20 \mathrm{~mL})$. The aqueous phase was extracted with $\mathrm{CH}_{2} \mathrm{Cl}_{2}(2 \times 15 \mathrm{~mL})$. The organic phases washed brine, dried over $\mathrm{Na}_{2} \mathrm{SO}_{4}$ and evaporated under reduced 
pressure. The residue was chromatographed on silica gel, using $\mathrm{CH}_{2} \mathrm{Cl}_{2} / \mathrm{MeOH}$ 50:1 $\rightarrow 5: 1$, to obtain pure compound 8a. White powder, 78\% yield; $\mathrm{mp} 119-121^{\circ} \mathrm{C}(\mathrm{EtOH}) ;[\alpha]_{\mathrm{D}}^{21}-7.4^{\circ}\left(c 0.5, \mathrm{CHCl}_{3}\right) ; \mathrm{IR}\left(\mathrm{CHCl}_{3}\right)$ $v_{\max } 1735(\mathrm{C}=\mathrm{O}), 3361(\mathrm{NH}) \mathrm{cm}^{-1} ;{ }^{1} \mathrm{H}-\mathrm{NMR}\left(500 \mathrm{MHz}, \mathrm{CDCl}_{3}\right) \delta: 6.79(\mathrm{t}, J=5.5 \mathrm{~Hz}, 1 \mathrm{H}, \mathrm{CONH})$, 4.47-4.44 (m, 1H, H-3), 3.31-3.25 (m, 2H, H-1'), 2.78-2.77 (m, 2H, H-1"), 2.50-2.42 (m, 12H, H-3'-H-5', H-3"-H-5"), 2.41-0.98 (m, 25H, CH, CH $\mathrm{CH}_{2}$ in pentacyclic skeleton, $\left.4 \mathrm{H}, \mathrm{H}-2^{\prime}, \mathrm{H}-2^{\prime \prime}\right), 2.02$ (s, 3H, $\left.\mathrm{CH}_{3} \mathrm{CO}-\right)$, 0.93, 0.92, 0.91, 0.83, 0.82, 0.81 (3H each, all s, H-23-H-27 and H-29), 0.77 (d, J = 10.5 Hz, 1H, H-5), 0.72 (d, $J=6.5 \mathrm{~Hz}, 3 \mathrm{H}, \mathrm{H}-30) ;{ }^{13} \mathrm{C}-\mathrm{NMR}\left(125 \mathrm{MHz}, \mathrm{CDCl}_{3}\right) \delta: 176.3(\mathrm{C}-28), 171.0\left(\mathrm{COCH}_{3}\right), 80.9(\mathrm{C}-3), 57.8\left(\mathrm{C}-3^{\prime}\right)$, 56.7 (C-3"), 55.9 (C-17), 55.4 (C-5), 53.5 (C-5', C-5"), 53.3 (C-4'), 53.3 (C-4"), 50.3 (C-9), 49.6 (C-19), 44.1 (C-18), 42.6 (C-14), 40.9 (C-1"), 40.8 (C-8), 39.3 (C-1'), 38.8 (C-22), 38.4 (C-1), 37.8 (C-4), 37.4 (C-13), 37.1 (C-10), 34.4 (C-7), 33.7 (C-16), 29.9 (C-20), 29.8 (C-2'), 29.7 (C-15), 27.9 (C-23), 26.9 (C-2), 25.3 (C-2"), 23.7 (C-12), 23.0 (C-21, C-29), $21.3\left(\mathrm{COCH}_{3}\right), 21.0$ (C-11), 18.2 (C-6), 16.5 (C-25), 16.3 (C-24), 16.2 (C-26), 14.6 (C-30), 14.5 (C-27); Anal. Calcd. for $\mathrm{C}_{42} \mathrm{H}_{74} \mathrm{~N}_{4} \mathrm{O}_{3}$ : C, 73.85, H, 10.92. Found: C, 74.13, $\mathrm{H}, 10.84 \%$. MS: $m / z 683.52$ $[\mathrm{M}+\mathrm{H}]^{+}$(calcd. for $\mathrm{C}_{42} \mathrm{H}_{74} \mathrm{~N}_{4} \mathrm{O}_{3}, 682.58$ ).

\subsubsection{General Procedure for the Synthesis of Compounds 15, 18-21}

Acid chlorides of $\mathbf{3}, \mathbf{1 6}, \mathbf{1 7}$ was synthesized according to the general procedure for synthesis of amines 4-7. Then the acid chlorides of 3, 16, 17 (1 mmol) was dissolved in a mixture of pyridine $(4 \mathrm{~mL}), \mathrm{CH}_{2} \mathrm{Cl}_{2}(1 \mathrm{~mL})$ and DMAP $(0.09 \mathrm{~g}, 0.7 \mathrm{mmol})$ was added. After complete dissolution of DMAP, a solution containing of TRIS (tris(hydroxymethyl)aminomethane) $(0.24 \mathrm{~g}, 2 \mathrm{mmol})$ in pyridine $(0,5 \mathrm{~mL})$ was added. The mixture was stirred for $10 \mathrm{~h}$ at room temperature and the solvent was removed rapidly under vacuum. The residue was chromatographed on silica gel, using $\mathrm{CH}_{2} \mathrm{Cl}_{2} / \mathrm{MeOH}$ 30:1 $\rightarrow 1: 1$, to obtain pure compounds $15,18-21$.

3ß-[2-Amino-3-hydroxy-2-(hydroxymethyl)propyl]-3-O-acetyl-lupane-28-oate (15), White powder, $16 \%$ yield; $\mathrm{mp} 134-136^{\circ} \mathrm{C}(\mathrm{EtOH}) ;[\alpha]_{\mathrm{D}}^{21}-13.1^{\circ}\left(\mathrm{c} 0.51, \mathrm{CHCl}_{3}\right) ; \mathrm{IR}\left(\mathrm{CHCl}_{3}\right) v_{\max } 1731(\mathrm{C}=\mathrm{O}), 3366(\mathrm{OH}), 3446(\mathrm{NH})$ $\mathrm{cm}^{-1} ;{ }^{1} \mathrm{H}-\mathrm{NMR}\left(400 \mathrm{MHz}, \mathrm{CDCl}_{3}\right) \delta: 4.49-4.45(\mathrm{~m}, 1 \mathrm{H}, \mathrm{H}-3), 4.09,4.03$ (both d, $J=11.6 \mathrm{~Hz}, 1 \mathrm{H}$ each, $\mathrm{H}-1^{\prime}$ ), 3.52 (br s, 4H, H-3', $\left.\mathrm{H}-4^{\prime}\right), 2.70$ (br s, $\left.4 \mathrm{H}, \mathrm{NH}_{2}, \mathrm{OH}\right), 2.05$ (s, 3H, $\left.\mathrm{CH}_{3} \mathrm{CO}-\right), 2.24-0.81$ (m, 26H, $\mathrm{CH}, \mathrm{CH}_{2}$ in pentacyclic skeleton), 0.95, 0.91, 0.85, 0.84, 0.83, 0.82 (all s, 3H each, $\mathrm{H}-23-\mathrm{H}-27$ and $\mathrm{H}-29$ ), $0.76(\mathrm{~d}, J=6.8 \mathrm{~Hz}, 3 \mathrm{H}, \mathrm{H}-30) ;{ }^{13} \mathrm{C}-\mathrm{NMR}\left(100 \mathrm{MHz}, \mathrm{CDCl}_{3}\right) \delta: 177.0(\mathrm{C}-28), 171.1\left(\mathrm{COCH}_{3}\right), 80.9(\mathrm{C}-3)$, 64.9 (C-1'), 64.2 (C-3', C-4'), 57.3 (C-17, C-2'), 55.4 (C-5), 50.2 (C-9), 48.8 (C-19), 44.2 (C-18), 42.6 (C-14), 40.7 (C-8), 38.4 (C-22), 38.1 (C-1), 37.8 (C-4), 37.5 (C-13), 37.1 (C-10), 34.3 (C-7), 32.0 (C-16), 29.7 (C-15, C-20), 27.9 (C-23), 26.9 (C-2), 23.7 (C-12), 23.0 (C-29), 22.8 (C-21), $21.3\left(\mathrm{COCH}_{3}\right), 20.9$ (C-11), 18.2 (C-6), 16.5 (C-25), 16.2 (C-24), 16.1 (C-26), 14.7 (C-30), 14.6 (C-27); Anal. Calcd. for $\mathrm{C}_{36} \mathrm{H}_{61} \mathrm{NO}_{6}: \mathrm{C}, 71.60, \mathrm{H}$, 10.18. Found: $\mathrm{C}, 72.09, \mathrm{H}, 10.11 \%$. MS: $m / z 604.42[\mathrm{M}+\mathrm{H}]^{+}$(calcd. for $\mathrm{C}_{36} \mathrm{H}_{61} \mathrm{NO}_{6}, 603.45$ ).

33-[2-Amino-3-hydroxy-2-(hydroxymethyl)propyl]-3-O-acetylurs-12-en-28-oate (18), White powder, 15\% yield; mp 129-131 ${ }^{\circ} \mathrm{C}(\mathrm{EtOH}) ;[\alpha]_{\mathrm{D}}^{18}+40^{\circ}\left(\mathrm{c} 0.74, \mathrm{CHCl}_{3}\right) ; \mathrm{IR}\left(\mathrm{CHCl}_{3}\right) v_{\max } 1721(\mathrm{C}=\mathrm{O}), 3444(\mathrm{NH}), 3468(\mathrm{OH})$ $\mathrm{cm}^{-1} ;{ }^{1} \mathrm{H}-\mathrm{NMR}\left(400 \mathrm{MHz}, \mathrm{CDCl}_{3}\right) \delta: 5.25$ (br s, $\left.1 \mathrm{H}, \mathrm{H}-12\right), 4.51-4.47$ (m, 1H, H-3), 4.02, 3.93 (both d, $J=12 \mathrm{~Hz}, 1 \mathrm{H}$ each, $\left.\mathrm{H}-1^{\prime}\right), 3.48\left(\mathrm{br} \mathrm{s}, 4 \mathrm{H}, \mathrm{H}-3^{\prime}, \mathrm{H}-4^{\prime}\right), 2.68\left(\right.$ br s, $\left.4 \mathrm{H}, \mathrm{NH}_{2}, \mathrm{OH}\right), 2.19(\mathrm{~d}, J=11.2 \mathrm{~Hz}, 1 \mathrm{H}$, $\mathrm{H}-18), 2.05$ (s, 3H, $\left.\mathrm{CH}_{3} \mathrm{CO}-\right)$, 1.99-0.81 (m, 22H, CH, $\mathrm{CH}_{2}$ in pentacyclic skeleton), 1.08, 0.96, 0.94, 0.88, 0.87, 0.86, 0.74 (all s, 3H each, H-23-H-27, H-29 and H-30); ${ }^{13} \mathrm{C}-\mathrm{NMR}\left(100 \mathrm{MHz}, \mathrm{CDCl}_{3}\right) \delta$ : 178.1 (C-28), $171.1\left(\mathrm{COCH}_{3}\right), 138.3(\mathrm{C}-13), 125.6(\mathrm{C}-12), 80.9(\mathrm{C}-3), 65.7\left(\mathrm{C}-1^{\prime}\right), 64.4\left(\mathrm{C}-3^{\prime}, \mathrm{C}-4^{\prime}\right), 56.6\left(\mathrm{C}-2^{\prime}\right), 55.3(\mathrm{C}-5)$, 53.0 (C-18), 48.6 (C-17), 47.4 (C-9), 42.1 (C-14), 39.5 (C-4, C-8), 38.9 (C-19), 38.3 (C-20), 37.7 (C-1), 37.1 (C-22), 36.8 (C-10), 32.9 (C-7), 30.6 (C-21), 28.1 (C-23), 27.9 (C-15), 24.3 (C-16, C-27), 23.5 (C-2, C-11), $21.3\left(\mathrm{COCH}_{3}\right)$, 21.1 (C-30), 18.2 (C-6), 17.2 (C-29), 17.0 (C-26), 16.7 (C-24), 15.5 (C-25); Anal. Calcd. for $\mathrm{C}_{36} \mathrm{H}_{59} \mathrm{NO}_{6}$ : C, 71.84, $\mathrm{H}, 9.88$. Found: $\mathrm{C}, 72.13, \mathrm{H}, 9.83 \%$. MS: $m / z 602.40[\mathrm{M}+\mathrm{H}]^{+}$(calcd. for $\mathrm{C}_{36} \mathrm{H}_{59} \mathrm{NO}_{6}, 601.43$ ).

$3 \beta-N-\left[\left(1^{\prime}, 1^{\prime}, 1^{\prime}\right.\right.$-tris-Hidroxymethyl)methyl]-3-O-acetyl-ursolamide (19), White powder, 24\% yield; mp $203-205^{\circ} \mathrm{C}(\mathrm{EtOH}) ;[\alpha]_{\mathrm{D}}^{18}+26.9^{\circ}\left(c\right.$ 0.74, $\left.\mathrm{CH}_{3} \mathrm{OH}\right) ; \mathrm{IR}\left(\mathrm{CH}_{3} \mathrm{OH}\right) v_{\max } 1734(\mathrm{C}=\mathrm{O}), 2923,2871,2852(\mathrm{OH})$, $3352(\mathrm{NH}) \mathrm{cm}^{-1}$; ${ }^{1} \mathrm{H}-\mathrm{NMR}$ (500 MHz, MeOD) $\delta: 5.38$ (br s, $\left.1 \mathrm{H}, \mathrm{H}-12\right), 4.50-4.47$ (m, 1H, H-3), 3.66, 3.58 (both d, $J=10 \mathrm{~Hz}, 3 \mathrm{H}$ each, $\left.\mathrm{H}-2^{\prime}-\mathrm{H}-4^{\prime}\right), 2.12-0.88\left(\mathrm{~m}, 23 \mathrm{H}, \mathrm{CH}, \mathrm{CH}_{2}\right.$ in pentacyclic skeleton), 2.05 (s, 3H, $\mathrm{CH}_{3} \mathrm{CO}-$ ), 1.18, 1.04, 0.99, 0.95, 0.93, 0.92, 0.91 (all s, 3H each, H-23-H-27, H-29 and H-30); 
${ }^{13} \mathrm{C}-\mathrm{NMR}\left(125 \mathrm{MHz}, \mathrm{CDCl}_{3}\right)$ 8: $178.5(\mathrm{C}-28), 170.7\left(\mathrm{COCH}_{3}\right), 138.1(\mathrm{C}-13), 125.8$ (C-12), 80.4 (C-3), $61.8\left(\mathrm{C}-1^{\prime}\right), 60.8\left(\mathrm{C}-2^{\prime}-\mathrm{C}-4^{\prime}\right), 55.1$ (C-5), 53.6 (C-18), 48.3 (C-17), 47.4 (C-9), 42.3 (C-14), 39.5 (C-4, C-8), 38.9 (C-19), 38.4 (C-20), 37.7 (C-22, C-1), 36.8 (C-10), 33 (C-7), 30.9 (C-21), 28.3 (C-23), 27.8 (C-15), 24.5 (C-16), 23.7 (C-2), $23.4(\mathrm{C}-11, \mathrm{C}-27), 21.5\left(\mathrm{COCH}_{3}\right), 21.4(\mathrm{C}-30), 18.2(\mathrm{C}-6), 17.5(\mathrm{C}-29, \mathrm{C}-26)$, 17.1 (C-24), 15.7 (C-25); Anal. Calcd. for $\mathrm{C}_{36} \mathrm{H}_{59} \mathrm{NO}_{6}: \mathrm{C}, 71.84, \mathrm{H}, 9.88$. Found: $\mathrm{C}, 72.09, \mathrm{H}, 9.79 \%$. MS: $m / z 602.41[\mathrm{M}+\mathrm{H}]^{+}$(calcd. for $\mathrm{C}_{36} \mathrm{H}_{59} \mathrm{NO}_{6}, 601.43$ ).

3ß-[2-Amino-3-hydroxy-2(hydroxymethyl)propyl]-3-O-acetylolean-12-en-28-oate (20), White powder, 23\% yield; mp 141-143 ${ }^{\circ} \mathrm{C}(\mathrm{EtOH}) ;[\alpha]_{\mathrm{D}}^{18}+49^{\circ}\left(\mathrm{c} 0.75, \mathrm{CHCl}_{3}\right) ; \mathrm{IR}\left(\mathrm{CHCl}_{3}\right) v_{\max } 1618,1727(\mathrm{C}=\mathrm{O}), 3447(\mathrm{NH})$ $\mathrm{cm}^{-1},{ }^{1} \mathrm{H}-\mathrm{NMR}\left(500 \mathrm{MHz}, \mathrm{CDCl}_{3}\right) \delta: 5.30$ (br s, 1H, H-12), 4.51-4.48 (m, 1H, H-3), 4.04, 3.99 (both d, $J=11.5 \mathrm{~Hz}, 1 \mathrm{H}$ each, $\left.\mathrm{H}-1^{\prime}\right), 3.50$ (br s, 4H, H-3', $\left.\mathrm{H}-4^{\prime}\right), 2.84$ (d, $\left.J=10.0 \mathrm{~Hz}, 1 \mathrm{H}, \mathrm{H}-18\right), 2.68-2.60$ (m, $\left.4 \mathrm{H}, \mathrm{NH}_{2}, \mathrm{OH}\right), 2.05$ (s, 3H, $\left.\mathrm{CH}_{3} \mathrm{CO}-\right), 2.01-0.83\left(\mathrm{~m}, 22 \mathrm{H}, \mathrm{CH}, \mathrm{CH}_{2}\right.$ in pentacyclic skeleton), 1.14, 0.94, 0.93, 0.92, 0.87, 0.86, 0.73 (all s, 3H each, H-23-H-27, H-29 and H-30); ${ }^{13} \mathrm{C}-\mathrm{NMR}\left(125 \mathrm{MHz}, \mathrm{CDCl}_{3}\right)$

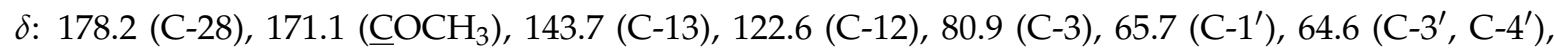
56.6 (C-2'), 55.3 (C-5), 47.5 (C-9), 47.2 (C-17), 45.7 (C-19), 41.8 (C-14), 41.5 (C-18), 39.3 (C-8), 38.1 (C-1), 37.7 (C-4), 36.9 (C-10), 33.8 (C-22), 33.0 (C-30), 32.8 (C-7), 32.7 (C-21), 30.7 (C-20), 28.0 (C-23), 27.6 (C-15), 25.8 (C-27), 23.6 (C-29), 23.5 (C-11), 23.4 (C-2), 23.1 (C-16), $21.3\left(\mathrm{COCH}_{3}\right), 18.2$ (C-6), 17.1 (C-26), 16.7 (C-24), 15.4 (C-25); Anal. Calcd. for $\mathrm{C}_{36} \mathrm{H}_{59} \mathrm{NO}_{6}$ : C, 71.84, H, 9.88. Found: C, 72.04, H, 9.82\%. MS: $m / z 602.40[\mathrm{M}+\mathrm{H}]^{+}$(calcd. for $\mathrm{C}_{36} \mathrm{H}_{59} \mathrm{NO}_{6}, 601.43$ ).

$3 \beta-N-\left[\left(1^{\prime}, 1^{\prime}, 1^{\prime}\right.\right.$-tris-Hydroxymethyl)methyl]-3-O-acetyl-oleanolamide (21), White powder, 32\% yield; $\mathrm{mp}$ $249-251{ }^{\circ} \mathrm{C}(\mathrm{EtOH}) ;[\alpha]_{\mathrm{D}}^{18}+33.9^{\circ}\left(c\right.$ 0.61, $\left.\mathrm{CH}_{3} \mathrm{OH}\right) ; \mathrm{IR}\left(\mathrm{CH}_{3} \mathrm{OH}\right) v_{\max } 1732(\mathrm{C}=\mathrm{O}), 2945,2927(\mathrm{OH})$, $3353(\mathrm{NH}) \mathrm{cm}^{-1} ;{ }^{1} \mathrm{H}-\mathrm{NMR}\left(500 \mathrm{MHz}, d_{6}\right.$-DMSO) $\delta: 6.62(\mathrm{~s}, 1 \mathrm{H}, \mathrm{NH}), 5.24(\mathrm{br} \mathrm{s}, 1 \mathrm{H}, \mathrm{H}-12), 4.97(\mathrm{t}$, $J=5 \mathrm{~Hz}, 3 \mathrm{H},-\mathrm{OH}), 4.42-4.38(\mathrm{~m}, 1 \mathrm{H}, \mathrm{H}-3), 3.49-3.42\left(\mathrm{~m}, 6 \mathrm{H}, \mathrm{H}-2^{\prime}-\mathrm{H}-4^{\prime}\right), 2.61$ (d, J = 10.0 Hz, 1H, H-18), $2.00\left(\mathrm{~s}, 3 \mathrm{H}, \mathrm{CH}_{3} \mathrm{CO}-\right), 1.97-0.84\left(\mathrm{~m}, 22 \mathrm{H}, \mathrm{CH}, \mathrm{CH}_{2}\right.$ in pentacyclic skeleton), 1.91, 0.90, 0.88, 0.87, 0.82, $0.81,0.78$ (all s, 3H each, H-23-H-27, H-29 and H-30); ${ }^{13} \mathrm{C}-\mathrm{NMR}\left(125 \mathrm{MHz}, d_{6}\right.$-DMSO) $\delta: 178.3$ (C-28), $170.6\left(\mathrm{COCH}_{3}\right), 143.7(\mathrm{C}-13), 122.6(\mathrm{C}-12), 80.4(\mathrm{C}-3), 61.8\left(\mathrm{C}-1^{\prime}\right), 60.8\left(\mathrm{C}-2^{\prime}-\mathrm{C}-4^{\prime}\right), 55(\mathrm{C}-5), 47.4$ (C-9), 46.8 (C-17), 46.6 (C-19), 42.0 (C-14), 41.9 (C-18), 39.5 (C-8), 38.2 (C-1), 37.7 (C-4), 36.9 (C-10), 34.1 (C-22), 33.3 (C-7), 33.2 (C-30), 32.7 (C-21), 30.8 (C-20), 28.2 (C-23), 27.4 (C-15), 25.8 (C-27), 23.8 (C-29), 23.7 (C-2), 23.4 (C-11, C-16), $21.4\left(\mathrm{COCH}_{3}\right), 18.2$ (C-6), 17.4 (C-26), 17.1 (C-24), 15.6 (C-25); Anal. Calcd. for $\mathrm{C}_{36} \mathrm{H}_{59} \mathrm{NO}_{6}: \mathrm{C}, 71.84, \mathrm{H}, 9.88$. Found: $\mathrm{C}, 72.11, \mathrm{H}, 9.85 \%$. MS: $m / z 602.39[\mathrm{M}+\mathrm{H}]^{+}$(calcd. for $\left.\mathrm{C}_{36} \mathrm{H}_{59} \mathrm{NO}_{6}, 601.43\right)$.

\subsubsection{General Procedure for the Guanilation of Amines 4-7, 8a, 15, 18 and 20}

The amine $(0.5 \mathrm{mmol})$ is added neat to a solution of 1,3-di-Boc-2-(trifluoromethyl-sulfonyl)guanidine $(0.18 \mathrm{~g}, 0.45 \mathrm{mmol})$ or $(0.60 \mathrm{~g}, 0.9 \mathrm{mmol})$ for amine 7 and $\mathrm{Et}_{3} \mathrm{~N}(0.07 \mathrm{~mL}, 0.5 \mathrm{mmol})$ in $\mathrm{CH}_{2} \mathrm{Cl}_{2}$ (at r.t.) of compounds 4-7, 8a or in $\mathrm{CHCl}_{3}$ (at reflux) of compounds 15, 18, $20(10 \mathrm{~mL})$. The mixture was stirred for 2-12 $\mathrm{h}$ (TLC monitoring $\mathrm{CH}_{2} \mathrm{Cl}_{2} / \mathrm{MeOH} 20: 1$ ). After completion of the reaction, the mixture is diluted with $\mathrm{CH}_{2} \mathrm{Cl}_{2}$ and washed witH- $\mathrm{NH}_{4} \mathrm{Cl}, \mathrm{NaHCO}_{3}$ and brine. After drying with sodium sulfate and filtering the solvent is removed under reduced pressure. The residue was chromatographed on silica gel, using hexane/EtOAc 10:1 $\rightarrow 1: 1$, to obtain pure compounds 9-13, 15a, 18a and 20a.

$\mathrm{N}$-[4-tert-Butyloxycarbonyl buthylguanidine]-3-oxo-lupane-28-amide (9), White powder, $88 \%$ yield; $\mathrm{mp}$ $158-160{ }^{\circ} \mathrm{C}(\mathrm{EtOH}) ;[\alpha]_{\mathrm{D}}^{23}+3.4^{\circ}\left(c 0.59, \mathrm{CH}_{2} \mathrm{Cl}_{2}\right)$; IR $\left(\mathrm{CHCl}_{3}\right) v_{\max } 1637,1718(\mathrm{C}=\mathrm{O}), 3337(\mathrm{NH}) \mathrm{cm}^{-1}$; ${ }^{1} \mathrm{H}-\mathrm{NMR}\left(500 \mathrm{MHz}, \mathrm{CDCl}_{3}\right) \delta: 11.52(\mathrm{~s}, 1 \mathrm{H}, \mathrm{NH}$ in $\mathrm{Boc}), 8.30(\mathrm{br} \mathrm{s}, 1 \mathrm{H}, \mathrm{NH}-\mathrm{C}=\mathrm{N}), 5.70(\mathrm{br} \mathrm{s}, 1 \mathrm{H}$, $\mathrm{CONH}$ ), 3.48-3.41 (m, 2H, H-2'), 3.37-3.20 (m, 2H, H-1'), 1.51, 1.48 (both s, 9H each, $\mathrm{CH}_{3}$ in Boc), 2.54-1.15 (m, 26H, CH, CH ${ }_{2}$ in pentacyclic skeleton, $\left.4 \mathrm{H}, \mathrm{H}-2^{\prime}, \mathrm{H}-3^{\prime}\right), 1.08,1.03,0.98,0.97,0.95$ (all s, 3H each, H-23-H-27), 0.87 (d, $J=6.5 \mathrm{~Hz}, 3 \mathrm{H}, \mathrm{H}-29), 0.75$ (d, $J=6.5 \mathrm{~Hz}, 3 \mathrm{H}, \mathrm{H}-30) ;{ }^{13} \mathrm{C}-\mathrm{NMR}$ $\left(125 \mathrm{MHz}, \mathrm{CDCl}_{3}\right) \delta$ : $218.1(\mathrm{C}-3), 176.3(\mathrm{C}-28), 163.6(\mathrm{C}=\mathrm{N}), 156.1,153.3$ (CONH-Boc), 83.0, $79.2(\mathrm{C}$ in Boc), 56.0 (C-17), 55.0 (C-5), 49.8 (C-9), 49.5 (C-19), 47.3 (C-4), 44.1 (C-18), 42.6 (C-14), 40.7 (C-8), 40.5 (C-4'), 39.6 (C-1), 38.7 (C-22, C-1'), 37.6 (C-13), 36.9 (C-10), 34.1 (C-2), 33.8 (C-16), 33.6 (C-7), 29.9 (C-20), 29.4 (C-15), 28.4, $28.0\left(\mathrm{CH}_{3}\right.$ in Boc), 27.7 (C-23), 27.0 (C-2', $\left.\mathrm{C}-3^{\prime}\right), 26.6$ (C-12), 23.0 (C-21, 
C-29), 21.5 (C-24), 21.0 (C-11), 19.6 (C-6), 16.0 (C-25), 15.9 (C-26), 14.6 (C-30), 14.5 (C-27); Anal. Calcd. for $\mathrm{C}_{45} \mathrm{H}_{76} \mathrm{~N}_{4} \mathrm{O}_{6}: \mathrm{C}, 70.27, \mathrm{H}, 9.96$. Found: $\mathrm{C}, 70.62, \mathrm{H}, 9.91 \%$. MS: $m / z 791.56[\mathrm{M}+\mathrm{Na}]^{+}$(calcd. for $\left.\mathrm{C}_{45} \mathrm{H}_{76} \mathrm{~N}_{4} \mathrm{O}_{6}, 768.58\right)$.

33-N-(2-tert-Butyloxycarbonylethylguanidine)-3-O-acetyl-lupane-28-amide (10), White powder, $86 \%$ yield; mp 176-177 ${ }^{\circ} \mathrm{C}(\mathrm{EtOH}) ;[\alpha]_{\mathrm{D}}^{23}+3.8^{\circ}\left(c \quad 0.56, \mathrm{CHCl}_{3}\right) ; \mathrm{IR}\left(\mathrm{CHCl}_{3}\right) v_{\max } 1724(\mathrm{C}=\mathrm{O}), 3329(\mathrm{NH}) \mathrm{cm}^{-1}$; ${ }^{1} \mathrm{H}-\mathrm{NMR}\left(500 \mathrm{MHz}, \mathrm{CDCl}_{3}\right) \delta: 11.53(\mathrm{~s}, 1 \mathrm{H}, \mathrm{NH}$ in $\mathrm{Boc}), 8.65$ (br s, $\left.1 \mathrm{H}, \mathrm{NH}-\mathrm{C}=\mathrm{N}\right), 6.88$ (br s, $1 \mathrm{H}$, $\mathrm{CONH}), 4.50-4.47$ (m, 1H, H-3), 3.69-3.54 (m, 2H, H-2'), 3.47-3.35 (m, 2H, H-1'), 2.05 (s, 3H, CH $\mathrm{CH}_{3} \mathrm{CO}-$ ), 1.51, 1.50 (both s, $9 \mathrm{H}$ each, $\mathrm{CH}_{3}$ in Boc), 2.46-0.96 (m, 25H, $\mathrm{CH}, \mathrm{CH}_{2}$ in pentacyclic skeleton), 0.94, 0.90, 0.87, 0.86, 0.85, 0.84 (all s, 3H each, H-23-H-27 and H-29), 0.79 (d, J = 9.5 Hz, 1H, H-5), 0.75 (d, $J=7.0 \mathrm{~Hz}, 3 \mathrm{H}, \mathrm{H}-30) ;{ }^{13} \mathrm{C}-\mathrm{NMR}\left(125 \mathrm{MHz}, \mathrm{CDCl}_{3}\right) \delta: 176.9(\mathrm{C}-28), 171.0\left(\mathrm{COCH}_{3}\right), 163.1(\mathrm{C}=\mathrm{N})$, 153.5, 153.0 (CONH-Boc), 83.5 (C in Boc), 80.9 (C-3), 77.3 (C in Boc), 56.0 (C-17), 55.4 (C-5), 50.3 (C-9), 49.7 (C-19), 44.2 (C-18), 42.5 (C-14), 41.2 (C-2'), 40.7 (C-8), 39.7 (C-1'), 38.6 (C-22), 38.4 (C-1), 37.8 (C-4), 37.5 (C-13), 37.1 (C-10), 34.3 (C-7), 33.4 (C-16), 29.8 (C-20), 29.4 (C-15), 28.3, $28.0\left(\mathrm{CH}_{3}\right.$ in Boc), 27.9 (C-23), 26.9 (C-2), 23.7 (C-12), 23.1 (C-29), 23.0 (C-21), $21.3\left(\mathrm{COCH}_{3}\right), 21.0(\mathrm{C}-11), 18.3$ (C-6), 16.5 (C-25), 16.2 (C-24), 16.1 (C-26), 14.7 (C-30), 14.6 (C-27); Anal. Calcd. for $\mathrm{C}_{45} \mathrm{H}_{76} \mathrm{~N}_{4} \mathrm{O}_{7}$ : C, 68.84, H, 9.76. Found: C, 69.23, H, 9.69\%. MS: $m / z$ 807.54 [M + Na] $]^{+}$(calcd. for $\mathrm{C}_{45} \mathrm{H}_{76} \mathrm{~N}_{4} \mathrm{O}_{7}, 784.57$ ).

$3 \beta$-N-(4-tert-Butyloxycarbonylbutylguanidine)-3-O-acetyl-lupane-28-amide (11), White powder, 82\% yield; mp $148-150{ }^{\circ} \mathrm{C}(\mathrm{EtOH}) ;[\alpha]_{\mathrm{D}}^{17}-4^{\circ}\left(c \quad 0.52, \mathrm{CHCl}_{3}\right) ; \mathrm{IR}\left(\mathrm{CHCl}_{3}\right) v_{\max } 1640,1720(\mathrm{C}=\mathrm{O}), 3288,3337$, $3410(\mathrm{NH}) \mathrm{cm}^{-1} ;{ }^{1} \mathrm{H}-\mathrm{NMR}\left(500 \mathrm{MHz}, \mathrm{CDCl}_{3}\right) \delta: 11.48(\mathrm{~s}, 1 \mathrm{H}, \mathrm{NH}$ in Boc), $8.30(\mathrm{t}, J=5.0 \mathrm{~Hz}, 1 \mathrm{H}$, $\mathrm{NH}-\mathrm{C}=\mathrm{N}), 5.73(\mathrm{t}, J=5.5 \mathrm{~Hz}, 1 \mathrm{H}, \mathrm{CONH}), 4.46-4.43(\mathrm{~m}, 1 \mathrm{H}, \mathrm{H}-3), 3.42-3.37\left(\mathrm{~m}, 2 \mathrm{H}, \mathrm{H}-2^{\prime}\right), 3.31-3.16(\mathrm{~m}$, $\left.2 \mathrm{H}, \mathrm{H}-1^{\prime}\right), 2.01$ (s, 3H, $\mathrm{CH}_{3} \mathrm{CO}-$ ), 1.47, 1.46 (both s, 9H each, $\mathrm{CH}_{3}$ in Boc), 2.45-0.94 (m, 25H, CH, $\mathrm{CH}_{2}$ in pentacyclic skeleton, $4 \mathrm{H}, \mathrm{H}-2^{\prime}, \mathrm{H}^{\prime} 3^{\prime}$ ), $0.91,0.90,0.83,0.82,0.81,0.80$ (all s, $3 \mathrm{H}$ each, $\mathrm{H}-23-\mathrm{H}-27$ and $\mathrm{H}-29), 0.75(\mathrm{~d}, J=9.5 \mathrm{~Hz}, 1 \mathrm{H}, \mathrm{H}-5), 0.71(\mathrm{~d}, J=7.0 \mathrm{~Hz}, 3 \mathrm{H}, \mathrm{H}-30) ;{ }^{13} \mathrm{C}-\mathrm{NMR}\left(125 \mathrm{MHz}, \mathrm{CDCl}_{3}\right) \delta$ : 176.2 (C-28), $170.9\left(\mathrm{COCH}_{3}\right), 163.6(\mathrm{C}=\mathrm{N}), 156.1,153.3(\mathrm{CONH}-\mathrm{Boc}), 83.0(\mathrm{C}$ in Boc), $81.0(\mathrm{C}-3), 79.2$ (C in Boc), 56.0 (C-17), 55.4 (C-5), 50.3 (C-9), 49.5 (C-19), 44.2 (C-18), 42.6 (C-14), 40.8 (C-8), 40.5 (C-4'), 38.7 (C-1' , C-22), 38.4 (C-1), 37.8 (C-4), 37.5 (C-13), 37.1 (C-10), 34.4 (C-7), 33.6 (C-16), 29.9 (C-3'), 29.4 (C-20), 28.3, 28.0 ( $\mathrm{CH}_{3}$ in Boc), 27.8 (C-15), 27.3 (C-23), 26.9 (C-2'), 26.5 (C-2), 23.7 (C-12), 23.0 (C-21, C-29), $21.3\left(\mathrm{COCH}_{3}\right), 21.0$ (C-11), 18.2 (C-6), 16.5 (C-25), 16.2 (C-24, C-26), 14.6 (C-30), 14.5 (C-27); Anal. Calcd. for $\mathrm{C}_{47} \mathrm{H}_{80} \mathrm{~N}_{4} \mathrm{O}_{7}: \mathrm{C}, 69.42, \mathrm{H}, 9.92$. Found: $\mathrm{C}, 69.74, \mathrm{H}, 9.85 \%$. MS: $m / z 835.51[\mathrm{M}+\mathrm{Na}]^{+}$(calcd. for $\mathrm{C}_{47} \mathrm{H}_{80} \mathrm{~N}_{4} \mathrm{O}_{7}, 812.60$ ).

$3 \beta-N-\left[2-\left(N, N^{\prime}\right.\right.$-bis-tert-Butyloxycarbonylethylgyanidine)-aminoethyl]-3-O-acetyl-lupane-28-amide (12), White powder, $87 \%$ yield; $\mathrm{mp} 188-190{ }^{\circ} \mathrm{C}(\mathrm{EtOH}) ;[\alpha]_{\mathrm{D}}^{19}+1.02^{\circ}\left(c \quad 0.96, \mathrm{CHCl}_{3}\right)$; IR $\left(\mathrm{CHCl}_{3}\right) v_{\max } 1641$, $1722(\mathrm{C}=\mathrm{O}), 3335,3442(\mathrm{NH}) \mathrm{cm}^{-1},{ }^{1} \mathrm{H}-\mathrm{NMR}\left(500 \mathrm{MHz}, \mathrm{CDCl}_{3}\right) \delta: 11.52(\mathrm{~s}, 2 \mathrm{H}, \mathrm{NH}$ in Boc), 8.52 (br s, $2 \mathrm{H}, \mathrm{NH}-\mathrm{C}=\mathrm{N}), 6.35(\mathrm{t}, 1 \mathrm{H}, J=5.5 \mathrm{~Hz}, \mathrm{CONH}), 4.49-4.46(\mathrm{~m}, 1 \mathrm{H}, \mathrm{H}-3), 3.53-3.43\left(\mathrm{~m}, 4 \mathrm{H}, \mathrm{H}-4^{\prime}, \mathrm{H}-4^{\prime \prime}\right)$, 3.41-3.22 (m, 2H, H-1'), 2.65-2.54 (m, 6H, H-2' $\left.{ }^{\prime} \mathrm{H}-3^{\prime}, \mathrm{H}-3^{\prime \prime}\right), 2.04$ (s, 3H, $\mathrm{CH}_{3} \mathrm{CO}-$ ) , 1.50, 1.48 (both br s, $18 \mathrm{H}$ each, $\mathrm{CH}_{3}$ in Boc), 2.32-0.98 (m, $25 \mathrm{H}, \mathrm{CH}, \mathrm{CH}_{2}$ in pentacyclic skeleton), 0.93, 0.92, 0.85, 0.84, 0.83, 0.82 (all s, 3H each, H-23-H-27 and H-29), 0.78 (d, $J=9.0 \mathrm{~Hz}, 1 \mathrm{H}, \mathrm{H}-5), 0.73(\mathrm{~d}, J=6.5 \mathrm{~Hz}, 3 \mathrm{H}, \mathrm{H}-30$ ); ${ }^{13} \mathrm{C}-\mathrm{NMR}\left(125 \mathrm{MHz}, \mathrm{CDCl}_{3}\right) \delta: 176.7(\mathrm{C}-28), 171.0\left(\mathrm{COCH}_{3}\right), 163.5(\mathrm{C}=\mathrm{N}), 155.9,153.2(\mathrm{CONH}-\mathrm{Boc})$, 82.9 (C in Boc), 81.0 (C-3), 79.2 (C in Boc), 55.9 (C-17), 55.5 (C-5), 54.8 (C-2'), 53.8 (C-3', C-3"), 50.4 (C-9), 49.6 (C-19), 43.8 (C-18), 42.5 (C-14), 40.8 (C-8), 39.0 (C-4', C-4"), 38.9 (C-22), 38.4 (C-1), 38.0 (C-13), $37.8\left(\mathrm{C}-1^{\prime}\right), 37.2$ (C-4), 37.1 (C-10), 34.4 (C-7), 33.4 (C-16), 29.8 (C-20), 29.5 (C-15), 28.3, $28.1\left(\mathrm{CH}_{3}\right.$ in Boc), 28.0 (C-23), 27.0 (C-2), 23.7 (C-12), 23.1 (C-29), 23.0 (C-21), $21.3\left(\mathrm{COCH}_{3}\right), 21.0(\mathrm{C}-11), 18.3$ (C-6), 16.5 (C-25), 16.4 (C-24), 16.2 (C-26), 14.7 (C-30), 14.4 (C-27); Anal. Calcd. for $\mathrm{C}_{60} \mathrm{H}_{104} \mathrm{~N}_{8} \mathrm{O}_{11}$ : C, 64.72; $\mathrm{H}$, 9.41. Found: $\mathrm{C}, 65.02 ; \mathrm{H}, 9.34 \%$. MS: $m / z 1135.71[\mathrm{M}+\mathrm{Na}]^{+}$(calcd. for $\mathrm{C}_{60} \mathrm{H}_{104} \mathrm{~N}_{8} \mathrm{O}_{11}, 1112.78$ ).

$3 \beta-N-\{[3-(3-t e r t-B u t y l o x y c a r b o n y l p r o p y l g y a n i d i n e) p i p e r a z i n y l] p r o p y l\}-3-O-a c e t y l-l u p a n e-28-a m i d e(13)$, White powder, $60 \%$ yield; mp $131-134^{\circ} \mathrm{C}(\mathrm{EtOH}) ;[\alpha]_{\mathrm{D}}^{21}-7.9^{\circ}\left(c 0.57, \mathrm{CHCl}_{3}\right)$; $\mathrm{IR}\left(\mathrm{CHCl}_{3}\right) v_{\max } 1640,1722(\mathrm{C}=\mathrm{O})$, 3289, $3333(\mathrm{NH}) \mathrm{cm}^{-1} ;{ }^{1} \mathrm{H}-\mathrm{NMR}\left(500 \mathrm{MHz}, \mathrm{CDCl}_{3}\right.$ ) $\delta: 11.50$ (br s, $1 \mathrm{H}, \mathrm{NH}$ in Boc), 8.53 (br s, $1 \mathrm{H}, \mathrm{NH}-\mathrm{C}=\mathrm{N}$ ), 6.86 (br s, 1H, CONH), 4.47-4.45 (m, 1H, H-3), 3.51-3.42 (m, 2H, H-1' ), 3.32-3.27 (m, 2H, H-1'), 2.48-2.41 (m, 
14H, H-3'-H-5', H-2"'-H-5"), 2.06 (s, 3H, CH ${ }_{3} \mathrm{CO}-$ ), 1.49 (br s, 18H, CH $\mathrm{CH}_{3}$ in Boc), 2.33-0.99 (m, 25H, CH, $\mathrm{CH}_{2}$ in pentacyclic skeleton, 2H, H-2'), 0.93, 0.92, 0.85, 0.84, 0.83, 0.81 (all s, 3H each, H-23-H-27 and H-29), $0.78(\mathrm{~d}, J=10.5 \mathrm{~Hz}, 1 \mathrm{H}, \mathrm{H}-5), 0.73(\mathrm{~d}, J=6.5 \mathrm{~Hz}, 3 \mathrm{H}, \mathrm{H}-30) ;{ }^{13} \mathrm{C}-\mathrm{NMR}\left(125 \mathrm{MHz}, \mathrm{CDCl}_{3}\right) \delta: 176.4(\mathrm{C}-28)$, $171.0\left(\mathrm{COCH}_{3}\right), 163.7(\mathrm{C}=\mathrm{N}), 156.1,153.0(\mathrm{CONH}-\mathrm{Boc}), 82.8$ (C in Boc), 80.9 (C-3), 79.2 (C in Boc), 56.4 (C-3'), 55.9 (C-17), 55.9 (C-3"), 55.4 (C-5), 53.1 (C-4', C-4", C-5', C-5"), 50.3 (C-9), 49.6 (C-19), 44.1 (C-18), 42.6 (C-14), 40.8 (C-8), 39.8 (C-22, C-1") 39.2 (C-1'), 38.8 (C-1), 38.4 (C-4), 37.8 (C-10), 37.4 (C-13), 34.5 (C-7), 33.7 (C-16), 29.8 (C-20), 29.4 (C-15), 28.3, 28.1 ( $\mathrm{CH}_{3}$ in Boc), 27.9 (C-23), 26.9 (C-2), 26.9 (C-2'), 25.9 (C-2"), 23.7 (C-12), 23.1 (C-21), 23.0 (C-29), $21.3\left(\mathrm{COCH}_{3}\right), 21.0$ (C-11), 18.2 (C-6), 16.5 (C-25), 16.3 (C-24), 16.2 (C-26), 14.6 (C-30), 14.5 (C-27); Anal. Calcd. for $\mathrm{C}_{53} \overline{\mathrm{H}_{92}} \mathrm{~N}_{6} \mathrm{O}_{7}: \mathrm{C}, 68.79, \mathrm{H}, 10.02$. Found: $\mathrm{C}, 69.04, \mathrm{H}, 9.96 \%$. MS: $m / z 947.58$ $[\mathrm{M}+\mathrm{Na}]^{+}$(calcd. for $\left.\mathrm{C}_{53} \mathrm{H}_{92} \mathrm{~N}_{6} \mathrm{O}_{7}, 924.70\right)$.

3ß-[2-tert-Butyloxycarbonylguanidine-3-hydroxy-2-(hydroxymethyl)propyl]-3-O-acetyl-lupane-28-oate (15a), White powder, $63 \%$ yield; $\mathrm{mp} 106-108^{\circ} \mathrm{C}(\mathrm{EtOH}) ;[\alpha]_{\mathrm{D}}^{21}-5.6^{\circ}\left(c 0.48, \mathrm{CHCl}_{3}\right) ; \mathrm{IR}\left(\mathrm{CHCl}_{3}\right) v_{\max } 1655$, $1714(\mathrm{C}=\mathrm{O}), 3271,3437(\mathrm{NH}) \mathrm{cm}^{-1} ;{ }^{1} \mathrm{H}-\mathrm{NMR}\left(400 \mathrm{MHz}, \mathrm{CDCl}_{3}\right) \delta: 11.47$ (s, 1H, NH in Boc), 9.05 (s, $1 \mathrm{H}, \mathrm{NH}-\mathrm{C}=\mathrm{N}$ ), 4.49-4.45 (m, 1H, H-3), 4.25 (br s, 2H, H-1'), 3.82-3.77, 3.57-3.53 (both m, 2H each, $\left.\mathrm{H}-3^{\prime}, \mathrm{H}_{-} 4^{\prime}\right), 2.05$ (s, 3H, $\mathrm{CH}_{3} \mathrm{CO}-$ ), 1.49, 1.47 (both br s, 9H each, $\mathrm{CH}_{3}$ in $\left.\mathrm{Boc}\right), 2.30-0.98$ (m, 25H, CH, $\mathrm{CH}_{2}$ in pentacyclic skeleton), $0.94,0.90,0.88,0.86,0.85,0.83$ (all s, 3H each, $\mathrm{H}-23-\mathrm{H}-27$ and $\mathrm{H}-29$ ), $0.79(\mathrm{~d}, J=9.6 \mathrm{~Hz}, 1 \mathrm{H}, \mathrm{H}-5), 0.75(\mathrm{~d}, J=6.4 \mathrm{~Hz}, 3 \mathrm{H}, \mathrm{H}-30) ;{ }^{13} \mathrm{C}-\mathrm{NMR}\left(100 \mathrm{MHz}, \mathrm{CDCl}_{3}\right) \delta: 176.3(\mathrm{C}-28)$, $171.1\left(\mathrm{COCH}_{3}\right), 161.8(\mathrm{C}=\mathrm{N}), 155.7,152.8$ (CONH-Boc), 83.8 (C in Boc), 80.9 (C-3), 80.1 (C in Boc), $62.9\left(\mathrm{C}-1^{\prime}\right), 62.8\left(\mathrm{C}-4^{\prime}\right), 62.8\left(\mathrm{C}-3^{\prime}\right), 61.9\left(\mathrm{C}-2^{\prime}\right), 57.3$ (C-17), 55.4 (C-5), 50.2 (C-9), 49.0 (C-19), 44.0 (C-18), 42.5 (C-14), 40.7 (C-8), 38.4 (C-22), 38.0 (C-1), 37.8 (C-4), 37.1 (C-13, C-10), 34.3 (C-7), 31.8 (C-16), 29.8 (C-20), 29.7 (C-15), 28.1 ( $\mathrm{CH}_{3}$ in Boc), $28.0\left(\mathrm{CH}_{3}\right.$ in Boc, C-23), 26.9 (C-2), 23.7 (C-12), 23.0 (C-29), 22.7 (C-21), $21.3\left(\mathrm{COCH}_{3}\right), 20.9$ (C-11), 18.2 (C-6), 16.5 (C-25), 16.2 (C-24), 15.9 (C-26), 14.7 (C-30), 14.6 (C-27); Anal. Calcd. for $\mathrm{C}_{47} \mathrm{H}_{79} \mathrm{~N}_{3} \mathrm{O}_{10}$ : $\mathrm{C}, 66.72, \mathrm{H}, 9.41$. Found: $\mathrm{C}, 67.13, \mathrm{H}, 9.36 \%$. MS: $m / z 868.45$ $[\mathrm{M}+\mathrm{Na}]^{+}$(calcd. for $\mathrm{C}_{47} \mathrm{H}_{79} \mathrm{~N}_{3} \mathrm{O}_{10}, 845.58$ ).

33-[2-tert-Butyloxycarbonylguanidine-3-hydroxy-2-(hydroxymethyl)propyl]-3-O-acetyl-urs-12-en-28-oate (18a), White powder, $75 \%$ yield; $\mathrm{mp} 118-120^{\circ} \mathrm{C}(\mathrm{EtOH}) ;[\alpha]_{\mathrm{D}}^{21}+31.3^{\circ}\left(\right.$ c $\left.0.53, \mathrm{CHCl}_{3}\right)$; IR $\left(\mathrm{CHCl}_{3}\right)$ $v_{\max } 1653,1729(\mathrm{C}=\mathrm{O}), 3271,3443(\mathrm{NH}) \mathrm{cm}^{-1} ;{ }^{1} \mathrm{H}-\mathrm{NMR}\left(500 \mathrm{MHz}, \mathrm{CDCl}_{3}\right) \delta: 11.50(\mathrm{~s}, 1 \mathrm{H}, \mathrm{NH}$ in Boc), 9.06 (s, 1H, NH-C=N), 5.26 (br s, 1H, H-12), 4.51-4.48 (m, 1H, H-3), 4.13 (br s, 2H each, H-1'), 3.82-3.76 (m, 2H, H-3'), 3.54-3.52 (m, 2H, H-4'), 2.26 (d, J = 11.0 Hz, 1H, H-18), 2.04 (s, 3H, $\left.\mathrm{CH}_{3} \mathrm{CO}-\right)$, 1.99-0.81 (m, 22H, CH, CH $\mathrm{CH}_{2}$ in pentacyclic skeleton), 1.50, 1.47 (both br s, $9 \mathrm{H}$ each, $\mathrm{CH}_{3}$ in Boc), 1.07, 0.94, 0.93, 0.86, 0.85, 0.83, 0.75 (all s, 3H each, H-23-H-27, H-29 and H-30); ${ }^{13} \mathrm{C}-\mathrm{NMR}\left(125 \mathrm{MHz}, \mathrm{CDCl}_{3}\right)$ $\delta: 177.4(\mathrm{C}-28), 171.0\left(\mathrm{COCH}_{3}\right), 161.8(\mathrm{C}=\mathrm{N}), 155.6,152.8$ (CONH-Boc), $138.1(\mathrm{C}-13), 125.8(\mathrm{C}-12)$, 83.7 (C in Boc), 80.9 (C-3), 79.9 (C in Boc), $63.4\left(\mathrm{C}-1^{\prime}\right), 62.9\left(\mathrm{C}-3^{\prime}\right), 62.6\left(\mathrm{C}-4^{\prime}\right), 61.6\left(\mathrm{C}-2^{\prime}\right), 55.3(\mathrm{C}-5)$, 52.8 (C-18), 48.5 (C-17), 47.5 (C-9), 42.0 (C-14), 39.5 (C-8), 39.0 (C-4), 38.7 (C-19), 38.3 (C-20), 37.7 (C-1), 36.8 (C-22), 36.5 (C-10), 32.9 (C-7), 30.6 (C-21), 28.1 ( $\mathrm{CH}_{3}$ in Boc), 28.0 (C-15), 28 (C-23), 24.1 (C-16), 23.6 (C-2), 23.5 (C-27), 23.3 (C-11), 21.3 (C-30), $21.0\left(\mathrm{COCH}_{3}\right), 18.2$ (C-6), 17.0 (C-29), 16.9 (C-26), 16.7 (C-24), 15.5 (C-25); Anal. Calcd. for $\mathrm{C}_{47} \mathrm{H}_{77} \mathrm{~N}_{3} \mathrm{O}_{10}$ : C, 66.87, H, 9.19. Found: C, 67.27, $\mathrm{H}, 9.14 \%$. MS: $m / z 866.43[\mathrm{M}+\mathrm{Na}]^{+}$(calcd. for $\mathrm{C}_{47} \mathrm{H}_{77} \mathrm{~N}_{3} \mathrm{O}_{10}, 843.56$ ).

33-[2-tert-Butyloxycarbonylguanidine-3-hydroxy-2-(hydroxymethyl)propyl]-3-O-acetyl-olean-12-en-28-oate (20a), White powder, 79\% yield; mp $140-142{ }^{\circ} \mathrm{C}(\mathrm{EtOH}) ;[\alpha]_{\mathrm{D}}^{19}+30.4^{\circ}\left(c 0.56, \mathrm{CHCl}_{3}\right) ; \mathrm{IR}\left(\mathrm{CHCl}_{3}\right) v_{\max }$ 1618, $1727(\mathrm{C}=\mathrm{O}), 3434(\mathrm{NH}) \mathrm{cm}^{-1},{ }^{1} \mathrm{H}-\mathrm{NMR}\left(400 \mathrm{MHz}, \mathrm{CDCl}_{3}\right) \delta: 11.49$ (s, 1H, NH in Boc), 9.03 (s, $1 \mathrm{H}, \mathrm{NH}-\mathrm{C}=\mathrm{N}$ ), 5.30 (br s, 1H, H-12), 5.10 (br s, 1H, OH), 4.49-4.45 (m, 1H, H-3), 4.26, 4.15 (both d, $J=11.6 \mathrm{~Hz}, 1 \mathrm{H}$ each, $\left.\mathrm{H}-1^{\prime}\right), 3.77,3.54\left(\right.$ both $\mathrm{d}, J=12.0 \mathrm{~Hz}, J=11.6 \mathrm{~Hz}, 2 \mathrm{H}$ each, $\left.\mathrm{H}-3^{\prime}, \mathrm{H}-4^{\prime}\right), 2.85$ (d, $J=10.0 \mathrm{~Hz}, 1 \mathrm{H}, \mathrm{H}-18), 2.03$ (s, 3H, $\left.\mathrm{CH}_{3} \mathrm{CO}-\right), 1.99-0.80\left(\mathrm{~m}, 22 \mathrm{H}, \mathrm{CH}, \mathrm{CH}_{2}\right.$ in pentacyclic skeleton), 1.51, 1.48 (both br s, $9 \mathrm{H}$ each, $\mathrm{CH}_{3}$ in Boc), 1.12, 0.91, 0.90, 0.89, 0.85, 0.84, 0.71 (3H each, all s, H-23-H-27, $\mathrm{H}-29$ and $\mathrm{H}-30) ;{ }^{13} \mathrm{C}-\mathrm{NMR}\left(100 \mathrm{MHz}, \mathrm{CDCl}_{3}\right) \delta$ : $177.4(\mathrm{C}-28), 171.0\left(\mathrm{COCH}_{3}\right), 161.8(\mathrm{C}=\mathrm{N}), 155.6$, 152.8 (CONH-Boc), 138.1 (C-13), 125.8 (C-12), 83.7 (C in Boc), 80.9 (C-3), 79.9 (C in Boc), 63.4 (C-1'), $62.9\left(\mathrm{C}-3^{\prime}\right), 62.6\left(\mathrm{C}-4^{\prime}\right), 61.6\left(\mathrm{C}-2^{\prime}\right), 55.3$ (C-5), 52.8 (C-18), 48.5 (C-17), 47.5 (C-9), 42.0 (C-14), 39.5 (C-8), 39.0 (C-4), 38.7 (C-19), 38.3 (C-20), 37.7 (C-1), 36.8 (C-22), 36.5 (C-10), 32.9 (C-7), 30.6 (C-21), $28.1{\left(\mathrm{CH}_{3}\right.}$ 
in Boc), 28.0 (C-15, C-23), 24.1 (C-16), 23.6 (C-2), 23.5 (C-27), 23.3 (C-11), 21.3 (C-30), $21.0\left(\mathrm{COCH}_{3}\right)$,

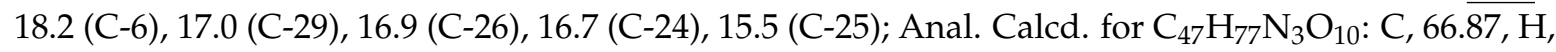
9.19. Found: $\mathrm{C}, 67.24, \mathrm{H}, 9.14 \%$. MS: $m / z 866.47[\mathrm{M}+\mathrm{Na}]^{+}$(calcd. for $\mathrm{C}_{47} \mathrm{H}_{77} \mathrm{~N}_{3} \mathrm{O}_{10}, 843.56$ ).

\subsubsection{General Procedure for the Synthesis of Compounds $\mathbf{9 a - 1 3 a , 1 5 b , 1 8 b}$ and $\mathbf{2 0 b}$}

Compounds 9-13 and 15a, 18a, 20a $(0.2 \mathrm{mmol})$ in $1 \mathrm{~mL}$ of dry $\mathrm{CH}_{2} \mathrm{Cl}_{2}$ were treated with TFA $(1 \mathrm{~mL})$ and the mixture was stirred for $4-6 \mathrm{~h}$ at room temperature (TLC control, hexane:EtOAc, 1:1, $v / v)$. The solution was evaporated to dryness to obtain pure compounds $9 \mathbf{a}-\mathbf{1 3} \mathbf{a}, \mathbf{1 5} \mathbf{b}, \mathbf{1 8} \mathbf{b}$ and $\mathbf{2 0} \mathbf{b}$.

$\mathrm{N}$-(4-Butylgyanidine)-3-oxolupane-28-amide trifluoroacetate (9a), White powder, $96 \%$ yield; $\mathrm{mp} 142-144{ }^{\circ} \mathrm{C}$ $(\mathrm{EtOH}) ;[\alpha]_{\mathrm{D}}^{19}-0.6^{\circ}\left(c 0.34, \mathrm{CHCl}_{3}\right) ; \mathrm{IR}\left(\mathrm{CHCl}_{3}\right) v_{\max } 1669(\mathrm{C}=\mathrm{O}), 3206,3437(\mathrm{NH}) \mathrm{cm}^{-1} ;{ }^{19} \mathrm{~F}-\mathrm{NMR}$ $\left(376.50 \mathrm{MHz}, \mathrm{CDCl}_{3}\right) \delta:-75.91 ;{ }^{1} \mathrm{H}-\mathrm{NMR}\left(400 \mathrm{MHz}, \mathrm{CDCl}_{3}\right) \delta: 11.13$ (br s, $1 \mathrm{H}, \mathrm{NH}$ in Boc), 7.50 (br s, $1 \mathrm{H}, \mathrm{NH}-\mathrm{C}=\mathrm{N}), 6.82\left(\mathrm{br} \mathrm{s}, 2 \mathrm{H}, \mathrm{NH}_{2}\right), 6.39$ (br s, $\left.1 \mathrm{H}, \mathrm{CONH}\right), 3.26\left(\mathrm{~m}, 4 \mathrm{H}, \mathrm{H}-1^{\prime}, \mathrm{H}-4^{\prime}\right), 2.45-1.19(\mathrm{~m}, 26 \mathrm{H}$, $\mathrm{CH}, \mathrm{CH}_{2}$ in pentacyclic skeleton, $4 \mathrm{H}, \mathrm{H}-2^{\prime}, \mathrm{H}-3^{\prime}$ ), 1.07, 1.01, 0.96, 0.92, 0.90 (all s, 3H each, H-23-H-27), $0.85(\mathrm{~d}, J=6.0 \mathrm{~Hz}, 3 \mathrm{H}, \mathrm{H}-29), 0.75(\mathrm{~d}, J=6.0 \mathrm{~Hz}, 3 \mathrm{H}, \mathrm{H}-30) ;{ }^{13} \mathrm{C}-\mathrm{NMR}\left(100 \mathrm{MHz}, \mathrm{CDCl}_{3}\right) \delta: 220.4(\mathrm{C}-3)$, $178.8(\mathrm{C}-28), 161.4\left(\mathrm{q}, J_{\mathrm{C}, \mathrm{F}}=37 \mathrm{~Hz}\right), 157.2(\mathrm{C}=\mathrm{N}), 117.5\left(\mathrm{q}, J_{\mathrm{C}, \mathrm{F}}=288 \mathrm{~Hz}\right), 56.4(\mathrm{C}-17), 54.8(\mathrm{C}-5)$, 49.6 (C-9), 49.2 (C-19), 47.4 (C-4), 44.4 (C-18), 42.7 (C-14), 40.9 (C-1, C-4'), 40.7 (C-8), 38.8 (C-22), 38.1 (C-1'), 38.0 (C-13), 36.8 (C-10), 34.2 (C-2), 33.6 (C-16), 33.3 (C-7), 29.9 (C-20), 29.7 (C-3'), 29.4 (C-15), 27.0 (C-2'), 26.7 (C-23), 25.5 (C-12), 23.0 (C-21), 22.9 (C-29), 20.9 (C-11, C-24), 19.6 (C-6), 15.8 (C-25), 15.6 (C-26), 14.5 (C-30), 14.4 (C-27); Anal. Calcd. for $\mathrm{C}_{37} \mathrm{H}_{61} \mathrm{~F}_{3} \mathrm{~N}_{4} \mathrm{O}_{4}$ : C, 65.08, H, 9.00. Found: $\mathrm{C}, 65.52$, $\mathrm{H}, 8.94 \%$. MS: $m / z 569.43[\mathrm{M}+\mathrm{H}]^{+}$(calcd. for $\mathrm{C}_{35} \mathrm{H}_{60} \mathrm{~N}_{4} \mathrm{O}_{2}, 568.47$ ).

33-N-(2-Ethylgyanidine)-3-O-acetyl-lupane-28-amide trifluoroacetate (10a), White powder, 93\% yield; mp $132-134{ }^{\circ} \mathrm{C}(\mathrm{EtOH}) ;[\alpha]_{\mathrm{D}}^{19}-5.6^{\circ}\left(\mathrm{c} 0.31, \mathrm{CHCl}_{3}\right) ; \mathrm{IR}\left(\mathrm{CHCl}_{3}\right) v_{\max } 1671(\mathrm{C}=\mathrm{O}), 3351(\mathrm{NH}) \mathrm{cm}^{-1} ;{ }^{19} \mathrm{~F}-\mathrm{NMR}$ $\left(470.59 \mathrm{MHz}, \mathrm{CDCl}_{3}\right) \delta:-75.80 ;{ }^{1} \mathrm{H}-\mathrm{NMR}\left(500 \mathrm{MHz}, \mathrm{CDCl}_{3}\right) \delta: 10.63$ (br s, $1 \mathrm{H}, \mathrm{NH}$ in Boc), 8.05 (br $\mathrm{s}, 1 \mathrm{H}, \mathrm{NH}-\mathrm{C}=\mathrm{N}), 7.00\left(\right.$ br s, $\left.2 \mathrm{H}, \mathrm{NH}_{2}\right), 6.79(\mathrm{br} \mathrm{s}, 1 \mathrm{H}, \mathrm{CONH}), 4.48-4.45(\mathrm{~m}, 1 \mathrm{H}, \mathrm{H}-3), 3.39-3.28(\mathrm{~m}$, $\left.4 \mathrm{H}, \mathrm{H}-1^{\prime}, \mathrm{H}-2^{\prime}\right), 2.09$ (s, 3H, $\left.\mathrm{CH}_{3} \mathrm{CO}-\right), 2.31-1.01\left(\mathrm{~m}, 25 \mathrm{H}, \mathrm{CH}, \mathrm{CH}_{2}\right.$ in pentacyclic skeleton), 0.95, 0.92, 0.89, 0.86, 0.85, 0.83 (all s, 3H each, H-23-H-27 and H-29), 0.79 (d, J = 11.0 Hz, 1H, H-5), 0.75 (d, $J=6.0 \mathrm{~Hz}, 3 \mathrm{H}, \mathrm{H}-30) ;{ }^{13} \mathrm{C}-\mathrm{NMR}\left(125 \mathrm{MHz}, \mathrm{CDCl}_{3}\right) \delta: 179.6(\mathrm{C}-28), 171.6\left(\mathrm{COCH}_{3}\right), 161.2\left(\mathrm{q}, J_{\mathrm{C}, \mathrm{F}}=37\right.$ $\mathrm{Hz}), 157.9(\mathrm{C}=\mathrm{N}), 117.2\left(\mathrm{q}, J_{\mathrm{C}, \mathrm{F}}=287 \mathrm{~Hz}\right), 81.2(\mathrm{C}-3), 56.4(\mathrm{C}-17), 55.4(\mathrm{C}-5), 50.2(\mathrm{C}-9), 49.3(\mathrm{C}-19), 44.3$ (C-18), 42.6 (C-14), 40.7 (C-1, C-2'), 40.6 (C-8), 38.6 (C-1'), 38.4 (C-22), 37.8 (C-4, C-13), 37.0 (C-10), 34.2 (C-7), 33.1 (C-16), 29.9 (C-20), 29.3 (C-15), 27.9 (C-23), 26.9 (C-2), 23.6 (C-12), 23.0 (C-21, C-29), 21.3 $\left(\mathrm{COCH}_{3}\right), 21.0(\mathrm{C}-11), 18.1$ (C-6), 16.4 (C-25), 16.0 (C-24), 15.9 (C-26), 14.5 (C-27, C-30); Anal. Calcd. for $\mathrm{C}_{37} \mathrm{H}_{61} \mathrm{~F}_{3} \mathrm{~N}_{4} \mathrm{O}_{5}: \mathrm{C}, 63.59, \mathrm{H}, 8.80$. Found: $\mathrm{C}, 63.88, \mathrm{H}, 8.73 \%$. MS: $m / z 585.62[\mathrm{M}+\mathrm{H}]^{+}$(calcd. for $\left.\mathrm{C}_{35} \mathrm{H}_{60} \mathrm{~N}_{4} \mathrm{O}_{3}, 584.47\right)$.

33-N-(4-Butylgyanidine)-3-O-acetyl-lupane-28-amide trifluoroacetate (11a), White powder, 95\% yield; mp $148-150{ }^{\circ} \mathrm{C}(\mathrm{EtOH}) ;[\alpha]_{\mathrm{D}}^{17}-12^{\circ}\left(c 0.49, \mathrm{CHCl}_{3}\right) ; \mathrm{IR}\left(\mathrm{CHCl}_{3}\right) v_{\max } 1672(\mathrm{C}=\mathrm{O}), 3207,3354(\mathrm{NH}) \mathrm{cm}^{-1}$; ${ }^{19} \mathrm{~F}-\mathrm{NMR}\left(470.59 \mathrm{MHz}, \mathrm{CDCl}_{3}\right) \delta:-77.19 ;{ }^{1} \mathrm{H}-\mathrm{NMR}(500 \mathrm{MHz}, \mathrm{MeOD}) \delta: 4.48-4.45$ (m, $\left.1 \mathrm{H}, \mathrm{H}-3\right)$, 3.28-3.15 (m, $\left.4 \mathrm{H}, \mathrm{H}-\mathrm{1}^{\prime}, \mathrm{H}-4^{\prime}\right), 2.04\left(\mathrm{~s}, 3 \mathrm{H}, \mathrm{CH}_{3} \mathrm{CO}-\right), 2.61-1.04\left(\mathrm{~m}, 25 \mathrm{H}, \mathrm{CH}, \mathrm{CH}_{2}\right.$ in pentacyclic skeleton, $\left.4 \mathrm{H}, \mathrm{H}-2^{\prime}, \mathrm{H}^{\prime} \mathrm{3}^{\prime}\right), 1.02,0.98,0.92,0.90,0.89,0.88$ (3H each, all s, H-23-H-27 and H-29), 0.84 (d, $J=11.0 \mathrm{~Hz}$, $1 \mathrm{H}, \mathrm{H}-5), 0.79$ (d, $J=7.0 \mathrm{~Hz}, 3 \mathrm{H}, \mathrm{H}-30) ;{ }^{13} \mathrm{C}-\mathrm{NMR}(125 \mathrm{MHz}, \mathrm{MeOD}) \delta: 179.6(\mathrm{C}-28), 172.9\left(\mathrm{COCH}_{3}\right)$, $161.2\left(\mathrm{q}, J_{\mathrm{C}, \mathrm{F}}=37 \mathrm{~Hz}\right), 158.8(\mathrm{C}=\mathrm{N}), 117.2\left(\mathrm{q}, J_{\mathrm{C}, \mathrm{F}}=287 \mathrm{~Hz}\right), 82.6(\mathrm{C}-3), 57.5(\mathrm{C}-17), 57.0(\mathrm{C}-5), 51.9(\mathrm{C}-9)$, 51.1 (C-19), 45.5 (C-18), 43.8 (C-14), 42.2 (C-8, C-4'), 40.0 (C-22), 39.8 (C-1), 39.4 (C-1'), 39.0 (C-4), 38.9 (C-13), 38.4 (C-10), 35.8 (C-7), 34.1 (C-16), 31.3 (C-20), 30.7 (C-3'), 28.7 (C-15), 28.5 (C-23), 28.1 (C-2'), 27.4 (C-2), 24.8 (C-12), 24.2 (C-29), 23.7 (C-21), $22.5(\mathrm{C}-11), 21.3\left(\mathrm{COCH}_{3}\right), 19.4(\mathrm{C}-6), 17.2(\mathrm{C}-25)$, 17.0 (C-24, C-26), 15.3 (C-30), 15.2 (C-27); Anal. Calcd. for $\mathrm{C}_{39} \mathrm{H}_{65} \mathrm{~F}_{3} \mathrm{~N}_{4} \mathrm{O}_{5}: \mathrm{C}, 64.44, \mathrm{H}, 9.01$. Found: $\mathrm{C}$, 64.87, $\mathrm{H}, 8.94 \%$. MS: $m / z$ 613.48 [M + H] ${ }^{+}$(calcd. for $\mathrm{C}_{37} \mathrm{H}_{64} \mathrm{~N}_{4} \mathrm{O}_{3}, 612.50$ ).

$3 \beta-N-\left[2-\left(N, N^{\prime}\right.\right.$-bis-Ethylgyanidine)-aminoethyl]-3-O-acetyl-lupane-28-amide trifluoroacetate (12a), White powder, $96 \%$ yield; mp $116-118^{\circ} \mathrm{C}(\mathrm{EtOH}) ;[\alpha]_{\mathrm{D}}^{17}-10.5^{\circ}\left(c 0.2, \mathrm{C}_{2} \mathrm{H}_{5} \mathrm{OH}\right) ; \mathrm{IR}\left(\mathrm{CHCl}_{3}\right) v_{\max } 1681(\mathrm{C}=\mathrm{O})$, 3199, $3362(\mathrm{NH}) \mathrm{cm}^{-1},{ }^{19} \mathrm{~F}-\mathrm{NMR}(470.59 \mathrm{MHz}, \mathrm{MeOD}) \delta:-76.98 ;{ }^{1} \mathrm{H}-\mathrm{NMR}(500 \mathrm{MHz}, \mathrm{MeOD}) \delta$ : 
4.48-4.44 (m, 1H, H-3), 3.73-3.70 (m, 4H, H-4' $\left.{ }^{\prime} \mathrm{H}-4^{\prime \prime}\right), 3.56-3.53\left(\mathrm{~m}, 2 \mathrm{H}, \mathrm{H}-1^{\prime}\right), 3.46(\mathrm{t}, J=6.5 \mathrm{~Hz}, 4 \mathrm{H}$, $\left.\mathrm{H}-3^{\prime}, \mathrm{H}-3{ }^{\prime \prime}\right), 3.29-3.26\left(\mathrm{~m}, 2 \mathrm{H}, \mathrm{H}-2^{\prime}\right), 2.04\left(\mathrm{~s}, 3 \mathrm{H}, \mathrm{CH}_{3} \mathrm{CO}-\right), 2.52-1.06\left(\mathrm{~m}, 25 \mathrm{H}, \mathrm{CH}, \mathrm{CH}_{2}\right.$ in pentacyclic skeleton), 1.02, 0.97, 0.92, 0.90, 0.88, 0.87 (all s, 3H each, H-23-H-27 and H-29), 0.85 (d, J = $11.5 \mathrm{~Hz}, 1 \mathrm{H}$, $\mathrm{H}-5), 0.79(\mathrm{~d}, J=6.5 \mathrm{~Hz}, 3 \mathrm{H}, \mathrm{H}-30) ;{ }^{13} \mathrm{C}-\mathrm{NMR}(125 \mathrm{MHz}, \mathrm{MeOD}) \delta: 181.2(\mathrm{C}-28), 173.0\left(\mathrm{COCH}_{3}\right), 161.7(\mathrm{q}$, $\left.J_{\mathrm{C}, \mathrm{F}}=37 \mathrm{~Hz}\right), 159.1(\mathrm{C}=\mathrm{N}), 117.5\left(\mathrm{q}, J_{\mathrm{C}, \mathrm{F}}=288 \mathrm{~Hz}\right), 35.6\left(\mathrm{C}-4^{\prime \prime}\right), 53.4\left(\mathrm{C}-3^{\prime \prime}\right), 82.6(\mathrm{C}-3), 57.6(\mathrm{C}-17)$, 56.9 (C-5), 53.9 (C-2'), 53.4 (C-3'), 51.8 (C-9), 51.0 (C-19), 45.5 (C-18), 43.8 (C-14), 42.2 (C-8), 39.7 (C-1), 39.7 (C-22), 39.0 (C-13, C-4), 38.4 (C-1'), 37.8 (C-10), 35.6 (C-4', C-7), 33.8 (C-16), 31.3 (C-20), 30.7 (C-15), 28.6 (C-23), 28.4 (C-2), 24.8 (C-12), 24.1 (C-21), 23.5 (C-29), 22.3 (C-11), $21.3\left(\mathrm{COCH}_{3}\right), 19.4$ (C-6), 17.1 (C-25), 17.0 (C-24), 16.9 (C-26), 15.2 (C-30), 15.1 (C-27); Anal. Calcd. for $\mathrm{C}_{44} \mathrm{H}_{74} \mathrm{~F}_{6} \mathrm{~N}_{8} \mathrm{O}_{7}$ : C, 56.16, $\mathrm{H}$, 7.93. Found: $\mathrm{C}, 56.63, \mathrm{H}, 7.86 \%$. MS: $m / z 713.59[\mathrm{M}+\mathrm{H}]^{+}$(calcd. for $\mathrm{C}_{40} \mathrm{H}_{72} \mathrm{~N}_{8} \mathrm{O}_{3}$, 712.57).

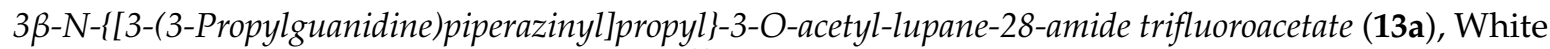
powder, $96 \%$ yield; mp $92-94{ }^{\circ} \mathrm{C}(\mathrm{EtOH}) ;[\alpha]_{\mathrm{D}}^{19}+8^{\circ}\left(c 0.54, \mathrm{CHCl}_{3}\right)$; $\mathrm{IR}\left(\mathrm{CHCl}_{3}\right) v_{\max } 1673,1773(\mathrm{C}=\mathrm{O})$, 3190, $3367(\mathrm{NH}) \mathrm{cm}^{-1} ;{ }^{19} \mathrm{~F}-\mathrm{NMR}(470.59 \mathrm{MHz}, \mathrm{MeOD}) \delta:-77.25 ;{ }^{1} \mathrm{H}-\mathrm{NMR}(500 \mathrm{MHz}, \mathrm{MeOD}) \delta$ : 4.48-4.45 (m, 1H, H-3), 3.49-3.40 (m, 4H, H-2", H-3"), 3.31-3.22 (m, 8H, H-4', H-4", H-5', H-5"), 3.13-3.10 (m, 2H, H-1"), 3.00-2.98 (m, 2H, H-1'), 2.58-0.84 (m, 26H, CH, $\mathrm{CH}_{2}$ in pentacyclic skeleton, $4 \mathrm{H}, \mathrm{H}-2^{\prime}, \mathrm{H}_{-}{ }^{\prime}$ ), 2.08 (s, 3H, $\mathrm{CH}_{3} \mathrm{CO}-$ ), 1.02, 0.99, 0.92, 0.89, 0.86, 0.84 (all s, 3H each, H-23-H-27 and $\mathrm{H}-29), 0.80(\mathrm{~d}, J=7.0 \mathrm{~Hz}, 3 \mathrm{H}, \mathrm{H}-30) ;{ }^{13} \mathrm{C}-\mathrm{NMR}(125 \mathrm{MHz}, \mathrm{MeOD}) \delta: 180.2(\mathrm{C}-28), 173.0\left(\mathrm{COCH}_{3}\right)$, $161.7\left(\mathrm{q}, J_{\mathrm{C}, \mathrm{F}}=37 \mathrm{~Hz}\right), 158.9(\mathrm{C}=\mathrm{N}), 117.5\left(\mathrm{q}, J_{\mathrm{C}, \mathrm{F}}=288 \mathrm{~Hz}\right), 82.6(\mathrm{C}-3), 57.6(\mathrm{C}-17), 57.0(\mathrm{C}-5), 56.0\left(\mathrm{C}-3{ }^{\prime \prime}\right)$, $55.2\left(\mathrm{C}-3^{\prime}\right), 51.9$ (C-9), 51.0 (C-19), 50.1 (C-4', C-4", C-5', C-5"), 45.5 (C-18), 43.8 (C-14), 42.2 (C-8), $39.9\left(\mathrm{C}-1^{\prime}\right), 39.8$ (C-1"), 39.6 (C-1, C-22), 39.0 (C-4), 38.9 (C-13), 38.4 (C-10), 35.7 (C-7), 34.0 (C-16), 31.3 (C-20), 30.7 (C-15), 28.6 (C-23), 28.5 (C-2"), 25.6 (C-2'), 24.9 (C-2), 24.2 (C-12), 23.6 (C-21, C-29), 22.4 (C-11), $21.3\left(\mathrm{COCH}_{3}\right), 19.4$ (C-6), 17.1 (C-25), 17.0 (C-24), 16.9 (C-26), 15.2 (C-30), 15.1 (C-27); Anal.

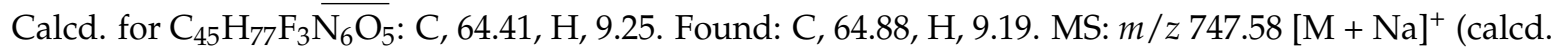
for $\mathrm{C}_{43} \mathrm{H}_{76} \mathrm{~N}_{6} \mathrm{O}_{3}, 724.60$ ).

33-[2-Guanidine-3-hydroxy-2-(hydroxymethyl)propyl]-3-O-acetyl-lupane-28-oate trifluoroacetate (15b), White powder, $95 \%$ yield; mp $126-129{ }^{\circ} \mathrm{C}(\mathrm{EtOH}) ;[\alpha]_{\mathrm{D}}^{19}-9.5^{\circ}\left(\mathrm{c} 0.34, \mathrm{CHCl}_{3}\right)$; IR $\left(\mathrm{CHCl}_{3}\right) v_{\max } 1620$, $1698(\mathrm{C}=\mathrm{O}), 3437(\mathrm{NH}) \mathrm{cm}^{-1} ;{ }^{19} \mathrm{~F}-\mathrm{NMR}\left(470.59 \mathrm{MHz}, \mathrm{CDCl}_{3}\right) \delta:-75.97 ;{ }^{1} \mathrm{H}-\mathrm{NMR}(500 \mathrm{MHz}, \mathrm{MeOD})$ $\delta$ : 4.50-4.47 (m, 1H, H-3), 4.31 (2H, m, H-1' $), 3.75$ (m, 4H, H-3', $\left.\mathrm{H}-4^{\prime}\right), 2.18-0.99\left(\mathrm{~m}, 26 \mathrm{H}, \mathrm{CH}, \mathrm{CH}_{2}\right.$ in pentacyclic skeleton), 2.08 (s, 3H, $\mathrm{CH}_{3} \mathrm{CO}-$ ), 0.98, 0.97, 0.96, 0.87, 0.86 (all s, $3 \mathrm{H}$ each, $\mathrm{H}-23-\mathrm{H}-27$ ), 0.89 (d, $J=6.0 \mathrm{~Hz}, 3 \mathrm{H}, \mathrm{H}-29), 0.76$ (d, $J=6.0 \mathrm{~Hz}, 3 \mathrm{H}, \mathrm{H}-30) ;{ }^{13} \mathrm{C}-\mathrm{NMR}(125 \mathrm{MHz}, \mathrm{MeOD}) \delta: 177.4(\mathrm{C}-28)$, $172.3\left(\mathrm{COCH}_{3}\right), 161.4\left(\mathrm{q}, J_{\mathrm{C}, \mathrm{F}}=37 \mathrm{~Hz}\right), 157.5(\mathrm{C}=\mathrm{N}), 117.5\left(\mathrm{q}, J_{\mathrm{C}, \mathrm{F}}=288 \mathrm{~Hz}\right), 81.7(\mathrm{C}-3), 63.1\left(\mathrm{C}-3^{\prime}, \mathrm{C}-4^{\prime}\right)$, $62.0\left(\mathrm{C}-2^{\prime}\right), 60.2\left(\mathrm{C}-1^{\prime}\right), 57.5$ (C-17), 55.4 (C-5), 50.2 (C-9), 48.8 (C-19), 44.1 (C-18), 42.6 (C-14), 40.7 (C-8), 38.4 (C-22), 38.2 (C-1), 37.8 (C-4, C-13), 37.0 (C-10), 34.2 (C-7), 31.9 (C-16), 29.7 (C-20), 29.0 (C-15), 27.9 (C-23), 26.8 (C-2), 23.6 (C-12), 22.9 (C-29, C-21), $21.3\left(\mathrm{COCH}_{3}\right), 20.9$ (C-11), 18.1 (C-6), 16.4 (C-25), 16.1 (C-24), 15.8 (C-26), 14.6 (C-27, C-30); Anal. Calcd. for $\mathrm{C}_{39} \overline{\mathrm{H}}_{64} \mathrm{~F}_{3} \mathrm{~N}_{3} \mathrm{O}_{8}$ : C, 61.64; H, 8.49. Found: C, 62.34; $\mathrm{H}, 8.43 \%$. MS: $m / z 646.39[\mathrm{M}+\mathrm{H}]^{+}$(calcd. for $\mathrm{C}_{37} \mathrm{H}_{63} \mathrm{~N}_{3} \mathrm{O}_{6}, 645.47$ ).

33-[2-Guanidine-3-hydroxy-2-(hydroxymethyl)propyl]-3-O-acetyl-urs-12-en-28-oate trifluoroacetate (18b), White powder, $98 \%$ yield; mp $124-126^{\circ} \mathrm{C}(\mathrm{EtOH}) ;[\alpha]_{\mathrm{D}}^{19}+30.0^{\circ}\left(c \mathrm{c} .72, \mathrm{CH}_{2} \mathrm{Cl}_{2}\right)$; IR $\left(\mathrm{CHCl}_{3}\right) v_{\max }$ 1619, $1682(\mathrm{C}=\mathrm{O}), 3438(\mathrm{NH}) \mathrm{cm}^{-1} ;{ }^{19} \mathrm{~F}-\mathrm{NMR}(470.59 \mathrm{MHz}, \mathrm{MeOD}) \delta:-77.17 ;{ }^{1} \mathrm{H}-\mathrm{NMR}(500 \mathrm{MHz}$, MeOD) $\delta: 5.29$ (br s, 1H, H-12), 4.49-4.46 (m, 1H, H-3), 4.31, 4.17 (both d, $J=11.5 \mathrm{~Hz}, 1 \mathrm{H}$ each, $\mathrm{H}-1^{\prime}$ ), 3.75 (m, 4H, H-3' $\left.\mathrm{H}^{\prime}-4^{\prime}\right), 2.24$ (d, J = 11.0 Hz, 1H, H-18), 2.04 (s, 3H, $\left.\mathrm{CH}_{3} \mathrm{CO}-\right), 2.13-0.87$ (m, 22H, $\mathrm{CH}, \mathrm{CH}_{2}$ in pentacyclic skeleton), 1.15, 1.01, 0.97, 0.98, 0.92, 0.90, 0.81 (3H each, all s, H-23-H-27, $\mathrm{H}-29$ and H-30); ${ }^{13} \mathrm{C}-\mathrm{NMR}(125 \mathrm{MHz}, \mathrm{MeOD}) \delta$ : $179.2(\mathrm{C}-28), 173.0\left(\mathrm{COCH}_{3}\right), 161.4\left(\mathrm{q}, J_{\mathrm{C}, \mathrm{F}}=37 \mathrm{~Hz}\right)$, $159.2(\mathrm{C}=\mathrm{N}), 140.1(\mathrm{C}-13), 127.2(\mathrm{C}-12), 117.5\left(\mathrm{q}, J_{\mathrm{C}, \mathrm{F}}=288 \mathrm{~Hz}\right), 82.5(\mathrm{C}-3), 64.3\left(\mathrm{C}-3^{\prime}\right), 64.2\left(\mathrm{C}-4^{\prime}\right)$, $62.7\left(\mathrm{C}-2^{\prime}\right), 62.2\left(\mathrm{C}-1^{\prime}\right), 56.8$ (C-5), 54.4 (C-18), 49.5 (C-17), 48.6 (C-9), 43.3 (C-14), 40.9 (C-8), 40.4 (C-4, C-19), 39.6 (C-20), 38.8 (C-1), 38.1 (C-22), 38.0 (C-10), 34.2 (C-7), 31.7 (C-21), 29.2 (C-15), 28.7 (C-23), 25.5 (C-16), 24.6 (C-2), 24.5 (C-27), 24.4 (C-11), $21.6(\mathrm{C}-30), 21.3\left(\mathrm{COCH}_{3}\right), 19.4(\mathrm{C}-6), 17.9$ (C-29), 17.8 (C-26), 17.3 (C-24), 16.2 (C-25); Anal. Calcd. for $\mathrm{C}_{39} \mathrm{H}_{62} \mathrm{~F}_{3} \mathrm{~N}_{3} \mathrm{O}_{8}: \mathrm{C}, 61.80, \mathrm{H}, 8.25$. Found: $\mathrm{C}, 62.33$, $\mathrm{H}, 8.19 \%$. MS: $m / z 644.47[\mathrm{M}+\mathrm{H}]^{+}$(calcd. for $\mathrm{C}_{37} \mathrm{H}_{61} \mathrm{~N}_{3} \mathrm{O}_{6}, 643.46$ ). 
33-[2-Guanidine-3-hydroxy-2-(hydroxymethyl)propyl]-3-O-acetyl-olean-12-en-28-oate trifluoroacetate (20b), White powder, $97 \%$ yield; $\mathrm{mp} 130-132{ }^{\circ} \mathrm{C}(\mathrm{EtOH}) ;[\alpha]_{\mathrm{D}}^{17}+26.6^{\circ}\left(c 0.53, \mathrm{C}_{2} \mathrm{H}_{5} \mathrm{OH}\right) ; \mathrm{IR}\left(\mathrm{CHCl}_{3}\right) v_{\max } 1619$, $1682(\mathrm{C}=\mathrm{O}), 3438(\mathrm{NH}) \mathrm{cm}^{-1} ;{ }^{19} \mathrm{~F}-\mathrm{NMR}\left(470.59 \mathrm{MHz}, \mathrm{CDCl}_{3}\right) \delta:-77.24 ;{ }^{1} \mathrm{H}-\mathrm{NMR}(500 \mathrm{MHz}, \mathrm{MeOD}) \delta$ : 5.31 (br s, 1H, H-12), 4.49-4.46 (m, 1H, H-3), 4.33, 4.20 (d, J = 11.5 Hz, 1H each, H-1'), 3.75 (m, 4H, H-3', $\left.\mathrm{H}-4^{\prime}\right), 2.89(\mathrm{~d}, 1 \mathrm{H}, J=9.5 \mathrm{~Hz}, \mathrm{H}-18), 2.09-0.88\left(\mathrm{~m}, 22 \mathrm{H}, \mathrm{CH}, \mathrm{CH}_{2}\right.$ in pentacyclic skeleton), $2.04(\mathrm{~s}, 3 \mathrm{H}$, $\mathrm{CH}_{3} \mathrm{CO}-$ ) $, 1.19,1.00,0.97,0.95,0.90,0.89,0.79$ (all s, 3H each, H-23-H-27, H-29 and H-30); ${ }^{13} \mathrm{C}-\mathrm{NMR}$ (125 MHz, MeOD) $\delta$ : $178.9(\mathrm{C}-28), 173.0\left(\mathrm{COCH}_{3}\right), 161.4\left(\mathrm{q}, J_{\mathrm{C}, \mathrm{F}}=37 \mathrm{~Hz}\right), 159.2(\mathrm{C}=\mathrm{N}), 145.0(\mathrm{C}-13)$, $124.1(\mathrm{C}-12), 117.5\left(\mathrm{q}, J_{\mathrm{C}, \mathrm{F}}=288 \mathrm{~Hz}\right), 82.6(\mathrm{C}-3), 64.3\left(\mathrm{C}-4^{\prime}\right), 64.2\left(\mathrm{C}-3^{\prime}\right), 62.7\left(\mathrm{C}-2^{\prime}\right), 62.3\left(\mathrm{C}-1^{\prime}\right), 56.9(\mathrm{C}-5)$, 48.5 (C-9, C-17), 47.1 (C-19), 43.0 (C-14), 42.9 (C-18), 40.8 (C-8), 39.5 (C-1), 38.9 (C-4), 38.3 (C-10), 34.9 (C-22), 33.9 (C-30), 33.7 (C-7), 33.6 (C-21), 31.7 (C-20), 28.9 (C-15), 28.7 (C-23), 26.6 (C-27), 24.7 (C-11, C-29), 24.3 (C-2), 24.2 (C-16), $21.3\left(\mathrm{COCH}_{3}\right), 19.5$ (C-6), 17.9 (C-26), 17.3 (C-24), 16.1 (C-25); Anal. Calcd. for $\mathrm{C}_{39} \mathrm{H}_{62} \mathrm{~F}_{3} \mathrm{~N}_{3} \mathrm{O}_{8}$ : C, 61.80, F, 7.52, $\mathrm{H}, 8.25$. Found: C, 62.12, H, 8.21\%. MS: $m / z 644.57[\mathrm{M}+\mathrm{H}]^{+}$ (calcd. for $\mathrm{C}_{37} \mathrm{H}_{61} \mathrm{~N}_{3} \mathrm{O}_{6}, 643.46$ ).

\subsubsection{General Procedure for the Synthesis of Compounds $\mathbf{9 b - 1 2 b}, \mathbf{1 5 c}, \mathbf{1 8 c}$ and $\mathbf{2 0 c}$}

The compounds 9a-12a, 15b, 18b, 20b $(0.2 \mathrm{~g})$ were dissolved in $2 \mathrm{~mL} \mathrm{MeOH}$ and $5 \mathrm{M} \mathrm{HCl}$ was added dropwise until the precipiate formed. The solution was evaporated to dryness and this procedure was repeated three times. The precipitate which formed was filtered off and washed with water to $\mathrm{pH}=7$. The salts $\mathbf{9 b - 1 2 b}$ and $\mathbf{1 5 c}, \mathbf{1 8 c}, \mathbf{2 0 c}$ were obtained as white solids with a quantitative yield.

$\mathrm{N}$-(4-Butylgyanidine)-3-oxolupane-28-amide dihydrochloride (9b), White powder, $87 \%$ yield; $\mathrm{mp} 176-178{ }^{\circ} \mathrm{C}$ $(\mathrm{EtOH}) ;[\alpha]_{\mathrm{D}}^{21}-11^{\circ}\left(\right.$ c $\left.0.29, \mathrm{C}_{2} \mathrm{H}_{5} \mathrm{OH}\right) ; \mathrm{IR}\left(\mathrm{CHCl}_{3}\right) v_{\max } 1721(\mathrm{C}=\mathrm{O}), 3342(\mathrm{NH}) \mathrm{cm}^{-1} ;{ }^{1} \mathrm{H}-\mathrm{NMR}$ (500 MHz, $d_{6}$-DMSO) $\delta: 7.71$ (br s, $\left.1 \mathrm{H}, \mathrm{NH}\right), 7.59$ (br s, $\left.1 \mathrm{H}, \mathrm{CONH}\right), 3.10-3.01\left(\mathrm{~m}, 4 \mathrm{H}, \mathrm{H}-1^{\prime}, \mathrm{H}-4^{\prime}\right)$, 2.61-1.04 (m, 26H, CH, $\mathrm{CH}_{2}$ in pentacyclic skeleton, $\left.4 \mathrm{H}, \mathrm{H}-2^{\prime}, \mathrm{H}_{-} 3^{\prime}\right), 0.99,0.93,0.91,0.87,0.86$ (3H each, all s, H-23-H-27), 0.81 (d, J = 6.5 Hz, 3H, H-29), 0.71 (d, J = 7.0 Hz, 3H, H-30); ${ }^{13} \mathrm{C}-\mathrm{NMR}(125 \mathrm{MHz}$, $d_{6}$-DMSO) $\delta$ : $217.1(\mathrm{C}-3), 176.1(\mathrm{C}-28), 157.4(\mathrm{C}=\mathrm{N}), 55.7(\mathrm{C}-17), 54.3(\mathrm{C}-5), 49.6(\mathrm{C}-9), 49.5$ (C-19), 47.0 (C-4), 43.8 (C-18), 42.6 (C-14), 40.9 (C-4'), 40.3 (C-8), 39.7 (C-1), 38.1 (C-22, C-1'), 37.0 (C-13), 36.8 (C-10), 34.1 (C-2), 33.8 (C-16), 32.7 (C-7), 30.0 (C-20), 29.4 (C-15), 27.2 (C-3'), 27.0 (C-2'), 26.9 (C-23), 26.4 (C-12), 23.6 (C-29), 23.1 (C-21), 21.7 (C-11), 21.2 (C-24), 19.7 (C-6), 16.2 (C-25), 16.1 (C-26), 15.0 (C-30), 14.6 (C-27); Anal. Calcd. for $\mathrm{C}_{35} \mathrm{H}_{62} \mathrm{Cl}_{2} \mathrm{~N}_{4} \mathrm{O}_{2}$ : C, 65.50, Cl, 11.05, H, 9.74. Found: $\mathrm{C}, 65.97, \mathrm{Cl}, 11.78, \mathrm{H}$, 9.68\%. MS: $m / z 569.49[\mathrm{M}+\mathrm{H}]^{+}$(calcd. for $\mathrm{C}_{35} \mathrm{H}_{60} \mathrm{~N}_{4} \mathrm{O}_{2}, 568.47$ ).

$3 \beta$-N-(2-Ethylgyanidine)-3-O-acetyl-lupane-28-amide hydrochloride (10b), White powder, $82 \%$ yield; $\mathrm{mp}$ $192-194{ }^{\circ} \mathrm{C}(\mathrm{EtOH}) ;[\alpha]_{\mathrm{D}}^{17}-16^{\circ}\left(c 0.23, \mathrm{C}_{2} \mathrm{H}_{5} \mathrm{OH}\right) ; \mathrm{IR}\left(\mathrm{CHCl}_{3}\right) v_{\max } 1652,1716(\mathrm{C}=\mathrm{O}), 3155,3327(\mathrm{NH})$ $\mathrm{cm}^{-1} ;{ }^{1} \mathrm{H}-\mathrm{NMR}(500 \mathrm{MHz}, \mathrm{MeOD}) \delta: 4.48-4.45(\mathrm{~m}, 1 \mathrm{H}, \mathrm{H}-3), 3.43-3.16\left(\mathrm{~m}, 4 \mathrm{H}, \mathrm{H}-1^{\prime}, \mathrm{H}-2^{\prime}\right), 2.04(\mathrm{~s}$, $3 \mathrm{H}, \mathrm{CH}_{3} \mathrm{CO}-$ ), $2.60-0.81$ (m, 25H, $\mathrm{CH}, \mathrm{CH}_{2}$ in pentacyclic skeleton), 1.02, 0.98, 0.92, 0.90, 0.88, 0.87 (all $\mathrm{s}, 3 \mathrm{H}$ each, H-23-H-27 and H-29), $0.80(\mathrm{~d}, J=6.5 \mathrm{~Hz}, 3 \mathrm{H}, \mathrm{H}-30) ;{ }^{13} \mathrm{C}-\mathrm{NMR}(125 \mathrm{MHz}, \mathrm{MeOD}) \delta$ : $180.8(\mathrm{C}-28), 173.0\left(\mathrm{COCH}_{3}\right), 159.0(\mathrm{C}=\mathrm{N}), 82.6(\mathrm{C}-3), 57.6(\mathrm{C}-17), 57.0(\mathrm{C}-5), 51.1(\mathrm{C}-9, \mathrm{C}-19), 45.5(\mathrm{C}-18)$, 42.7 (C-14, C-1'), 42.2 (C-8), 39.8 (C-1), 39.7 (C-2'), 39.4 (C-22), 39.0 (C-4), 38.9 (C-13), 38.4 (C-10), 35.7 (C-7), 34.0 (C-16), 31.4 (C-20), 30.7 (C-15), 28.6 (C-23), 28.5 (C-2), 24.8 (C-12), 24.1 (C-21), 23.6 (C-29), 22.4 (C-11), $21.3\left(\mathrm{COCH}_{3}\right), 19.4$ (C-6), 17.1 (C-25), 16.9 (C-24, C-26), 15.2 (C-30), 15.1 (C-27); Anal. Calcd. for $\mathrm{C}_{35} \mathrm{H}_{61} \mathrm{ClN}_{4} \mathrm{O}_{3}$ : $\mathrm{C}, 67.66, \mathrm{Cl}, 5.71, \mathrm{H}, 9.90$. Found: $\mathrm{C}, 67.99, \mathrm{Cl}, 5.40, \mathrm{H}, 9.84 \%$. MS: $m / z 585.54$ $[\mathrm{M}+\mathrm{H}]^{+}$(calcd. for $\mathrm{C}_{35} \mathrm{H}_{60} \mathrm{~N}_{4} \mathrm{O}_{3}, 584.47$ ).

3B-N-(4-Butylgyanidine)-3-O-acetyl-lupane-28-amide hydrochloride (11b), White powder, 79\% yield; mp $156-158^{\circ} \mathrm{C}(\mathrm{EtOH}) ;[\alpha]_{\mathrm{D}}^{22}-14.5^{\circ}\left(\mathrm{c} 0.53, \mathrm{C}_{2} \mathrm{H}_{5} \mathrm{OH}\right) ; \mathrm{IR}\left(\mathrm{CHCl}_{3}\right) v_{\max } 1645,1716(\mathrm{C}=\mathrm{O}), 3168,3338(\mathrm{NH})$ $\mathrm{cm}^{-1}{ }^{1}{ }^{1} \mathrm{H}-\mathrm{NMR}(500 \mathrm{MHz}, \mathrm{MeOD}) \delta: 7.45(\mathrm{br} \mathrm{s}, 1 \mathrm{H}, \mathrm{NH}), 4.48-4.45(\mathrm{~m}, 1 \mathrm{H}, \mathrm{H}-3), 3.23-3.18\left(\mathrm{~m}, 4 \mathrm{H}, \mathrm{H}-1^{\prime}\right.$, $\left.\mathrm{H}-4^{\prime}\right), 2.04\left(\mathrm{~s}, 3 \mathrm{H}, \mathrm{CH}_{3} \mathrm{CO}-\right), 2.61-0.84\left(\mathrm{~m}, 26 \mathrm{H}, \mathrm{CH}, \mathrm{CH}_{2}\right.$ in pentacyclic skeleton, $\left.4 \mathrm{H}, \mathrm{H}-2^{\prime}, \mathrm{H}^{\prime} 3^{\prime}\right), 1.01$, 0.98, 0.92, 0.89, 0.88, 0.86 (all s, 3H each, H-23-H-27 and H-29), 0.79 (d, J = 7.0 Hz, 3H, H-30); ${ }^{13} \mathrm{C}-\mathrm{NMR}$ (125 MHz, MeOD) $\delta: 179.6(\mathrm{C}-28), 172.9\left(\mathrm{COCH}_{3}\right), 158.8(\mathrm{C}=\mathrm{N}), 82.6(\mathrm{C}-3), 57.5(\mathrm{C}-17), 57.0(\mathrm{C}-5)$, 51.9 (C-9), 51.1 (C-19), 45.5 (C-18), 43.8 (C-14), 42.4 (C-8), 42.2 (C-4'), 40.0 (C-22, C-1'), 39.8 (C-1), 39.0 (C-4), 38.9 (C-13), 38.4 (C-10), 35.8 (C-7), 34.1 (C-16), 31.4 (C-20), 30.8 (C-3'), 28.6 (C-15), 28.2 (C-23, 
C-2') 27.4 (C-2), 24.8 (C-12), 24.4 (C-21), 24.2 (C-29), 22.5 (C-11), $21.3\left(\mathrm{COCH}_{3}\right), 19.4(\mathrm{C}-6), 17.1$ (C-25), 17 (C-24), 16.9 (C-26), 15.2 (C-30), 15.1 (C-27); Anal. Calcd. for $\mathrm{C}_{37} \mathrm{H}_{65} \mathrm{ClN}_{4} \mathrm{O}_{3}$ : C, 68.43, Cl, 5.46, H, 10.09. Found: $\mathrm{C}, 68.88 ; \mathrm{Cl}, 5.12 ; \mathrm{H}, 10.02 \%$. MS: $m / z 614.51[\mathrm{M}+2 \mathrm{H}]^{+}$(calcd. for $\mathrm{C}_{37} \mathrm{H}_{64} \mathrm{~N}_{4} \mathrm{O}_{3}, 612.50$ ).

$3 \beta-N-\left[2-\left(N, N^{\prime}\right.\right.$-bis-Ethylgyanidine)-aminoethyl]-3-O-acetyl-lupane-28-amide dihydrochloride (12b), White powder, 88\% yield; $\mathrm{mp} 198-200{ }^{\circ} \mathrm{C}(\mathrm{EtOH}) ;[\alpha]_{\mathrm{D}}^{17}-16^{\circ}\left(c 0.29, \mathrm{C}_{2} \mathrm{H}_{5} \mathrm{OH}\right) ; \mathrm{IR}\left(\mathrm{CHCl}_{3}\right) v_{\max } 1637,1672$, $1734(\mathrm{C}=\mathrm{O}), 3162,3271,3324(\mathrm{NH}) \mathrm{cm}^{-1}$; ${ }^{1} \mathrm{H}-\mathrm{NMR}$ (500 MHz, MeOD) $\delta: 4.48-4.45(\mathrm{~m}, 1 \mathrm{H}, \mathrm{H}-3)$, 3.90-3.83 (m, 4H, H-4', $\left.\mathrm{H}-4^{\prime \prime}\right), 3.66-3.59$ (m, 6H, H-2' , H-3', H-3"), $3.38-3.33$ (m, 2H, H-1'), 2.04 (s, 3H, $\left.\mathrm{CH}_{3} \mathrm{CO}-\right), 2.51-0.85\left(\mathrm{~m}, 26 \mathrm{H}, \mathrm{CH}, \mathrm{CH}_{2}\right.$ in pentacyclic skeleton), 1.03, 0.99, 0.93, 0.90, 0.88, 0.87 (all s, $3 \mathrm{H}$ each, H-23-H-27 and H-29), 0.80 (d, $J=6.5 \mathrm{~Hz}, 3 \mathrm{H}, \mathrm{H}-30) ;{ }^{13} \mathrm{C}-\mathrm{NMR}(125 \mathrm{MHz}, \mathrm{MeOD}) \delta: 181.0$ (C-28), $172.9\left(\mathrm{COCH}_{3}\right), 158.9(\mathrm{C}=\mathrm{N}), 82.5(\mathrm{C}-3), 57.7$ (C-17), 56.9 (C-5), 53.7 (C-3', C-3"), $53.6\left(\mathrm{C}-2^{\prime}\right), 51.8(\mathrm{C}-9)$, 51.0 (C-19), 45.5 (C-18), 43.8 (C-14), 42.2 (C-8), 39.7 (C-22), 39.0 (C-1, C-13), 38.4 (C-4), 37.7 (C-10, C-1'), 35.7 (C-7), 35.0 (C-4', C-4"), 33.9 (C-16), 31.3 (C-20), 30.8 (C-15), 28.6 (C-23), 28.4 (C-2), 24.8 (C-12), 24.2 (C-21), 23.6 (C-29), 22.4 (C-11), $21.3\left(\mathrm{COCH}_{3}\right), 19.4$ (C-6), 17.1 (C-25, C-24), 16.9 (C-26), 15.2 (C-30), 15.1 (C-27); Anal. Calcd. for $\mathrm{C}_{40} \mathrm{H}_{74} \mathrm{Cl}_{2} \mathrm{~N}_{8} \mathrm{O}_{3}$ : C, 61.13, $\mathrm{Cl}, 9.02, \mathrm{H}, 9.49$. Found: C, 61.55, $\mathrm{Cl}, 11.40, \mathrm{H}$, 9.42\%. MS: $m / z 713.51[\mathrm{M}+\mathrm{H}]^{+}$(calcd. for $\mathrm{C}_{40} \mathrm{H}_{72} \mathrm{~N}_{8} \mathrm{O}_{3}, 712.57$ ).

3ß-[2-Guanidine-3-hydroxy-2-(hydroxymethyl)propyl]-3-O-acetyl-lupane-28-oate hydrochloride (15c), White powder, $68 \%$ yield; mp $136-138^{\circ} \mathrm{C}(\mathrm{EtOH}) ;[\alpha]_{\mathrm{D}}^{22}-14.5^{\circ}\left(c 0.53, \mathrm{C}_{2} \mathrm{H}_{5} \mathrm{OH}\right) ; \mathrm{IR}\left(\mathrm{CHCl}_{3}\right) v_{\max } 1673$, $1733(\mathrm{C}=\mathrm{O}), 3325(\mathrm{NH}) \mathrm{cm}^{-1} ;{ }^{1} \mathrm{H}-\mathrm{NMR}(500 \mathrm{MHz}, \mathrm{MeOD}) \delta: 4.48-4.45(\mathrm{~m}, 1 \mathrm{H}, \mathrm{H}-3), 4.31(2 \mathrm{H}, \mathrm{m}$, H-1'), 3.75 (m, 4H, H-3', H-4'), $2.04\left(\mathrm{~s}, 3 \mathrm{H}, \mathrm{CH}_{3} \mathrm{CO}-\right)$, 2.29-0.85 (m, 26H, CH, $\mathrm{CH}_{2}$ in pentacyclic skeleton), 1.03, 1.00, 0.98, 0.91, 0.88, 0.87 (all s, 3H each, H-23-H-27 and H-29), 0.81 (d, $J=6.5 \mathrm{~Hz}$, 3H, H-30); ${ }^{13} \mathrm{C}-\mathrm{NMR}(125 \mathrm{MHz}, \mathrm{MeOD}) \delta: 177.1\left(\mathrm{C}-28, \mathrm{COCH}_{3}\right), 159.1(\mathrm{C}=\mathrm{N}), 82.6(\mathrm{C}-3), 64.1\left(\mathrm{C}-3^{\prime}\right)$, 64.1 (C-4'), 62.8 (C-2'), 61.8 (C-1'), 58.7 (C-17), 56.9 (C-5), 51.8 (C-9), 50.4 (C-19), 45.8 (C-18), 43.9 (C-14), 42.1 (C-8), 39.7 (C-22), 39.6 (C-1), 39.0 (C-4), 38.4 (C-10, C-13), 35.6 (C-7), 33.2 (C-16), 31.2 (C-20), 30.9 (C-15), 28.6 (C-23), 28.4 (C-2), 24.8 (C-12), 23.9 (C-21), 23.5 (C-29), 22.3 (C-11), $21.3\left(\mathrm{COCH}_{3}\right)$, 19.4 (C-6), 17.1 (C-25), 16.9 (C-24), 16.8 (C-26), 15.2 (C-30), 15.1 (C-27); Anal. Calcd. for $\mathrm{C}_{37} \mathrm{H}_{64} \mathrm{ClN}_{3} \mathrm{O}_{6}$ : C, 65.13, $\mathrm{Cl}, 5.20, \mathrm{H}, 9.45$. Found: $\mathrm{C}, 65.64, \mathrm{Cl}, 4.50 ; \mathrm{H}, 9.39 \%$. MS: $m / z 647.47[\mathrm{M}+2 \mathrm{H}]^{+}$(calcd. for $\left.\mathrm{C}_{37} \mathrm{H}_{63} \mathrm{~N}_{3} \mathrm{O}_{6}, 645.47\right)$.

33-[2-Guanidine-3-hydroxy-2-(hydroxymethyl)propyl]-3-O-acetyl-urs-12-en-28-oate hydrochloride (18c), White powder, $62 \%$ yield; mp $142-144{ }^{\circ} \mathrm{C}(\mathrm{EtOH}) ;[\alpha]_{\mathrm{D}}^{19}+37^{\circ}\left(c 0.51, \mathrm{C}_{2} \mathrm{H}_{5} \mathrm{OH}\right) ; \mathrm{IR}\left(\mathrm{CHCl}_{3}\right) v_{\max }$ 1675, $1733(\mathrm{C}=\mathrm{O}), 3186,3335(\mathrm{NH}) \mathrm{cm}^{-1}$; ${ }^{1} \mathrm{H}-\mathrm{NMR}(500 \mathrm{MHz}, \mathrm{MeOD}) \delta: 7.07$ (s, 1H, NH), 5.30 (br s, 1H, H-12), 4.50-4.47 (m, 1H, H-3), 4.29, 4.23 (both d, $J=11.5 \mathrm{~Hz}, 1 \mathrm{H}$ each, H-1'), 3.75 (m, 4H, H-3', $\left.\mathrm{H}-4^{\prime}\right), 2.25(\mathrm{~d}, J=11.5 \mathrm{~Hz}, 1 \mathrm{H}, \mathrm{H}-18), 2.05\left(\mathrm{~s}, 3 \mathrm{H}, \mathrm{CH}_{3} \mathrm{CO}-\right), 2.14-0.88\left(\mathrm{~m}, 22 \mathrm{H}, \mathrm{CH}, \mathrm{CH}_{2}\right.$ in pentacyclic skeleton), 1.16, 1.02, 1.00, 0.92, 0.91, 0.90, 0.81 (all s, 3H each, H-23-H-27, H-29 and H-30); ${ }^{13} \mathrm{C}-\mathrm{NMR}$ (125 MHz, MeOD) $\delta: 178.6(\mathrm{C}-28), 173.0\left(\mathrm{COCH}_{3}\right), 159.2(\mathrm{C}=\mathrm{N}), 139.6(\mathrm{C}-13), 127.3(\mathrm{C}-12), 82.6(\mathrm{C}-3)$, $64.2\left(\mathrm{C}-3^{\prime}, \mathrm{C}-4^{\prime}\right), 62.9$ (C-2' $), 62.3$ (C-1'), 56.8 (C-5), 54.5 (C-18), 49.3 (C-17), 49.0 (C-9), 43.4 (C-14), 41.0 (C-8), 40.5 (C-4, C-19), 39.6 (C-20), 38.9 (C-1), 38.2 (C-22), 38.0 (C-10), 34.2 (C-7), 31.8 (C-21), 29.3 (C-15), 28.8 (C-23), 25.5 (C-16), 24.7 (C-2), 24.5 (C-27), 24.4 (C-11), 21.7 (C-30), $21.3\left(\mathrm{COCH}_{3}\right)$, 19.5 (C-6), 17.9 (C-29), 17.8 (C-26), 17.4 (C-24), 16.2 (C-25); Anal. Calcd. for $\mathrm{C}_{37} \mathrm{H}_{62} \mathrm{ClN}_{3} \mathrm{O}_{6}$ : C, 65.32, $\mathrm{Cl}$, 5.21, H, 9.19. Found: $\mathrm{C}, 65.74, \mathrm{Cl}, 4.51, \mathrm{H}, 9.14 \%$. MS: $m / z 644.34[\mathrm{M}+\mathrm{H}]^{+}$(calcd. for $\mathrm{C}_{37} \mathrm{H}_{61} \mathrm{~N}_{3} \mathrm{O}_{6}$, 643.46).

3ß-[2-Guanidine-3-hydroxy-2-(hydroxymethyl)propyl]-3-O-acetyl-olean-12-en-28-oate hydrochloride (20c), White powder, $53 \%$ yield; mp $124-128^{\circ} \mathrm{C}(\mathrm{EtOH}) ;[\alpha]_{\mathrm{D}}^{19}+34^{\circ}\left(c 0.34, \mathrm{C}_{2} \mathrm{H}_{5} \mathrm{OH}\right) ; \mathrm{IR}\left(\mathrm{CHCl}_{3}\right) v_{\max } 1662$, $1733(\mathrm{C}=\mathrm{O}), 3344(\mathrm{NH}) \mathrm{cm}^{-1},{ }^{1} \mathrm{H}-\mathrm{NMR}(500 \mathrm{MHz}, \mathrm{MeOD}) \delta$ : 5.32 (br s, $\left.1 \mathrm{H}, \mathrm{H}-12\right), 4.49-4.46(\mathrm{~m}, 1 \mathrm{H}$, H-3), 4.33, 4.20 (both d, $J=11.5 \mathrm{~Hz}, 1 \mathrm{H}$ each, $\left.\mathrm{H}-1^{\prime}\right), 3.76\left(\mathrm{~m}, 4 \mathrm{H}, \mathrm{H}-3^{\prime}, \mathrm{H}-4^{\prime}\right), 2.89(\mathrm{~d}, J=9.5 \mathrm{~Hz}, 1 \mathrm{H}$, $\mathrm{H}-18), 2.13-0.90$ (m, 22H, CH, $\mathrm{CH}_{2}$ in pentacyclic skeleton), 2.05 (s, $\left.3 \mathrm{H}, \mathrm{CH}_{3} \mathrm{CO}-\right), 1.20,1.00,0.98,0.96$, 0.94, 0.91, 0.88 (all s, 3H each, H-23-H-27, H-29 and H-30); ${ }^{13} \mathrm{C}-\mathrm{NMR}$ (125 MHz, MeOD) $\delta: 178.8$ (C-28), $172.9\left(\mathrm{COCH}_{3}\right), 159.1(\mathrm{C}=\mathrm{N}), 145.0(\mathrm{C}-13), 124.1(\mathrm{C}-12), 82.6(\mathrm{C}-3), 64.2\left(\mathrm{C}-4^{\prime}\right), 64.1\left(\mathrm{C}-3^{\prime}\right), 62.8\left(\mathrm{C}-2^{\prime}\right)$, 62.3 (C-1'), 56.8 (C-5), 49.0 (C-9), 48.5 (C-17), 47.1 (C-19), 43.0 (C-14), 42.9 (C-18), 40.7 (C-8), 39.5 (C-1), 
38.9 (C-4), 38.2 (C-10), 34.9 (C-22), 33.9 (C-30), 33.7 (C-7, C-21), 31.7 (C-20), 28.9 (C-15), 28.7 (C-23), 26.6 (C-27), 24.7 (C-11, C-29), 24.3 (C-2), 24.2 (C-16), $21.3\left(\mathrm{COCH}_{3}\right), 19.5$ (C-6), 17.9 (C-26), 17.3 (C-24), 15.6 (C-25); Anal. Calcd. for $\mathrm{C}_{37} \mathrm{H}_{62} \mathrm{ClN}_{3} \mathrm{O}_{6}: \mathrm{C}, 65.32, \mathrm{Cl}, 5 . \overline{21}, \mathrm{H}, 9.19$. Found: $\mathrm{C}, 65.74, \mathrm{Cl}, 4.80, \mathrm{H}$, 9.12\%. MS: $m / z 644.44[\mathrm{M}+\mathrm{H}]^{+}$(calcd. for $\mathrm{C}_{37} \mathrm{H}_{61} \mathrm{~N}_{3} \mathrm{O}_{6}, 643.46$ ).

$3 \beta-N$-(4-Butylgyanidine)-3-hydroxy-lupane-28-amide (14), To a solution of the compound $\mathbf{1 1 b} \mathbf{b}(0.33 \mathrm{~g}$, $0.5 \mathrm{mmol})$ in $\mathrm{MeOH}(4 \mathrm{~mL})$ and THF $(4 \mathrm{~mL})$ was added $4 \mathrm{~N} \mathrm{NaOH}(4 \mathrm{~mL})$. The reaction mixture was stirred at room temperature for $24 \mathrm{~h}$ (monitoring by TLC) and then neutralized with $20 \% \mathrm{HCl}$. The solution was dried under vacuum and reconstituted with $\mathrm{CH}_{2} \mathrm{Cl}_{2}$. The organic layer was washed with brine and dried over anhydrous $\mathrm{MgSO}_{4}$ and concentrated under reduced pressure to obtain pure compound 14. White powder, $79 \%$ yield; $\mathrm{mp} 260-262{ }^{\circ} \mathrm{C}(\mathrm{EtOH}) ;[\alpha]_{\mathrm{D}}^{19}-10^{\circ}(c 0.24, \mathrm{DMSO}) ; \mathrm{IR}\left(\mathrm{CHCl}_{3}\right)$ $v_{\max } 1731(\mathrm{C}=\mathrm{O}), 3366(\mathrm{NH}) \mathrm{cm}^{-1},{ }^{1} \mathrm{H}-\mathrm{NMR}\left(500 \mathrm{MHz}, \mathrm{DMSO}-\mathrm{d}_{5}\right) \delta: 7.73(\mathrm{br} \mathrm{s}, 1 \mathrm{H}, \mathrm{NH}), 7.58$ (br s, $1 \mathrm{H}, \mathrm{CONH}), 4.29$ (br s, $1 \mathrm{H}, \mathrm{OH}), 3.09-2.98\left(\mathrm{~m}, 5 \mathrm{H}, \mathrm{H}-3, \mathrm{H}-1^{\prime}, \mathrm{H}-4^{\prime}\right), 2.19-1.02\left(\mathrm{~m}, 26 \mathrm{H}, \mathrm{CH}, \mathrm{CH}_{2}\right.$ in pentacyclic skeleton, $\left.4 \mathrm{H}, \mathrm{H}-2^{\prime}, \mathrm{H}-3^{\prime}\right), 0.89,0.87,0.84,0.78,0.66$ (all s, 3H each, H-23-H-27), 0.81 (d, $J=6.5 \mathrm{~Hz}, 3 \mathrm{H}, \mathrm{H}-29), 0.72(\mathrm{~d}, J=6.5 \mathrm{~Hz}, 3 \mathrm{H}, \mathrm{H}-30) ;{ }^{13} \mathrm{C}-\mathrm{NMR}\left(125 \mathrm{MHz}, \mathrm{DMSO}-\mathrm{d}_{5}\right) \delta: 176.1(\mathrm{C}-28)$, $157.4(\mathrm{C}=\mathrm{N}), 77.2$ (C-3), 55.7 (C-17), 55.4 (C-5), 50.3 (C-9), 49.6 (C-19), 43.8 (C-18), 42.5 (C-14), 40.9 (C-8), 40.8 (C-4'), 39.0 (C-22), 38.8 (C-1), 38.6 (C-4), 38.1 (C-1'), 37.2 (C-13), 36.9 (C-10), 34.6 (C-7), 32.8 (C-16), 30.0 (C-20), 29.4 (C-15), 28.6 (C-23), 27.4 (C-2), 27.2 (C-3'), 27.0 (C-2'), 26.4 (C-12), 23.6 (C-29), 23.2 (C-21), 21.1 (C-11), 18.5 (C-6), 16.4 (C-25), 16.3 (C-24, C-26), 15.0 (C-30), 14.7 (C-27); Anal. Calcd. for $\mathrm{C}_{35} \mathrm{H}_{62} \mathrm{~N}_{4} \mathrm{O}_{2}: \mathrm{C}, 73.63, \mathrm{H}, 10.95$. Found: $\mathrm{C}, 73.74, \mathrm{H}, 10.88 \%$. MS: $m / z 593.31[\mathrm{M}+\mathrm{Na}]^{+}$(calcd. for $\mathrm{C}_{35} \mathrm{H}_{62} \mathrm{~N}_{4} \mathrm{O}_{2}, 570.49$ ).

\subsection{Biology}

\subsubsection{Cell Culturing}

Cells (Jurkat, K562, U937, HeLa, HEK293 and normal Fibroblasts) were purchased from Russian Cell Culture Collection (Institute of Cytology of the Russian Academy of Sciences, Saint Petersburg, Russia) and cultured according to standard mammalian tissue culture protocols and sterile technique. Human cell lines HEK293 and HeLa were obtained from the HPA Culture Collections (Salisbury, UK). All cell lines used in the study were tested and shown to be free of mycoplasma and viral contamination.

HEK293, HeLa cell lines and fibroblasts were cultured as monolayers and maintained in Dulbecco's modified Eagle's medium (DMEM, Gibco BRL, Waltham, MA, USA) supplemented with $10 \%$ foetal bovine serum and $1 \%$ penicillin-streptomycin solution at $37^{\circ} \mathrm{C}$ in a humidified incubator under a $5 \% \mathrm{CO}_{2}$ atmosphere.

Cells were maintained in RPMI 1640 (Jurkat, K562, U937) (Gibco, Thermo Fisher Scientific, Waltham, MA, USA) supplemented with $4 \mathrm{mM}$ glutamine, 10\% FBS (Sigma, Burlington, MA, USA) and 100 units $/ \mathrm{mL}$ penicillin-streptomycin (Sigma). All types of cells were grown in an atmosphere of $5 \% \mathrm{CO}_{2}$ at $37^{\circ} \mathrm{C}$. The cells were subcultures at 2-3 days intervals. Adherent cells (HEK293, HeLa, fibroblasts) were suspended using trypsin/EDTA and counted after they have reached $80 \%$ confluency. Cells were then seeded in 24 well plates at $5 \times 104$ cells per well and incubated overnight. Jurkat, K562, U937 cells were subcultured at 2 day intervals with a seeding density of $1 \times 105$ cells per 24 well plates in RPMI with 10\% FBS.

\subsubsection{Cytotoxicity Assay}

Viability (Live/dead) assessment was performed by staining cells with 7-AAD (7-Aminoactinomycin D) (Biolegend, San Diego, CA, USA). Cells were treated of test compounds with six different concentrations $(1,5,10,15,30$ and $60 \mu \mathrm{M})$. After treatment, cells were harvested, washed 1-2 times with phosphate-buffered saline (PBS) and centrifuged at $400 \times g$ for $5 \mathrm{~min}$. Cell pellets were resuspended in $200 \mu \mathrm{L}$ of flow cytometry staining buffer ( $\mathrm{PBS}$ without $\mathrm{Ca}^{2+}$ and $\mathrm{Mg}^{2+}, 2.5 \% \mathrm{FBS}$ ) and stained with $5 \mu \mathrm{L}$ of 7-AAD staining solutionfor $15 \mathrm{~min}$ at room temperature in the dark. Samples were acquired on NovoCyteTM 2000 FlowCytometry 
System (ACEA, San Diego, CA, USA) equipped with $488 \mathrm{~nm}$ argon laser. Detection of 7-AAD emission was collected through a $675 / 30 \mathrm{~nm}$ filter in FL4 channel.

\subsubsection{Viability and Apoptosis}

Apoptosis was determined by flow cytometric analysis of Annexin V and 7-aminoactinomycin D staining. Briefly, $200 \mu \mathrm{L}$ of Guava Nexin reagent (Millipore, Bedford, MA, USA) was added to $5 \times 105$ cells in $200 \mu \mathrm{L}$, and the cells were incubated with the reagent for $20 \mathrm{~min}$ at room temperature in the dark. The plates were treated with compounds $15,15 c, 18 c, 20 c$ and dihydrobetulinic acid at $\mathrm{IC}_{50}$ concentration $(4,8$ and $59 \mu \mathrm{M})$ for $24 \mathrm{~h}$ and $48 \mathrm{~h}$. At the end of incubation, the cells were analyzed on NovoCyteTM 2000 FlowCytometry System (ACEA). Different states of cell death were defined as follows: normal cells are localized in the lower-left quadrant (Annexin $\mathrm{V}^{-} / \mathrm{PI}^{-}$); early apoptotic cells are in the lower-right quadrant (Annexin $\mathrm{V}^{+} / \mathrm{PI}^{-}$); late apoptotic cells and necrotic cells are in the upper-right quadrant (Annexin $\mathrm{V}^{+} / \mathrm{PI}^{+}$); and necrotic cells are in the upper-left quadrant (Annexin $\left.\mathrm{V}^{-} / \mathrm{PI}^{+}\right)$.

\subsubsection{Cell Cycle Analysis}

Cell cycle was analyzed using the method of propidium iodide staining. Briefly, cells were plated in 24-well round bottom plates at density $10 \times 105$ cells per well, centrifuged at $450 \times g$ for $5 \mathrm{~min}$, and fixed with ice-cold $70 \%$ ethanol for $24 \mathrm{~h}$ at $0{ }^{\circ} \mathrm{C}$. Cells were then washed with PBS and incubated with $250 \mu \mathrm{L}$ of Guava Cell Cycle Reagent (Millipore, Burlington, MA, USA) for $30 \mathrm{~min}$ at room temperature in the dark. Samples were analyzed on NovoCyte ${ }^{\mathrm{TM}} 2000$ FlowCytometry System (ACEA, San Diego, CA, USA).

\section{Conclusions}

Novel betulinic, ursolic, and oleanolic acid derivatives, containing a guanidine moiety have been designed and synthesized in an attempt to develop potent antitumor agents. These compounds and their precursors, monoamine, diamine and triamine derivatives, were tested for cytotoxic activity on various human tumor cell lines. Guanidine-functionalized triterpenoids demonstrated higher cytotoxicity in Jurkat cells, compared with original triterpenoic acids. Most of the tested guanidine derivatives showed higher $\mathrm{IC}_{50}$ values than amines, but were less toxic to human fibroblasts. The lead molecules-dihydrobetulinic acid amine 15, its guanidine derivative 15c, and guanidinium salts of ursolic and oleanolic acids 18c and 20c were selected for extended biological testing by using flow cytometry analysis. Our results showed that the antitumor activity of compounds $15,15 \mathrm{c}$, and $18 \mathrm{c}$ is caused by apoptotic processes and induction of cell cycle arrest in the S-phase. Nevertheless, addition information concerning the molecular mechanisms and targets of these triterpene acid derivatives is needed.

Supplementary Materials: The following are available online: ${ }^{1} \mathrm{H}-\mathrm{NMR}$ and ${ }^{13} \mathrm{C}-\mathrm{NMR}$ spectra of all new compounds.

Author Contributions: Supervision, U.D. and V.O.; validation and writing-review \& editing, A.S. and L.D.; performing the chemistry experiments R.K. and D.N.; performing the biology experiments M.Y., L.D. and V.D.; The manuscript was prepared through the contributions L.D., V.D. and D.N.

Funding: This work was performed under financial support from the Russian Science Foundation (Grant 16-13-10051).

Conflicts of Interest: The authors declare no conflict of interest.

\section{References}

1. Hill, R.A.; Connolly, J.D. Triterpenoids. Nat. Prod. Rep. 2017, 34, 90-122. [CrossRef] [PubMed]

2. Dzubak, P.; Hajduch, M.; Vydra, D.; Hustova, A.; Kvasnica, M.; Biedermann, D.; Markova, L.; Urban, M.; Sarek, J. Pharmacological activities of natural triterpenoids and their therapeutic implications. Nat. Prod. Rep. 2006, 23, 394-411. [CrossRef] [PubMed] 
3. Sarek, J.; Kvasnica, M.; Vlk, M.; Urban, M.; Dzubak, P.; Hajduch, M. The potential of triterpenoids in the treatment of melanoma. In Research on Melanoma: A Glimpse into Current Directions and Future Trends; Murph, M., Ed.; IntechOpen: Rijeka, Croatia, 2011; pp. 125-158.

4. Sheng, H.; Sun, H. Synthesis, biology and clinical significance of pentacyclic triterpenes: A multi-target approach to prevention and treatment of metabolic and vascular diseases. Nat. Prod. Rep. 2011, 28, 543-593. [CrossRef] [PubMed]

5. Salvador, J.A.R.; Moreira, V.M.; Goncalves, B.M.F.; Lealab, A.S.; Jing, Y. Ursane-type pentacyclic triterpenoids as useful platforms to discover anticancer drugs. Nat. Prod. Rep. 2012, 29, 1463-1479. [CrossRef] [PubMed]

6. Chen, H.; Gao, Y.; Wang, A.; Zhou, X.; Zheng, Y.; Zhou, J. Evolution in medicinal chemistry of ursolic acid derivatives as anticancer agents. Eur. J. Med. Chem. 2015, 92, 648-655. [CrossRef] [PubMed]

7. Cichewicz, R.H.; Kouzi, S.A. Chemistry, biological activity, and chemotherapeutic potential of betulinic acid for the prevention and treatment of cancer and HIV infection. Med. Res. Rev. 2004, 24, 90-114. [CrossRef] [PubMed]

8. Csuk, R. Betulinic acid and its derivatives: A patent review (2008-2013). Expert Opin. Ther. Pat. 2014, 24, 913-923. [CrossRef] [PubMed]

9. Fulda, S.; Galluzzi, L.; Kroemer, G. Targeting mitochondria for cancer therapy. Nat. Rev. Drug Discov. 2010, 9, 447-464. [CrossRef] [PubMed]

10. Damle, A.A.; Pawar, Y.P.; Narkar, A.A. Anticancer activity of betulinic acid on MCF-7 tumors in nude mice. Indian J. Exp. Biol. 2013, 51, 485-491. [PubMed]

11. Mullauer, F.B.; Bloois, L.; Daalhuisen, J.B.; Brink, M.S.T.; Storm, G.; Medema, J.P.; Schiffelers, R.M.; Kessler, J.H. Betulinic acid delivered in liposomes reduces growth of human lung and colon cancers in mice without causing systemic toxicity. Anticancer Drugs. 2011, 22, 223-233. [CrossRef] [PubMed]

12. Pathak, A.K.; Bhutani, M.; Nair, A.S.; Ahn, K.S.; Chakraborty, A.; Kadara, H.; Guha, S.; Sethi, G.; Aggarwal, B.B. Ursolic acid inhibits STAT3 activation pathway leading to suppression of proliferation and chemosensitization of human multiple myeloma cells. Clin. Cancer Res. 2007, 5, 943-955. [CrossRef] [PubMed]

13. Villar, V.H.; Vögler, O.; Barceló, F.; Broto, J.M.; Serra, J.M.; Gutiérrez, V.R.; Alemany, R. Down-regulation of AKT signalling by ursolic acid induces intrinsic apoptosis and sensitization to doxorubicin in soft tissue sarcoma. PLoS ONE 2016, 11, e0155946. [CrossRef] [PubMed]

14. Lin, C.; Wen, X.; Sun, H. Oleanolic acid derivatives for pharmaceutical use: A patent review. Expert Opin. Ther. Pat. 2016, 26, 643-655. [CrossRef] [PubMed]

15. Hussain, H.; Green, I.R.; Ali, I.; Khan, I.A.; Ali, Z.; Al-Sadi, A.M.; Ahmed, I. Ursolic acid derivatives for pharmaceutical use: A patent review (2012-2016). Expert Opin. Ther. Pat. 2017, 27, 1061-1072. [CrossRef] [PubMed]

16. Biedermann, D.; Eignerova, B.; Hajduch, M.; Sarek, J. Synthesis and evaluation of biological activity of the quaternary ammonium salts of lupane-, oleanane-, and ursane-type acids. Synthesis 2010, 22, 2839-3848. [CrossRef]

17. Kataev, V.E.; Strobykina, Y.; Zakharova, L.Y. Quaternary ammonium derivatives of natural terpenoids. Synthesis and properties. Russ. Chem. Bull. 2014, 63, 1884-1900. [CrossRef]

18. Serafim, T.L.; Carvalho, F.S.; Bernardo, T.C.; Pereira, G.C.; Perkins, E.; Holy, J.; Krasutsky, D.A.; Kolomitsyna, O.N.; Krasutsky, P.A.; Oliveira, P.J. New derivatives of lupine triterpenoids disturb breast cancer mitochondria and induce cell death. Bioorg. Med. Chem. 2014, 22, 6270-6287. [CrossRef] [PubMed]

19. Bernardo, T.C.; Cunha-Oliveira, T.; Serafim, T.L.; Holy, J.; Krasutsky, D.; Kolomitsyna, O.; Krasutsky, P.; Moreno, A.M.; Oliveira, P.J. Dimethylaminopyridine derivatives of lupine triterpenoids cause mitochondrial disruption and induce the permeability transition. Bioorg. Med. Chem. 2013, 21, 7239-7249. [CrossRef] [PubMed]

20. Tsepaeva, O.V.; Nemtarev, A.V.; Abdullin, T.I.; Grigor'eva, L.R.; Kuznetsova, E.V.; Akhmadishina, R.A.; Ziganshina, L.E.; Cong, H.H.; Mironov, V.F. Design, synthesis, and cancer cell growth inhibitory activity of triphenylphosphonium derivatives of the triterpenoid betulin. J. Nat. Prod. 2017, 80, 2232-2239. [CrossRef] [PubMed]

21. Ye, Y.; Zhang, T.; Yuan, H.; Li, D.; Lou, H.; Fan, P. Mitochondria-targeted lupanetriterpenoid derivatives and their selective apoptosis-Inducing anticancer mechanisms. J. Med. Chem. 2017, 60, 6353-6363. [CrossRef] [PubMed] 
22. Strobykina, I.Y.; Belenok, M.G.; Semenova, M.N.; Semenov, V.V.; Babaev, V.M.; Rizvanov, I.K.; Mironov, V.F.; Kataev, V.E. Triphenylphosphonium cations of the diterpenoid isosteviol: Synthesis and antimitotic activity in a sea urchin embryo model. J. Nat. Prod. 2015, 78, 1300-1308. [CrossRef] [PubMed]

23. Spivak, A.Y.; Nedopekina, D.A.; Shakurova, E.R.; Khalitova, R.R.; Gubaidullin, R.R.; Odinokov, V.N.; Dzhemilev, U.M.; Bel'skii, Y.P.; Bel'skaya, N.V.; Stankevich, S.A.; et al. Synthesis of lupine triterpenoids with triphenylphosphonium substituents and studies of their antitumor activity. Russ. Chem. Bull. 2013, 62, 188-198. [CrossRef]

24. Spivak, A.Y.; Nedopekina, D.A.; Khalitova, R.R.; Gubaidullin, R.R.; Odinokov, V.N.; Bel'skii, Y.P.; Bel'skaya, N.V.; Khazanov, V.A. Triphenylphosphonium cations of betulinic acid derivatives: Synthesis and antitumor activity. Med. Chem. Res. 2017, 26, 518-531. [CrossRef]

25. Nedopekina, D.A.; Gubaidullin, R.R.; Odinokov, V.N.; Maximchik, P.V.; Zhivotovsky, B.; Bel'skii, Y.P.; Khazanov, V.A.; Manuylova, A.V.; Gogvadze, V.; Spivak, A.Y. Mitohondria-targeted betulinic and ursolic acid derivatives: Synthesis and anticancer activity. Med. Chem. Commun. 2017, 8, 1934-1945. [CrossRef] [PubMed]

26. Saczewski, F.; Balewski, L. Biological activities of guanidine compounds. Expert Opin. Ther. Pat. 2009, 19, 1417-1448. [CrossRef] [PubMed]

27. Wexselblatt, E.; Esko, J.D.; Tor, Y. On guanidinium and cellular uptake. J. Org. Chem. 2014, 79, 6766-6774. [CrossRef] [PubMed]

28. Pantos, A.; Tsogas, I.; Paleos, C.M. Guanidinium group: A versatile moiety inducing transport and multicompartmentalization in complementary membranes. Biochim. Biophys. Acta 2008, 1778, 811-823. [CrossRef] [PubMed]

29. Castagnolo, D.; Schenone, S.; Botta, M. Guanylated diamines, triamines, and polyamines: Chemistry and biological properties. Chem. Rev. 2011, 111, 5247-5300. [CrossRef] [PubMed]

30. Sibrian-Vazquez, M.; Nesterova, I.V.; Jensen, T.J.; Vicente, M.G. Mitochondria targeting by guanidine- and biguanidine-porphyrin photosensitizers. Bioconjug. Chem. 2008, 19, 705-713. [CrossRef] [PubMed]

31. Blanchet, M.; Borselli, D.; Brunel, J.M. Polyamine derivatives: A revival of an old neglected scaffold to fight resistant Gram-negative bacteria? Future Med. Chem. 2016, 8, 963-973. [CrossRef] [PubMed]

32. Nowotarski, S.L.; Woster, P.M.; Casero, R.A. Polyamines and cancer: Implications for chemotherapy and chemoprevention. Expert Rev. Mol. Med. 2013, 15, e3. [CrossRef] [PubMed]

33. Fujiwara, T.; Hasegawa, S.; Hirashima, N.; Nakanishi, M.; Ohwada, T. Gene transfection activities of amphiphilic steroid-polyamine conjugates. Biochim. Biophys. Acta 2000, 1468, 396-402. [CrossRef]

34. Brycki, B.; Koenig, H.; Kowalczyk, I.; Pospieszny, T. Synthesis, spectroscopic and theoretical studies of new dimeric quaternary alkylammonium conjugates of sterols. Molecules 2014, 19, 9419-9434. [CrossRef] [PubMed]

35. Vida, N.; Svobodova, H.; Rarova, L.; Drasar, P.; Saman, D.; Cvacka, J.; Wimmer, Z. Polyamine conjugates of stigmasterol. Steroids 2012, 77, 1212-1218. [CrossRef] [PubMed]

36. Brycki, B.; Koenig, H.; Pospieszny, T. Quaternary alkylammonium conjugates of steroids: Synthesis, molecular structure, and biological studies. Molecules 2015, 20, 20887-20900. [CrossRef] [PubMed]

37. Giniyatullina, G.V.; Flekhter, O.B.; Tolstikov, G.A. Synthesis of squalamine analogues on the basis of lupine triterpenoids. Mendeleev Commun. 2009, 19, 32-33. [CrossRef]

38. Kazakova, O.B.; Giniyatullina, G.V.; Medvedeva, N.I.; Tolstikov, G.A. Synthesis of a triterpene-spermidine conjugate. Russ. J. Org. Chem. 2012, 48, 1370-1373. [CrossRef]

39. Bildziukevich, U.; Vida, N.; Rárová, L.; Kolář, M.; Šaman, D.; Havlíček, L.; Drašar, P.; Wimmer, Z. Polyamine derivatives of betulinic acid and $\beta$-sitosterol: A comparative investigation. Steroids 2015, 100, 27-35. [CrossRef] [PubMed]

40. Wang, J.; Jiang, Z.; Xiang, L.; Li, Y.; Ou, M.; Yang, X.; Shao, J.; Lu, Y.; Lin, L.; Chen, J.; et al. Synergism of ursolic acid derivative US597 with 2-deoxy-D-glucose to preferentially induce tumor cell death by dual-targeting of apoptosis and glycolysis. Sci. Rep. 2014, 4, 5006. [CrossRef] [PubMed]

41. Kim, D.S.; Pezzuto, J.M.; Pisha, E. Synthesis of betulinic acid derivatives with activity against human melanoma. Bioorg. Med. Chem. Lett. 1998, 8, 1707-1712. [CrossRef]

42. You, Y.J.; Kim, Y.; Nam, N.H.; Ahn, B.Z. Synthesis and cytotoxic activity of A-ring modified betulinic acid derivatives. Bioorg. Med. Chem. Lett. 2003, 13, 3137-3140. [CrossRef] 
43. Coulibaly, W.K.; Paquin, L.; Benie, A.; Bekro, Y.A.; Guevel, R.L.; Ravache, M.; Corlu, A.; Bazureau, J.P. Prospective study directed to the synthesis of unsymmetrical linked bis-5-arylidene rhodanine derivatives via "one-pot two steps" reactions under microwave irradiation with their antitumor activity. Med. Chem. Res. 2015, 24, 1653-1661. [CrossRef]

44. Feichtinger, K.; Zapf, C.; Sings, H.L.; Goodman, M. Diprotected triflyl-guanidines: A new class of guanidinylation reagents. J. Org. Chem. 1998, 63, 3804-3805. [CrossRef]

45. Kommera, H.; Kaluderovic, G.N.; Kalbitz, J.; Dräger, B.; Paschke, R. Small structural changes of pentacycliclupane type triterpenoid derivatives lead to significant differences in their anticancer properties. Eur. J. Med. Chem. 2010, 45, 3346-3353. [CrossRef] [PubMed]

46. Willmann, M.; Wacheck, V.; Buckley, J.; Nagy, K.; Thalhammer, J.; Paschke, R.; Triche, T.; Jansen, B.; Selzer, E. Characterization of NVX-207, a novel betulinic acid-derived anti-cancer compound. Eur. J. Clin. Investig. 2009, 39, 384-394. [CrossRef] [PubMed]

47. Bache, M.; Bernhardt, S.; Passin, S.; Wichmann, H.; Hein, A.; Zschornak, M.; Kappler, M.; Taubert, H.; Paschke, R.; Vordermark, D. Betulinic acid derivatives NVX-207 and B10 for treatment of glioblastoma-An in vitro study of cytotoxicity and radiosensitization. Int. J. Mol. Sci. 2014, 15, 19777-19790. [CrossRef] [PubMed]

48. Liebscher, G.; Vanchangiri, K.; Mueller, T.; Feige, K.; Cavalleri, J.M.; Paschke, R. In vitro anticancer activity of betulinic acid and derivatives thereof on equine melanoma cell lines from grey horses and in vivo safety assessment of the compound NVX-207 in two horses. Chem. Biol. Interact. 2016, 246, 20-29. [CrossRef] [PubMed]

Sample Availability: Samples of all compounds are available from the authors.

(C) 2018 by the authors. Licensee MDPI, Basel, Switzerland. This article is an open access article distributed under the terms and conditions of the Creative Commons Attribution (CC BY) license (http://creativecommons.org/licenses/by/4.0/). 